\title{
EPIDEMIOLOGIA E FATORES DE RISCO DA MALÁRIA POR PLASMODIUM FALCIPARUM (WELCH, 1897), NA SUB-REGIÃO DE JAÉN, 2000- 2004 CAJAMARCA, PERU.
}

SARA E. PALACIOS SÁNCHEZ

Tese apresentada ao Programa de Pós-Graduação em Saúde Pública da Faculdade de Saúde Pública da Universidade de São Paulo para obtenção do título de Doutor em Saúde Pública.

Área de concentração: Epidemiología Orientador: Prof. Dr. Delsio Natal

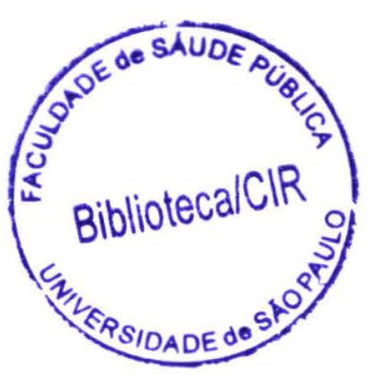

São Paulo

2005 
Autorizo, exclusivamente para fins acadêmicos e científicos, a reprodução total ou parcial desta tese,por processos fotocopiadores.

Assinatura:

Data

$46636 / 2005$ dve 
"A vida é um continuo querer viver. É uma contínua escolha da vida contra morte. Por isso é vigilância, prudência, trabalho. Cada célula o faz, cada tecido, cada glândula pelo organismo de que é parte. Nós o fizemos por milênios, pelos nossos lares, pela nossa comunidades.Agora devemos fazê-lo pelo mundo, cuidando dele como se fosse nosso corpo, a nossa casa, com a consciência de que vale más do que nós".

(Francesco Alberoni) 


\section{AGRADECIMENTOS}

A meus filhos Herman, Cesar, Guillermo, e minha mãe, razões da minha existência, pelo carinho e por ter suportado a solidão, as saudades e a distância física obrigada.

A meu orientador, professor Delsio Natal, pela acolhida e ter oferecido sua amizade, compreensão, confiança, paciência e atenção demonstrada nas horas difíceis.

Aos professores componentes da banca examinadora, Professor Dr. Barata, Dra. Stela Branquinho, Dra. Regiane Menezes e Dra. Carmen Costa pela leitura criteriosa, valiosa e pelas brilhantes sugestões para enriqueceram este trabalho.

Aos funcionários da Faculdade, em especial do Departamento de Epidemiologia e Biblioteca, Regina, Roxana, Marcia, Carminha, pela disposição permanente para nos ajudar.

Aos amigos da jornada durante todo o processo de pós-graduação desde o Mestrado até hoje principalmente por serem amigos: Margarita Del Pilar, Marina Violeta, Luz Marina, Ana Teresa Torres e Lizardo Osório da Colômbia, Paulo Urbinatti, Walter especialmente a Rosa de Lourdes, Azevedo dos Santos que se tornou uma boa amiga, assim como também para Giliana, Zelma.

A Rodrigo e Neuber pela ajuda no momento certo.

À inesquecível Professora Keiko Ogura Buralli pelas atitudes tão acolhedoras.

A Rubens Adorno, orientador do mestrado, pela sua amizade e disposição para ajudar.

A Universidade Nacional de Cajamarca que deu facilidades na permissão para fazer os estudos 
Aos meus colegas do trabalho pela força e incentivo: Margarita; Luis, Rosita, Aida Lola, Julio, Luis Escalante, Simon Cusma e minha gratidão para Emiliano, Elena, Manuela que ajudaram nos momentos mais difíceis da coleta de dados.

Ao Diretor da Sub-Região de Saúde de Jaén- Cajamarca Dr. Alex Canelo e em especial a minha gratidão eterna, para Zoila Villegas, chefa da Direção de Epidemiologia da DISA de Jaén e pessoal dos serviços de Saúde , Domitila, Cliver, Marina, pelas facilidades para coletar os dados

Aos entrevistados, meu agradecimento especial, pela participação na pesquisa, pela receptividade, pela informação e as conversas que permitiram e, por ter aprendido muito com eles, minha eterna gratidão.

A Faculdade de Saúde Pública e professores que me acolheram, oferecendo um espaço para desenvolver me de maneira integral.

A Jose Espinoza pelo apoio estatístico. 


\section{RESUMO}

Palacios SS. Epidemiologia e fatores de risco da malária por plasmodium falciparum (Welch, 1897), na Sub-Região de Jaén, 2000-2004 Cajamarca, Peru. [Tese de Doutorado - Faculdade de Saúde Pública da USP].

Objetivo: Estudar a epidemiologia e os fatores de risco da malária por $P$. falciparum, na Sub-Região e Província de Jaén. Métodos: No primeiro lugar foi realizado um estudo da incidência da malária entre 2000 e 2004, com dados do $50 \%$ das fichas de Controle de Assistência e Administração de Tratamento da Malária. E o desenvolvimento de um estudo de Caso-Controle (90/180). Se coletaram dados das condições de vida, percepções, crendices e conhecimento da doença, utilizando um questionário e a traves da entrevista, grupos focais, visitas domiciliares dos atendidos nos serviços de saúde dos distritos de Jaén e Bellavista e trabalhadores de saúde. Foram feitas análises quanti-qualitativas dos dados. Resultados: Trata-se de uma zona hipoendêmica, instável, de baixo e médio risco, com tendência à inversão da relação de $P$. falciparum sobre $P$. vivax, sendo que os mais atingidos são os menores de 19 anos, estudantes, donas de casa e agricultores. Foi observada relação significativa entre malária e temperatura média mensal $(\mathrm{p}=0,008)$ nos anos de estudo. As condições de vida da maioria das unidades de estudo correspondem a estratos pobres, encontrando-se que: não contar com água potável $(\mathrm{OR}=4,16)$, má distribuição de resíduos sólidos $(\mathrm{OR}=2,12)$, não ter luz elétrica $(\mathrm{OR}=3,16)$, Ter entre 7 e 11 integrantes na família $(O R=3,78)$, não saber como se transmite a doença $(\mathrm{OR}=8,26), \quad(\mathrm{OR}=4,66)$, não saber quais os sintomas da doença $(\mathrm{OR}=2,17)$ não saber qual é o tratamento da doença $(\mathrm{OR}=3,93)$ e não fazer nada para proteger-se da picada do mosquito $(\mathrm{OR}=6,12)$ estariam atuando como fatores de risco para adquirir malária. Para a população deste lugar, essa doença não tem importância mostrando confusão quanto à malária e seus mecanismos de transmissão. $\mathrm{O}$ mosquito não é considerado problema para a saúde. A transmissão da doença depende do tamanho deste. A febre é a sinal percebida predominante, qualificada como não perigosa tratada com medidas caseiras e um esquema de automedicação. A maioria desconhece a gratuidade do tratamento antimalárico. Os serviços públicos de saúde, diante este problema presta serviço assistencialista-recuperativo, baseado na demanda. Na visão desses trabalhadores a malária não é prioritária pela existência de tratamento específico e rápida recuperação.

Descritores: malária; $P$. falciparum; fatores de risco. Sub-região, epidemiologia. 


\section{SUMMARY}

Palacios SS. Epidemiology of and risk factors of malaria by plasmodium falciparum (Welch, 1897) in the Jaén Sub-Region. 2000-2004 Cajamarca, Peru. [Doctoral thesis-school of Public Health of de University of Sao Paulo].

Objective: The study of the epidemiology of and risk factors for malaria for $P$. falciparum, in the Sub-Region and province of Jaén. Method: First, a study of the incidence of malaria between 2000 and 2004 was undertaken on the basis of the data takem from $50 \%$ of the files of the control of care and administration of treatment of malaria. Then and case-control study was conducted (90/180). Information was obtained on the living conditions, perceptions popular beliefs and knowledge of the disease of the people attended to at the health service clinics of the Jaén and Bellavista districts by means of a questionnaire, interviews, focus groups and visits to dwellings and health's workers. Quanti-qualitative analyses of the data were made. Results: the area studied is hipoendemic instable and of low to medium risk, with a tendency to the inversion of the relationship of $P$. falciparum to $P$. vivax, those most affected being of less them 19 years of age school children, housewives and small farmers. A significant relationship was observed between the incidence of malaria and overage monthly temperature $(\mathrm{p}=0,008)$ during of study period. The living conditions of the majority of the persons interviewed correspond to the those of the poor strata and was found that: absence of drinking water $(\mathrm{OR}=4,16)$, poor distribution of solid waste $(\mathrm{OR}=2,12)$, absence electric light $(\mathrm{OR}=3,16)$, family members numbering between 7 and $11(\mathrm{OR}=3,78)$, ignorance of how the disease is transmitted $\mathrm{OR}=8,26$ ), ignorance of the symptoms of the disease $\mathrm{OR}=2,17$ ) not knowing how the treat the disease $(\mathrm{OR}=3,93)$ and doing nothing to protect oneself from mosquito bites $(\mathrm{OR}=6,12)$ were all acting as factors risk for acquiring malaria. For the population of this area this disease is of no importance and people confused as to malaria and the mechanizing of the transmissions. The mosquito is not regarded as a health problem. Transmission is regarded as being due to the mosquitoes size. Fever is the main perceived sign, though it is not regarded as dangerous and is treated with home remedies and self medication. The majority do not know that antimalaria treatment is free. The public health services, in the face of this problem, render assistential and remedial support according to the demand. In the perception of the workers, malaria is not priority, by virtue of the existence of specific treatment and the assurance of rapid recovery.

Descriptors: malaria; P. falciparum; risk factors, Sub-Region,epidemiology. 


\section{INDICE}

1. INRODUÇ ÃO 1

1.1. A malária no Continente Americano 3

1.2 A malária no Peru. Histórico 4

1.3 A malaria em Cajamarca e na Sub-Região de Jaén 7

\section{OBJETIVOS}

2.1. Geral 15

2.2. Específicos 15

2.3.Hipóteses 15

3 METODO

3.1. Área de estudo 16

3.2.Tipo de estudo $\quad 23$

3.3. Definição de caso 23

3.4. Definição de controle 23

3.5 Amostra 23

3.6 Métodos e técnicas de coleta de dados 24

3.7 Processamento e análise dos resultados $\quad 25$

4. RESULTADOS E DISCUSÃO

4.1. A epidemiología da malária na zona de estudo 26

4.2 Fatores de risco da malaria por P. falciparum 56

5. CONCLUSÕES 122

$\begin{array}{ll}\text { 6. REFERENCIAS } & 125\end{array}$

. ANEXOS

Anexo 1- questionário

Anexo 2- Modelo de ficha de Tratamento e Controle de malária. Peru

Anexo 3 Modelo da ficha epidemiológica de malaria- Peru

Anexo 4 Registro de temperatura média mensal da Sub-Região de Jaén

Anexo 5 Registro da precipitação pluvial da Sub- Região de Jaén.

Anexo 6 Informe da qualidade da água da Cidade de Jaén. 


\section{.1. INTRODUÇÃO}

Há mais de um século foram descobertas o agente e o vetor da malária e aplicadas inúmeras estratégias para sua prevenção e controle. Atualmente, no início deste novo milênio, o balanço dos esforços contra a doença confirma que esta se mantém como um dos mais graves problemas de Saúde Pública do mundo (PREVENTIG EMERGING INFECTION DISEASE, 1998; OMS/OPS, 2000).

Segundo WALDMAN et al. (1999) e FORATTINI (2002), a malária que era uma doença típica de comunidades rurais, está-se expandindo, nos dias atuais, para populações urbanas, ocorrendo tanto em países em vias de desenvolvimento (quanto nos desenvolvidos KNUDSEN \& SLOFF, 1992), evidenciando-se sua re-emergência nos primeiros anos da última década de 70 na Ásia e América, fato que foi ignorado por longo tempo e que agora pode ser muito difícil reverter seus efeitos (ROBERTS, 1997). Estes resultados constituem uma evidencia do fracasso das medidas de controle, já que estas continuam sendo de caráter vertical.

A partir de 1990, após de décadas de controle (anos 50, 60 e 70 do século XX), observou-se um aumento da incidência da malária no mundo, fato associado com a resistência aos medicamentos antimaláricos, particularmente, no caso do Plasmodiun falciparium (Welch, 1897). Estudos recentes assinalaram que o mecanismo celular da resistência deste parasito à cloroquina é resultado do transporte ativo do medicamento que efetua o agente mediante os seus sistemas enzimáticos expulsandoo d o eritrócito parasitado, ação que não permite alcançar concentrações letais no citoplasma do plasmódio (WEISSENBACHER, 1997).

Para o controle da malária foram experimentadas múltiplas estratégias e estas, através do tempo, enquadrava-se em múltiplos modelos, como o ecológicoambientalista, o técnico-campanhista e o preventivo local (BARATA, R 1998), modelo que é reforçado desde 1998, com a proposta de fazer retroceder a doença “Roll Back Malaria” (WHO, 2000a) nos 111 países, onde a doença é endêmica. Segundo a Organização Mundial da Saúde (OMS), estes componentes-chaves vêm 
melhorar a estratégia mundial da luta contra a malária, ressaltando a necessidade de uma gerência mais eficaz, do diagnóstico precoce e do tratamento imediato dos casos. O resultado é que a re-emergência da malária, com a crescente morbidade e mortalidade, afeta, não somente a saúde da população em muitos países em desenvolvimento, como também do próprio desenvolvimento sócio-econômico.

Atualmente, após sete anos das aplicações de estratégias de controle, o Informe da Secretaria do Conselho Executivo da OMS (2005), concluiu que a malária não é somente uma carga pesada para as economias domésticas, mas também um fator muito importante de persuasão para os investimentos nos países e zonas com endemia desta doença. Isto porque as propostas de redução da incidência da malária têm fracassado, já que esta é a principal causa de morte para $20 \%$ dos menores de cinco anos na África. Esses dados indicam que a incidência para o ano $2004 \mathrm{em} 111$ países foi entre 350 e 450 milhões de casos e aproximadamente 1,1 a 1,3 milhões de mortes sendo que a taxa de mortalidade duplicou-se entre 1990 e 1998, provavelmente como resultado da resistência do plasmódio à cloroquina.

De concreto, em todos esses anos investiram-se apenas 130 milhões de dólares nos países considerados endêmicos de malária, que representa a décima parte do programado, baseados em esquemas de tratamento padronizado, como o uso de artemisina (para alguns países), mosquiteiros tratados com inseticida e fumigação em zonas epidêmicas.

Diante do fracasso das inúmeras intervenções para o controle dessa doença, o Fundo das Nações Unidas para a Infância (UNICEF), o Programa de Desenvolvimento das Nações Unidas (PNUD) e o Banco Mundial (WB), têm unido esforços para alcançar esses objetivos até o ano 2010 (HEGGENHOUGEN et al., 2003), porém não indicam quais seriam as estratégias a aplicar. 


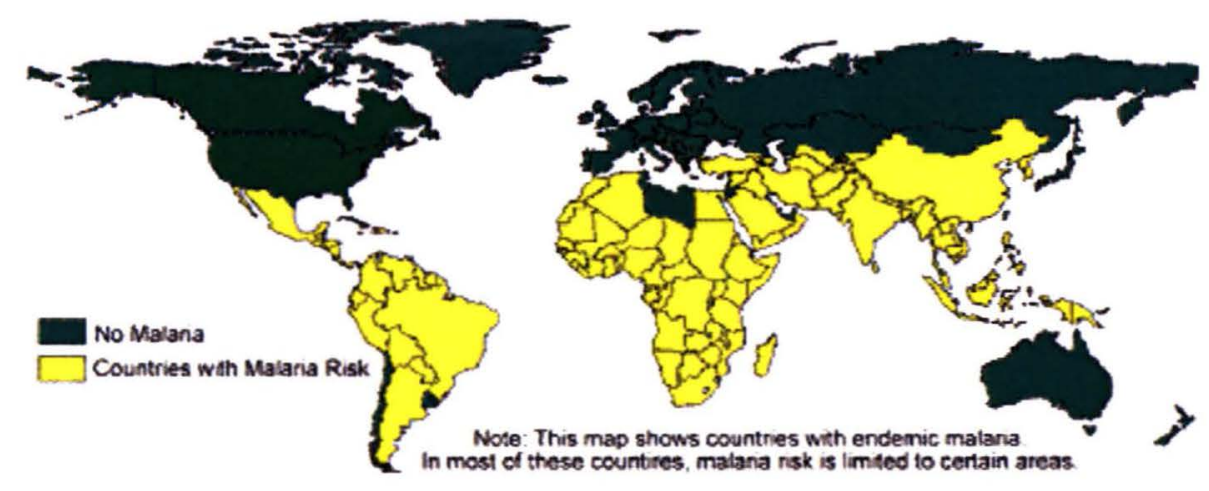

Figura 1. Países endêmicos de malária. 2003.

Fonte: NASA, 2004.

A figura 1 mostra a geografia da malária na atualidade, evidenciando que os países em vias de desenvolvimento são os mais atingidos.

\section{1 A malária no Continente Americano}

No continente Americano, a malária é considerada doença re-emergente na maioria dos lugares endêmicos da América do Sul. As razões deste fenômeno após décadas de êxito no controle da doença, ainda não foram bem determinadas (SAN SEBASTIÁN et al., 2000). É importante lembrar que todos os países endêmicos da doença têm orientado seus programas em função das propostas de fazer retroceder a malária, e os princípios da Estratégia Mundial para o Controle da Malária, compromisso assumido em Amsterdã em 1992 (OPS, 2001)

O enfoque predominantemente bioecológico é apreciado no relato da Organização Pan-americana da Saúde (OPS), a qual indica que em 1995, neste Continente a malária parecia estar estabilizada, com tendência a diminuir moderadamente, contudo a partir de 1998 iniciou-se um aumento contínuo. Somente no ano 2000 , foram notificados 1,14 milhões de casos, destes $53,6 \%$ foram informados pelo Brasil e o restante pela Colômbia, Equador e Peru. Em 1999 esta instituição informa que dos 818 milhões de habitantes do continente, $36,5 \%$ viviam em zona endêmica de malária, destes $16,5 \%$ viviam em países de zonas tropicais e 32,8\% em zonas de alto e médio risco (OPS/OMS, 2002a) 
Neste continente o Plasmodium vivax (Grassi e Feletti, 1890), se mantém como o agente etiológico de maior incidência. Em 1999 constatou-se que 73,7\% dos casos de malária são provocados por esta espécie, aumentando a 82,2\% no ano 2000, em zonas consideradas de alto e médio risco. Entretanto se registra uma proporção importante de malária por $P$. falciparum, somando-se a isso, um pequeno número de casos notificados de malária por Plasmodium malariae (Laveram, 1881) (OPS/OMS, 2001), e a circulação de variedades da espécie $P$. vivax na população humana (SULZER et al., 1981; FRANKE et al., 1992; ARRUDA et al., 1998; RODRIGUEZ, et al., 2000; BRANQUINHO, 2001).

Alguns especialistas afirmam que a migração de pessoas suscetíveis para as áreas endêmicas, seria um dos fatores de risco para a malária, dificultando qualquer estratégia de controle da doença. Essa condição pode estar originando freqüentes re-introduções da doença, na forma de epidemia, em áreas antes eliminada (MOTTA, 1992; COSTA, 1994; WALDMAN et al., 1999). Em conseqüência atualmente a migração e a mobilidade da população é considerada de grande importância na dispersão e na re-emergência da malária no mundo.

\subsection{A malária no Peru. Histórico.}

Devido a sua magnitude, a malária é considerada uma das principais doenças transmissíveis re-emergentes no Peru, país com população aproximada de 26 milhões de habitantes, dos quais 73\% vivem em zona urbana (INEI, 2003). Esta doença nesse país está associada com zonas tropicais e zonas de deserto, com risco na costa norte e em toda a área da região amazônica, apresentando um padrão cíclico e estacional. Considera-se que $30 \%$ da população total está exposta à malária ou vive em zonas com fatores ecológicos que favorecem a transmissão (MINSA, 1996). Por tanto aproximadamente 2.500 .000 pessoas vivem em áreas de risco para adquirir malária, sendo que uma dessas pertencem ao departamento de Cajamarca, mostrando um padrão expansivo aos vales interandinos. A estratificação epidemiológica indica que $8 \%$ da população mora 
em regiões de alto risco de transmissão (MINSA, 2000). Neste país, 19 dos 24 departamentos (divisão política) são considerados endêmicos desta doença ${ }^{1}$.

Essa re-emergência manifesta-se por um aumento progressivo da incidência desde 1965, sendo que os dados oficiais apenas são publicados desde 1993, ano em que se registram 85.504 casos, elevando-se a 121.268 em 1996, já no ano de 2004 registrou-se um total de 86.697 casos. Ressalta-se que desde 1993 se notificam casos de malária por $P$. falciparum, tendo-se produzido em 1998 uma inversão na relação de malária por $P$. vivax $/ P$. falciparum, nas regiões de Loreto e San Martin, situação inusitada nas últimas décadas.

Segundo ARAMBURÚ et al. (1999) os elementos que tiveram influência sobre esse fenômeno, são a dinâmica do vetor, o clima e a terapêutica utilizada nos programas de controle de vetores. Esta situação que se torna mais grave com o desenvolvimento de resistência dos parasitas a cloroquina e pirimetaminasulfadoxina, (WONGSRICHANALAI, et al, 2002), fenômeno que também foi detectado no nordeste do Peru, lugares que ocasionalmente informavam casos de malária por $P$. falciparum, provenientes do Equador, Colômbia e Brasil (BLAIR, et al., 2001). Por tanto os objetivos do compromisso de "fazer retroceder a malária" não foram alcançados.

Segundo CUETO (1998), foram destinados grande elevados orçamentos para o Programa de Erradicação da Malária, observando-se uma redução muito acentuada da incidência entre 1950 e 1960. Esta proposta posteriormente se converteu em um "programa horizontal", experimentando um processo de desarticulação. Tudo isso se agravou com a crise econômico-social da comunidade e do Estado e a redução dramática dos recursos destinados para a Saúde.

\footnotetext{
${ }^{1}$ Ministério da Saúde do Peru,. Nota de Imprensa. Março, 2005.
} 
Neste contexto, o fenômeno "El Niño" (El Niño/ Southern Oscillation ENSO) adquire um papel importante como fator de risco para adquirir malária, já que as alterações do clima contribuem para elevar a densidade do vetor (LINDBLADE et al., 1999). Observa-se ainda o descaso da população em relação ao papel do mosquito na transmissão do Plasmodium e, a importância do uso do mosquiteiro na prevenção desta transmissão (NAWAZ et al., 2001). A esta situação pode-se agregar o limitado acesso da população aos serviços de Saúde, especialmente os habitantes de zonas rurais e indígenas. Segundo a WHO (1998), tudo isso se relaciona com os surtos epidêmicos e a sua gravidade em populações com baixo nível de imunidade.

No Peru, o controle da malária na década dos 80 ' foi caracterizada pela aplicação de uma estratégia de tratamento sem vigilância, sob responsabilidade do Serviço de Erradicação da Malária (SNEM), baseada na terapia da cloroquina (CQ) para o tratamento dos casos febris e suspeitos de malária por $P$. vivax e $P$. falciparum. (MINSA, 1983). A esta terapia foi adicionada a primaquina (PQ) para prevenir as recaídas da malária por $P$. vivax e eliminar os gametócitos de $P$. falciparum (NEYRA et al., 2003). Este serviço em 1987 foi designado como Programa de Controle da Malária. Posteriormente, entre 1994 e 1999 testou-se a terapia múltipla, com três linhas terapêuticas: cloroquina e primaquina; sulfadoxina e primaquina; quinina-tetraciclina ou quinina-clindamicina mais primaquina (MINSA, 1993).

A partir do ano 2002, iniciou-se no Peru a aplicação de novos esquemas de tratamento antimalárico. Trata-se de regimes multidrogas ou combinado, como alternativa pela presença de resistência ao tratamento convencional, especialmente do $P$. falciparum à cloroquina e sulfadoxina. Esta decisão foi tomada após a realização de estudos de coorte ao norte do país e a Amazônia. Ressalta-se que o esquema baseado no artesunato e mefloquina, é a única alternativa atual. Se espera que esses esquemas tenham a eficácia que, segundo NOSTEN, et al. (2000), têm sido demonstrados, na Ásia: bons resultados, 
garantida proteção contra a resistência e redução da incidência de malária por $P$. falciparum.

Além do exposto, deve-se considerar que este esquema de tratamento para malária tem um custo elevado para todo o país.(MINSA, 2003). Mesmo que não se possa dizer até quando será efetivo, o fracasso dessa terapia teria graves conseqüências para o controle da malária no Peru e especialmente para os povos indígenas que vivem na Amazônia, onde os serviços de saúde são insuficientes e inadequados e que têm o mais importante transmissor da malária, o mosquito Anopheles (Nyssorhynchus) darlingi Root (CELIS et al., 2003). A administração atual faz referência dos sucessos até 2004, sendo que, o mais ressaltado é que a taxa de mortalidade tem diminuído até $0,01 \%$ e alcançado um IPA de 2,9 por mil habitantes em todo o país.

\subsection{A malária em Cajamarca e Sub-região de Jaén}

A Região de Cajamarca é considerada área endêmica de malária. A sua geografia é muito variada, cujos pisos ecológicos vão desde 200 a 4.200m de altitude (vide figura 8), marcando vales interandinos, sendo que em toda essa extensão a doença é endêmica. Os informes da Direção de Saúde (DIRESCajamarca), desta região indicam que a malária se apresenta na zona leste da SubRegião de Cajamarca e na Sub-Região de Cutervo. Sendo que na Sub-região de Jaén são notificados $90 \%$ do total de casos registrados na Região de Cajamarca, pelas duas espécies infectantes que predominam neste lugar, o $P$. vivax e $P$. falciparum (DIRES CAJAMARCA, 2003.)

Na figura 2 observa-se a tendência desta doença nos últimos 15 anos de registro, é evidente o decréscimo da incidência desta doença. Não se tem registro dos dados relacionados com o clima entre 1990 e 1997 que ajudariam a explicar em parte este comportamento, visto que o fenômeno El Niño, apenas se apresentou no ano 1998 não obstante a malária por $P$. falciparum está se 
estabelecendo em zonas muito delimitadas, especialmente nos distritos de Jaén e Bellavista. Essa situação está detalhada nos resultados deste estudo.

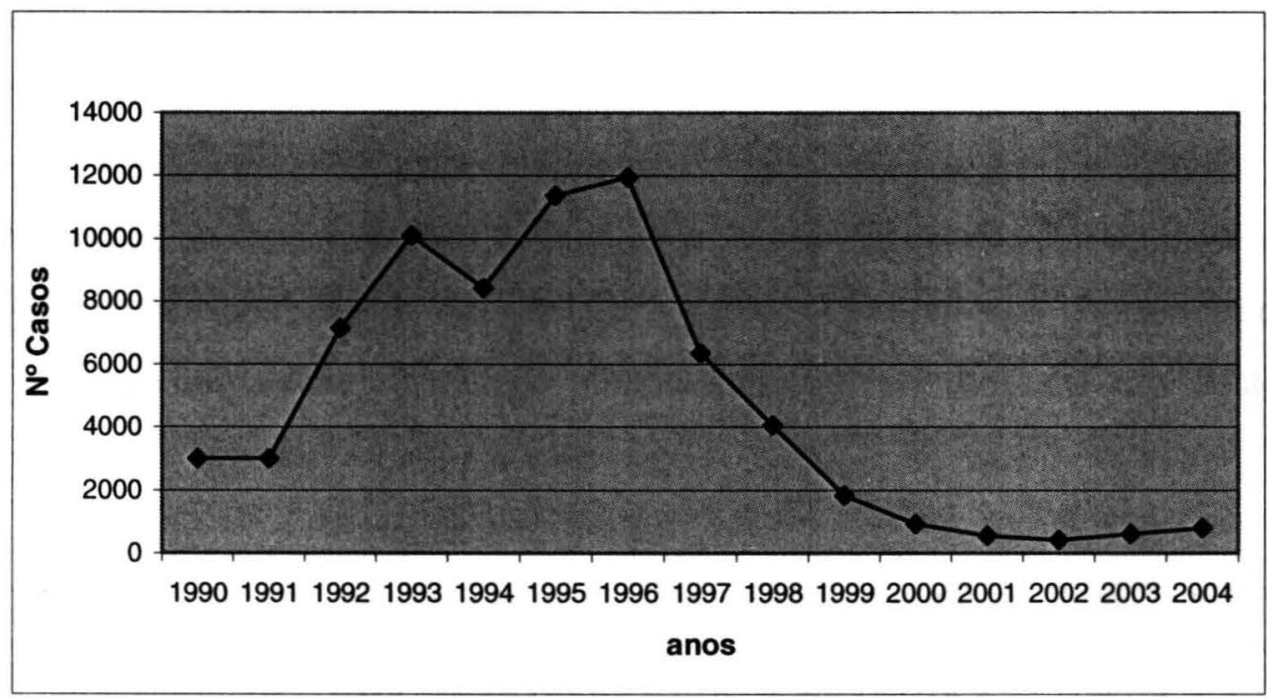

Figura 2. Casos de malária 1990-2004. Sub-Região de Jaén. Cajamarca. Peru. Fonte: Dados da Direção de Epidemiologia da DISA. Jaén. Cajamarca. Peru. 2004

A malária nesta área se mantém como um problema de Saúde Pública, apesar da incidência ter diminuído de maneira notória em comparação com o acontecido na década anterior. A figura 3 mostra a tendência do Índice Parasitário Anual (IPA), entre 1996 e 2002. Até o ano 2004 neste lugar se notifica um IPA de 1,52 por 1000 habitantes, índice menor ao reportado em nível nacional que é de 2,5 por 1000 habitantes.

Segundo as projeções do Instituto Nacional de Estatística (INEI, 2003) e a opinião do MINSA (2001) aproximadamente 183.359 habitantes nesta SubRegião vivem em áreas de médio risco de transmissão de malária que eqüivalem a 31,5\% dos distritos deste lugar. As áreas mais ativas em 2002 concentraram $91,08 \%$ do total de casos notificados e se encontram nos distritos de Namballe, San José del Alto, Huarango, San Ignacio, Jaén e Bellavista. Essa situação se mantém para 2004, com a diferença de que a maior concentração de casos se dá no distrito de Jaén, especialmente na zona urbana e periurbana e como já referido com predomínio da malária por $P$. falciparum. 
Os casos são, confirmados por exame de gota espessa e tratados com esquema convencional de mefloquina y artesunato, tendo sido registrado um caso de morte nas primeiras 25 semanas epidemiológicas do ano de 2004. No entanto, este não foi submetido a um diagnóstico diferencial, já que essa área geográfica é considerada de alta endemicidade de uma série de doenças febris além da malária, como a dengue, leptospirose, bartonelose e tifóide. Observa-se a ocorrência de casos em que o paciente é afetado simultaneamente por dois ou três destes agravos de uma só vez.

Quanto aos vetores envolvidos na transmissão da malária no Peru, tem sido registradas 40 espécies de vetores pertencentes ao gênero Anopheles e 3 do gênero Chagasia. Sendo que a primeira investigação entomológica sobre a fauna de anofelinos foi realizada entre 1953 e 1957 e complementada com pesquisas que atualizaram a distribuição altitudinal e longitudinal das espécies reconhecidas (ACOSTA \& LLANCARI, 1968; HAYES et al 1987; CALDERÓN et. al, 1995). Está ainda pendente a confirmação da presença de Anopheles (Nyssorhynchus) rondoni (Neiva \& Pinto) em Loreto que somaria 41 espécies de Anopheles existentes no Peru (MINSA, 2002).

No caso da Jurisdição da Sub-Região de Jaén, tem-se registrado 5 espécies: Anopheles (Anopheles) pseudopunctipennis Theobald; Anopheles (Nyssorhynchus) albimanus Wiedemann e Anopheles (Nyssorhynchus) benarrochi Gabaldon, Cova-Garcia \& Lopez, consideradas como principais vetores da malária, e Anopheles (Anopheles) calderoni Wilkerson e Anopheles (Nyssorhynchus) rangeli Gabaldon, Cova-Garcia \& Lopez, como vetores secundários. Ressalta-se que Anopheles (Nyssorhynchus) darlingi Root, já havia sido notificado na área endêmica de malária, na região de Piura, norte do Peru, a qual faz limite com a Província de San Ignacio e Jaén. A denominação de vetor principal e secundário está baseada na capacidade deste em transmitir o parasito (MINSA, 2002). 


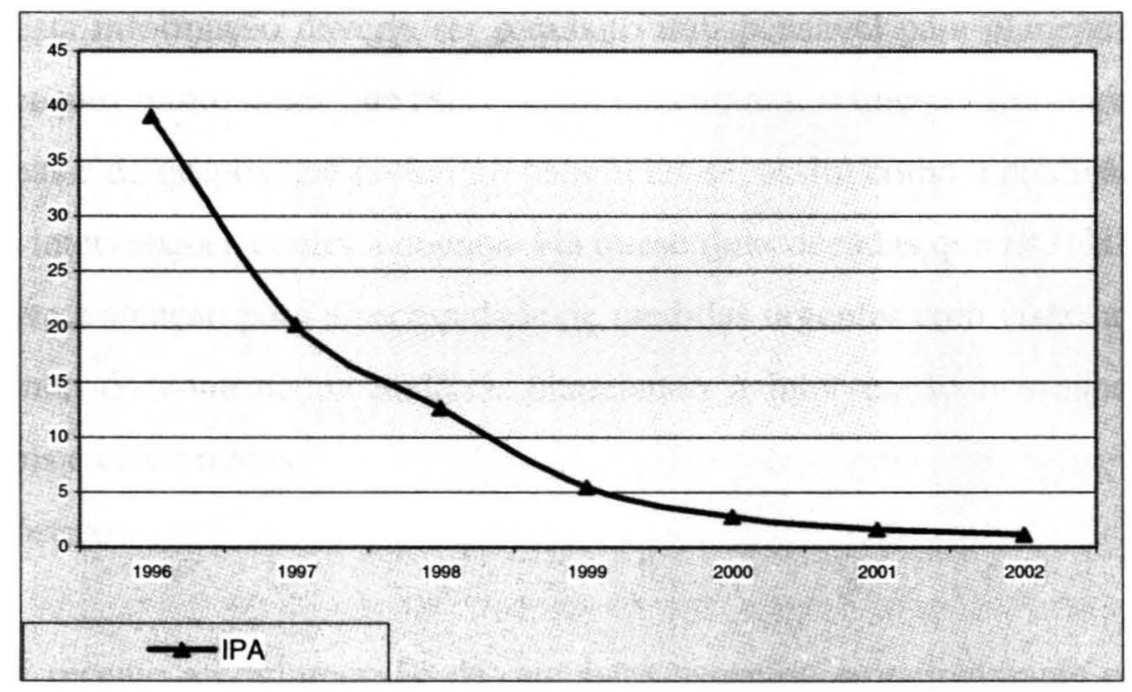

Figura 3. Tendência da malária, segundo Índice Parasitário Anual X 1000.

Direção de Saúde de Jaén. 1996-2002. Cajamarca. Peru. 2004.

Fonte: Direção da Epidemiologia. DISA. Jaén. Cajamarca. Peru. 2004

Pelos dados analisados a informação relacionada com a malária é predominantemente geral e quantitativa, referências que não explicam com clareza os fatores de risco que determinam o predomínio da malária por P. falciparum, visto que não se tem investigações que sirvam de referência, sendo que as existentes são realizadas em alguns lugares da Amazônia e da Região de Piura.

Sabe-se que a malária pode evoluir para formas graves e que com frequiência são mortais e, considerando que nesta área não se tem registrado casos fatais, supõem-se que a cepa de $P$. falciparum envolvida, deve ser uma das mais benignas ou também que o tratamento em muitos os casos é administrado oportunamente. Tal situação já foi encontrada por GONZALES et al. (1997) na Costa do Pacífico da Colômbia, onde são raros os casos de malária severa.

Estes resultados sugerem que a abordagem desse problema tem sido limitada e muito distante da realidade. A análise da mesma aparece como um fato isolado, sem considerar sua articulação com os aspectos sociais, econômicos, políticos, culturais e ambientais que vem a configurar as condições de vida diferenciadas da população. 
Esta informação deveria ser requisito indispensável para planejar e enfocar as intervenções muito antes que estas sejam executadas, o que possibilitaria a avaliação das áreas e de grupos que poderiam beneficiar-se, assim como a medição do impacto dessas intervenções contra a doença. Há quase duas décadas que BOTHELO, (1988), chamava a atenção para a necessidade de medidas urgentes com vistas a reformular a campanha de controle da malária, planejando a intervenção nos aspectos sociais, políticos e econômicos.

Prognóstico

É recente a compreensão de que estes aspectos, principalmente os parâmetros políticos e econômicos, devem ser vistos de dentro, isto é, que podem atuar como prognosticadores epidemiológicos de saúde e de padrões da doença, portanto, deveriam ser incluídos nos programas há mais de duas décadas (INHORN \& EBROWN, 1990). Neste sentido, MOTTA (1992) diz que o caráter social deve se integrar à maneira de compreender o problema da malária.

Assim proposto, o problema da malária deve ser entendido no marco do discurso do desenvolvimento humano, no qual se ressaltam a capacidade humana básica representada pelas oportunidades mais importantes e permanentes dentro daquelas com maior importância na vida, que reflita uma existência longa e saudável; um nível educacional que resuma os conhecimentos adquiridos e uma renda per capita que indique a capacidade de acesso aos recursos para viver dignamente (SEN, 1998).

Estes elementos são de particular importância, já que como se sabe a malária é uma doença desgastante, não só fisicamente, mas também porque afeta à renda e a estabilidade emocional da família ou do grupo humano com o qual esta convive. Esta realidade sentida pela população de algum modo é maquiada e dissimulada em sua magnitude pelo governo e pela sociedade em conjunto.

Conseqüentemente face o problema da malária ficam privadas muitas das capacidades do ser humano, já que não se trata somente de sua relação com a

\section{BIBLIOTECA/CIR FACULOADE DE SAUUDE PÚBLICA UNIVERSIDADEDE SAOO PAULO}


pobreza, mas também outras condições que vão limitar estas potencialidades de resposta, como exemplo, não ter conhecimento apropriado para prevenir a doença. Dessa maneira estaria expressando sua liberdade de escolha ou determinando suas ações de acordo com o conhecimento ou sentimento.

Essas liberdades são as oportunidades ou direitos que o sistema econômico, social e político oferece ás pessoas do qual dependem as liberdades individuais e liberdades constitutivas, que segundo GONZÁLEZ (2005) constituem o fim do desenvolvimento, porque se referem ao enriquecimento da vida humana, ou seja não ter privações como alimentação, anos de vida perdidos prematuramente, capacidade para ler, escrever, participação política e outras Esse desenvolvimento é referido ao mundo que se quer para todos, tentando estabelecer um ponto de vista ético, a partir do qual se avalia o progresso humano. Este desenvolvimento consistirá no esforço por superar essas privações, no qual está unido o crescimento econômico, não sendo uma variável única nem determinante.

Nesse sentido, é necessário lembrar que a "enfermidade é uma construção social" (Concone, 1991 citado por SAWAIA s.d), para tanto, todos os danos teriam que ser abordados nessa perspectiva, uma vez que incluem uma série de representações coletivas relacionadas com o estar enfermo ou sentir-se enfermo, fatos que vão refletir a natureza sócio-econômica de uma sociedade em determinado momento de sua história.

Também é importante sinalizar que a cultura de um povo ou comunidade pode oferecer critérios alternativos para avaliar a qualidade de vida e se estes resultam contrários ao desenvolvimento ou distintos à perspectiva moderna da liberdade, vai gerar um problema de eleição entre eles (GONZÁLEZ, 2005). Especialistas como Segundo Almond e Powel citado por TELLO (1995) afirmam que a cultura é o aspecto subjetivo que outorga significado, crenças, valores e capacidades que são comuns à população, assim como também os modelos e padrões que somente podem ser encontrados em setores particulares". 
Vê-se assim que a saúde ou a cura das doenças não é uma busca exclusiva dos profissionais de saúde, já que também tem lugar no imaginário popular. Todos querem explicações e usam recursos para combater as enfermidades. $\mathrm{O}$ que varia são os fundamentos das crenças e das ações (mágico-religiosa, científico, etc.). Como exemplo há muitos programas de educação e prevenção de diarréia infantil que apesar dos altos pressupostos e das técnicas apropriadas, têm fracassado por não ter considerado a linguagem, os costumes e os valores ligados à saúde e nutrição infantil da população (SAWAIA s.d)

Assim mesmo, quando se procura as representações na análise do processo saúde-doença, se possibilita conhecer as ações individuais e coletivas e a maneira como as pessoas se apropriam do conhecimento que circula sobre a saúde e a enfermidade. Assim, SAWAIA (copia s. d) afirma que “...somente a expressão da mensagem não é suficiente para trocar ações e relações. Em conseqüência, representação social, atividade e afetividade são elementos de um mesmo processo de orientação com o mundo e com os outros, onde as pessoas aprendem o significado e os símbolos que lhes permitem exercer sua capacidade de pensamento e que são capazes de modificá-los e alterná-los. Esta modificação se dá por sua capacidade de interagir consigo mesmo, que lhes permita examinar os possíveis cursos de ação e valorizar suas vantagens e desvantagens".

Portanto, a pertinência do presente estudo se justifica pela contribuição com o fortalecimento e a capacidade local de investigação básica e aplicada em malária, baseada em um dos objetivos do manejo e incidência desta doença, adotado pelos países endêmicos de malária. Esta tese vai permitir a avaliação da situação em cada uma das localidades, considerando seus padrões biológicos, ecológicos, socioculturais e econômicos, dentro da linha de seu desenvolvimento.

A análise das condições de vida e as representações da malária na população desta zona permitiram ter uma aproximação aos fatores de risco da enfermidade, informação esta necessária para reforçar o programa de prevenção e controle da malária nesta sub-região, que também é uma área endêmica de outras doenças 
metaxênicas febris, o que possibilitaria a recomendação de novas estratégias de intervenção, onde a população poderia assumir o papel principal no processo de prevenção da enfermidade, de acordo com a realidade. Fato que indiretamente relaciona-se com a administração apropriada dos escassos recursos destinados a este programa. 


\section{OBJETIVOS}

\subsection{Objetivo Geral}

Estudar a epidemiologia e os fatores de risco da malária por $P$. falciparum na Província de Jaén, zona endêmica de malária, Cajamarca, Peru, entre os 2000 e 2004.

\subsection{Objetivos Específicos}

- Estudar e avaliar as características epidemiológicas da malária, notificadas em termos de idade, sexo, temperatura, precipitação pluviométrica e distribuição geográfica, no período entre os anos 2000 e 2004.

- Descrever as condições de vida dos casos de malária por P. falciparum e controles incluídos no estudo que atuam como fatores de risco destes para adquirir a doença, limitando sua capacidade de resposta frente a este problema.

- Identificar as características das representações sociais diante da malária em indivíduos afetados ou não por esta doença, assim como as medidas praticadas frente à manifestação dos sinais e sintomas.

- Descrever criticamente o sistema organizacional institucionalizado para o tratamento da malária dentro do setor Saúde, como um fator interveniente na eficiência do processo de atenção.

\subsection{Hipóteses}

- As condições pessoais de vida e do meio que envolve a moradia e o imaginário social a respeito da malária, atuam como fatores de risco para que os habitantes do distrito de Jaén e Bellavista adquiram malária por $P$. falciparum, limitando sua capacidade de resposta para enfrentar este problema.

- O sistema organizacional para o tratamento da malária na zona de estudo representa um fator interveniente no processo de atenção. 


\section{MÉTODO}

\section{1. Área de estudo}

\subsubsection{Características geográficas}

A sub-região de Jaén localiza-se na parte norte da Região de Cajamarca, no extremo-norte do Peru, (figura 4) que compreende 19 distritos (distribuídos nas províncias de Jaén e San Ignácio). Tendo uma população aproximada de 350,086 habitantes no ano de 2004 (INEI, 2003), que inclui a comunidades nativas, (que falam o dialeto próprio).

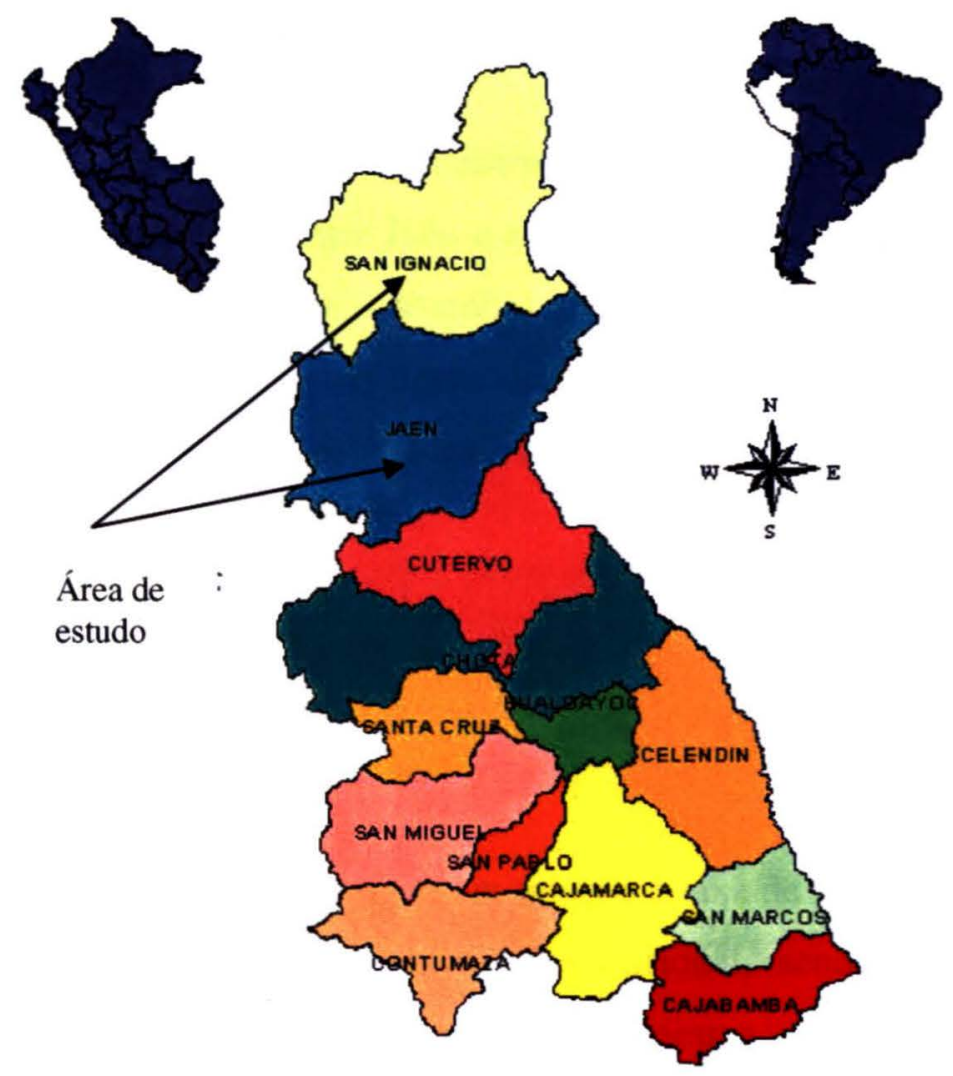

Figura 4. Localização geográfica da Sub-Região de Jaén. Cajamarca. Peru Fonte: INEI 2003

A capital da província de Jaén é a cidade de Jaén de Bracamoros, que tem uma extensão territorial de $5.232 .56 \mathrm{Km}^{2}$. Ocupa o segundo lugar em extensão depois da província de Cajamarca, possui altitude de $729 \mathrm{~m}$. Entretanto a província de San Ignacio que tem como capital ao distrito do mesmo nome, esta dividida em 7 (sete) 
distritos, com uma extensão territorial de $4.990,30 \mathrm{Km}^{2}$ e altitude de $1.324 \mathrm{~m}$. tendo áreas fronteiriças com o Equador. Nesta Sub-Região se configura uma superfície de variados relevos que vão de 441 a $3.200 \mathrm{~m}$ de altitude e seu solo está atravessado de Sul a Norte pela Cordilheira El Páramo,

O distrito de Jaén concentra a 23\% (84.083 habitantes) da população total da Sub-Região. Os demais distritos em média têm entre $2 \%$ e $9 \%$ de habitantes morando em áreas urbanas. O relevo é predominantemente variado e acidentado pelo contraste entre suas cordilheiras, vales e planícies (ASOCIACIÓN DE MUNICIPALIDADES DISTRITALES DE JAÉN, 2004).

\subsubsection{Hidrografia}

O sistema hidrográfico está conformado pelo rio Marañón em $87 \mathrm{Km}$ que percorre a linha da fronteira entre Jaén e a Região do Amazonas, circulando dentre esta área os rios Chamaya (Huamcabamba), o rio Chunchuca, rios Chinchipe, o rio Tabaconas e o rio Tamborapa. As águas desses são aproveitadas para a geração de energia elétrica nas áreas onde estão localizados.

\subsubsection{Indicadores Sociais}

\section{Dinâmica populacional}

Não existe informação fidedigna em relação à taxa de mortalidade, taxa global de fecundidade e taxa de crescimento populacional, sendo considerada como referência, as taxas nacionais do ano 2000, a mesma que registra una taxa de mortalidade geral 6,4 por 1000 habitantes, uma taxa global de fecundidade de 2,6 filhos por mulher e uma taxa de crescimento populacional de 2,0\% para o mesmo período. Essa estrutura populacional é similar em todo o país, observando-se uma diminuição de $1,6 \%$ na população menor de 15 anos entre os anos de 2002 e 2003, o que determina uma ligeira ampliação do corpo da pirâmide populacional dessa área (INEI, 2003). 


\section{Taxa de Migração Interna}

Esta Sub-Região mostra uma migração geral negativa. O deslocamento é gerado pela população jovem, particularmente a feminina que emigram por motivos de estudo ou trabalho (INEI, 2000). As províncias de Cajamarca, Chiclayo, Tarapoto e Lima convertem-se em pólos de atração para esta população migrante. Esses deslocamentos da população podem conduzir-se para lugares muito distantes do local de origem, estabelecendo mecanismos de transporte de enfermidades transmissíveis, (ALARCON, 2003) em especial aqueles grupos ou pessoas que saem de áreas endêmicas de malária para outras regiões onde persiste a presença do mosquito transmissor da doença, como neste caso, onde os lugares mais freqüentados pelos migrantes têm características ecológicas e populacionais que facilitariam a transmissão da doença, afetando a situação de pobreza (MARTENS \& HALL, 2000).

\section{Escolaridade}

O distrito de Jaén possui uma média de escolaridade de 6 a 8 anos, níveis menores ao do nacional, que segundo o INEI ( 2003) em média a população do Peru, teria 9,2 anos de estudos, sendo que Sallique, Tabaconas, La Coipa e Colasay, em média têm $32 \%$ de analfabetismo, uma das mais elevadas do país.

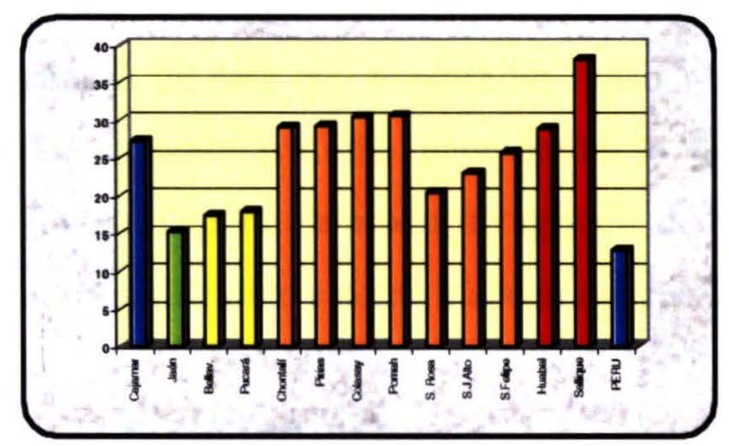

Figura 5. Taxa de analfabetismo por estratos de pobreza. Província de Jaén. 1993

Fonte: INEI. PERU. 2003

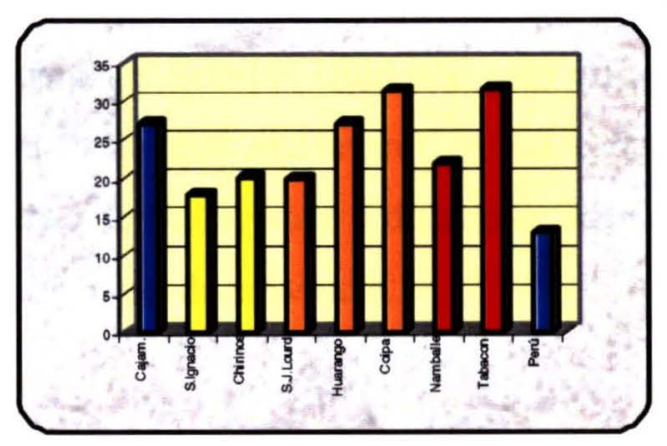

Figura 6. Taxa de analfabetismo por estratos de pobreza. Província de San Ignacio. 1993 
As figuras 5 e 6 mostram as diferenças nas taxas de analfabetismo dentre os distritos nas duas províncias ( Jaén e San Ignacio) comparado-as com as taxas da Região de Cajamarca e o país ( barras azuis).

\section{Indicadores de Pobreza}

A proporção de lares com uma Necessidade Básica Insatisfeita (NBI) é de $28,9 \%$, colocando-se abaixo da média nacional $(30,6 \%)$ e, as que têm duas ou mais NBI representam o 46,3\%. Enquanto que e do Peru é de $23,2 \%$, significa que aproximadamente a metade de lares na Sub-Região de Jaén encontram-se em extrema pobreza. (INDACOCHEA, 1998)

\subsubsection{Aspectos Econômicos}

\section{Atividades Laborais}

Segundo INEI (2003), as atividades laborais que predominam na região são a agricultura, pecuária, caça, silvicultura, atividades de ensino, comércio, reparação de veículos automotores e motocicletas, artesanato e afazeres domésticos.

\section{Estrutura da Produção}

A economia deste lugar se baseia, fundamentalmente na atividade agrícola e pecuária, com uma incipiente transformação agro-industrial. Jaén é reconhecida pela produção de café que exporta ao Japão, Alemanha e Estados Unidos e pelo arroz, milho amarelo e milho para produção de maisena que abastecem os mercados regionais. O porte da produção agrícola do distrito de Bellavista e o distrito de Jaén é muito significativo e soma mais da metade da produção da província.

\section{Fluxos de comercialização}

A principal área em termos de fluxo de comercialização é fracionada em quatro grandes espaços de abastecimento e distribuição, segundo a localização dos mercados e principalmente da via nacional articulada com a costa (figura 7). A dinâmica do seu comportamento verificada no intercâmbio econômico que este gera. 
Assim a maior parte da (população economicamente ativa) PEA ocupada está distribuída no interior do espaço da Sub-Região e manifesta uma articulação desde o interior até o exterior e vice-versa, com exceção do distrito de Jaén que é um mercado de demanda importante que, por sua vez, utiliza a mesma lógica de intercâmbio comercial com outras localidades que não a província.

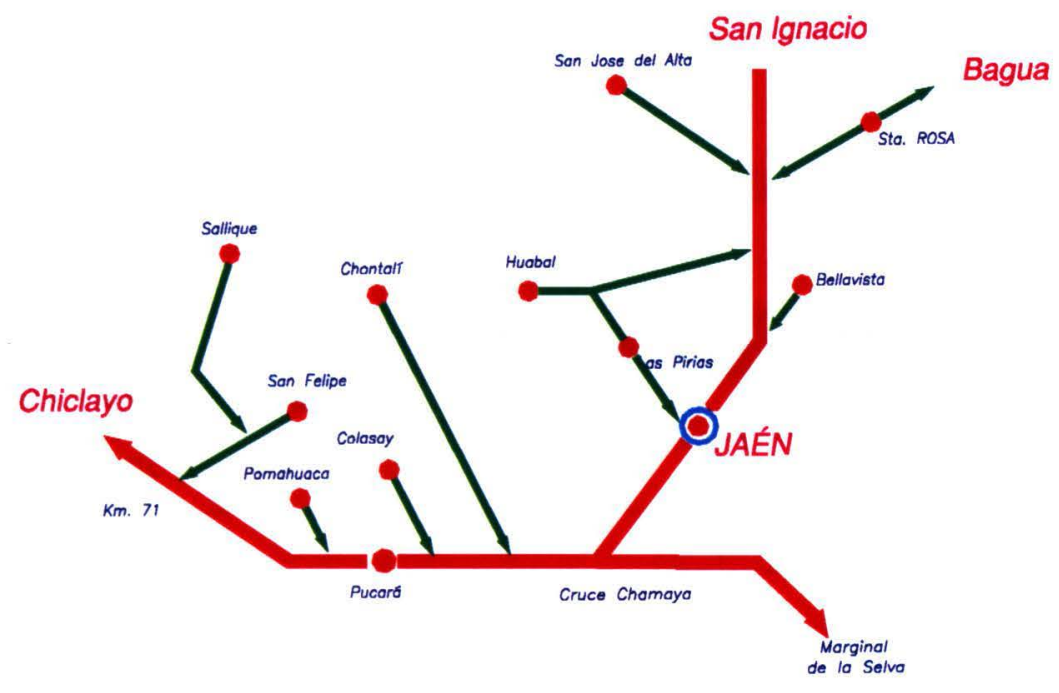

Figura 7. Fluxo comercial da Sub-Região de Jaén. Cajamarca. Peru 2004

Fonte: Direção da Sub-Região de Jaén.

Os fluxos econômicos se mobilizam em função dos centros de demanda e distribuição, através dos "corredores econômicos" (rodovias), onde confluem os centros de produção que destinam seus produtos aos centros de consumo em condição de intercâmbio desfavorável, observado na sub-valorização dos preços. A comercialização dos produtos agropecuários realiza-se de forma individual pela falta de uma organização. As atividades comerciais de maior dinamismo são a venda de "por maior" em chácara (por intermediários) e "por menor" no mercado de abastecimento de produtos agropecuários e feiras.

O intercâmbio comercial desta Sub-Região envolve a saída de produtos agroindustriais como café, arroz, cacau, mandioca, fruta e outros cereais. As atividades comerciais que se destacam são também de serviços, como venda de medicamentos, combustíveis, comidas e bebidas. 


\subsubsection{Morbidade}

A tabela 1 mostra uma continuidade nas primeiras causas de morbidade geral, para o ano de 2003, na Jurisdição da Sub-Região de Jaén, no qual se observa que a quinta parte das consultas nos estabelecimentos é por parasitose, sendo referida como a primeira causa. Apesar disso, é notório o predomínio das doenças do aparelho respiratório, já que $37,75 \%$ dos casos atendidos têm como causa essas doenças.

Tabela 1. Dez primeiras causas de Morbidade Geral. Direção de Saúde Jaén. Cajamarca. Peru. 2003.

\begin{tabular}{llcc}
\hline \hline$N^{\circ}$ & Causas & TOTAL & $\%$ \\
\hline 01 & Parasitoses Intestinais & 48084 & 20.77 \\
\hline 02 & Faringite Aguda & 35968 & 15.54 \\
\hline 03 & Rinofaringites & 27776 & 12.00 \\
\hline 04 & Bronquites & 23636 & 10.21 \\
\hline 05 & Diarréia e gastroenterocolite & 22662 & 9.79 \\
\hline 06 & Amigdalite & 18801 & 8.12 \\
\hline 07 & Outros transtornos do sistema Urinário & 15779 & 6.82 \\
\hline 08 & Enfermidade da Pupila e dos tecidos blandos & 13280 & 5.74 \\
\hline 09 & Cárie dental & 13088 & 5.65 \\
\hline 10 & Outras enfermidades locais da pele & 12418 & 5.36 \\
\hline TOTAL & 231492 & 100 \\
\hline \hline
\end{tabular}

Fonte: Direção de Epidemiologia. DISA. Jaén. Cajamarca. Peru. 2004

Segundo os dados fornecidos pela chefia de Epidemiología da Direção SubRegional de Saúde (DISA) de Jaén, (DISA, JAEN, 2004), as parasitoses intestinais e infecções das vias respiratórias (bronquite, rinofaringite e amigdalite) seguido de anemias por deficiência de ferro, são as primeiras causas de morbidade das crianças, doenças que mantêm como um problema a mais de saúde pública, apesar dos esforços que se vem fazendo para diminuir a incidência.

Alem disso, esta zona é endêmica de outras enfermidades que são sujeitas à vigilância e notificação obrigatória, como por exemplo, o dengue clássico, a bartonelose (verruga peruana ou doença de Carrión). Estas duas doenças 
apresentaram um ano epidêmico em 2004, sendo que esta última registrou 4.600 casos entre bartonelose aguda e crônica, com 35 mortes. Provavelmente, os registros são subestimados probabelmente devido a um marcante problema de automedição na população A leishmaniose, peste bubônica, hepatite, tuberculose, tétano, são outras das doenças endêmicas consideradas como problemas para a saúde pública deste lugar, agravado pelos surtos epidêmicos de coqueluche.

Alem disso, nos documentos oficiais dos serviços de saúde observa-se a subnotificação dos casos da febre tifóide, referência dada pelos próprios moradores, no percurso da coleta de dados do presente estudo, no qual conseguiu-se constatar que esse "se curam automedicando-se". Situação que pode ser conferida nos registros hospitalares ou de outros estabelecimentos de saúde.

É evidente que a preocupação está centrada em alguns dos danos de natureza infecciosa, tendo pouca informação (somente hospitalar) das doenças crônicodegenerativas e aquelas que são produto da violência, como os acidentes, envenenamentos, drogas ilegais, lesões por assalto e violência familiar. Esses dados geralmente não são considerados como prioridade para o sistema de informação do serviço de saúde, o mesmo que também não inclui os registros da Seguridade Social. Esses danos constituem graves problemas de saúde pública, em especial na cidade de Jaén já que existe um ambiente de alto risco, ligado à delinqüência, prostituição e narcotráfico.

Como conseqüência, este perfil epidemiológico determina a necessidade de uma adequada estrutura organizada da sociedade e dos serviços, com a finalidade de prevenir e controlar estes danos da saúde que vão prejudicando as condições de vida da população.

Neste sentido, não basta garantir a presença de pessoal capacitado, más também, é necessários a implementação com materiais mínimos que possam garantir um serviço oportuno e apropriado. As características dos serviços de saúde existentes correspondem ao primeiro e segundo nível de atenção, (serviços básicos) com 
precária implementação e equipamento. Isso determina que a população afetada tenha que se deslocar ou ser transferida para outros lugares mais qualificados, sendo o mais próximo à cidade de Chiclayo que fica em média a $300 \mathrm{~km}$ de distância da cidade de Jaén.

\subsection{Tipo de estudo}

Trata-se de um estudo quantitativo e qualitativo, descritivo numa primeira parte e na segunda um estudo de desenho observacional de caso-controle para investigar os fatores de risco relacionados à aquisição da malária por $P$. falciparum .

\subsection{Definição de caso}

São considerados "casos" os pacientes de qualquer idade, residentes na área de estudo, com diagnóstico de malária por $P$. falciparum, confirmado por exame de gota espessa (diagnóstico convencional) e com sinais e sintomas (paroxismos típicos febris ou outros sintomas compatíveis com a malária: febre intermitente, dor de cabeça e no corpo, sintomas digestivos), iniciados em um período não maior de duas semanas antes do diagnóstico fornecido nos estabelecimentos de saúde no Distrito de Jaén e Bellavista da Sub-Região de Jaén-Cajamarca-Perú.

\subsection{Definição de controle.}

Os controles estiveram constituídos pelas pessoas que assistiram ao serviço de saúde e que não tiveram diagnostico clínico e de laboratório de malária dentro dos 30 dias prévios ao diagnóstico de caso.

\subsection{Amostra}

A amostra foi calculada no programa Epi-info 6,04, considerando dois controles para cada caso, com um OR esperado de 3, nível de confiança de 95\%, um poder de estudo (1- $\beta$ ) de $80 \%$, com erro alfa de $5 \%$ e porcentagem de exposição dos controles de $10 \%$. Foram estudados 90 casos e 180 controles. 
As unidades de estudo para esta pesquisa foram captadas nos estabelecimentos de Saúde da cidade de Jaén: Centro de Saúde do Morro Solar, Hospital Geral de Jaén e os atendidos no Hospital de Apoio de Bellavista que fica a $20 \mathrm{Km}$ da cidade de Jaén (croqui, Jaén).

A seleção dos casos realizou-se a partir da notificação destes nos estabelecimentos de saúde: Centro de Saúde Morro Solar, Hospital de Jaén e Hospital Bellavista, no período de setembro de 2004 a dezembro do mesmo ano. Essa seleção dos casos e controles no tempo foi feita com os casos incidentes ou com os diagnosticados desde o momento do início do estudo, os controles foram eleitos à medida que os casos ocorriam. Esse processo foi executado pela própria autora do trabalho. A coleta dos dados de caso e controle foi realizada dentro da semana de reconhecimento do caso. Quando se tratavam de crianças com menos de 15 (quinze) anos, a entrevista foi realizada com os pais ou responsável.

\subsection{Métodos e técnicas de coleta dos dados}

Para o estudo epidemiológico descritivo, utilizou-se como fonte de informação e consulta as Fichas de Controle da Assistência e Administração do Tratamento da Malária, cadernos de febris.

A coleta dos dados do meio intradomiciliar e extradomiciliar tanto dos casos como dos controles, foram registrados em um guia de observação (anexo 1). Assim também se entrevistou os casos e controles, em visitas domiciliares, usando um questionário padrão que contém perguntas abertas e fechadas de acordo com as variáveis a serem analisadas em correspondência às hipóteses e objetivos apresentados (Anexo 1)

Também foram feitas entrevistas com o pessoal responsável pelo programa nos estabelecimentos de saúde da Jurisdição e os funcionários dos estabelecimentos de saúde das zonas de estudo, a fim de obter informações que sirvam para comparação 
dos resultados, como por exemplo, as condutas visíveis e encobertas, importância e significado dos símbolos.

Além disso, trabalharam-se grupos focais para obter informação acerca do imaginário social em relação à malária e as atitudes que adotam frente ao quadro "febril". Técnica que também foi aplicada com os trabalhadores dos estabelecimentos de saúde. Os dados climatológicos foram obtidos do Ministério da Agricultura, Sub-Região Agrária de Jaén, Oficina de Informação Agrária, principalmente do Serviço de Metereología e Hidrologia (SENAMHI), de esse lugar, sendo que estes coletam os dados todos os dias.

\subsection{Processamento e análise dos resultados}

Para o processamento dos dados coletados utilizaram-se os programas estatísticos EXCEL e SPSS 9.0, a fim de calcular a força de associação e o nível de significância estatística dos fatores considerados como risco para malária.

A incidência da malária é representada por meio de tabelas, figuras e mapas. $\mathrm{O}$ tratamento dos dados quantitativos está baseado em análises e interpretações por meio da estatística descritiva e da regressão logística para determinar o valor de Odds Ratio e discriminar quais as variáveis que estariam atuando como fatores de risco para adquirir malária.

Para análise das variáveis qualitativas foi feito uso da triangulação e análise de conteúdo, tentando estabelecer relações qualitativas entre os resultados quantitativos e a informação obtida dos grupos focais, das perguntas abertas aos casos e controles e das entrevistas aos funcionários dos estabelecimentos. 


\section{RESULTADOS E DISCUSSÃO}

\section{1. A epidemiologia da malária na área de estudo}

Todas as informaç̃os da incidência de malária no Peru desde 1990 dizem do crescimento descontrolado. Esta doença, em 1998 (Fenômeno El Niño), registra a taxa mais alta dos últimos 60 anos e segundo o MINSA, o custo direto foi de quase US\$ 34 milhões. Esta situação tornou-se mais grave com o aumento da incidência da malária por $P$. falciparum desde 1993. Esta instituição reafirma que a epidemiologia da malária é afetada facilmente por mudanças do clima e de enchentes.

No Peru tem sido áreas delimitadas, nas quais o problema é mais agudo que em outras, e segundo a opinião dos responsáveis pela área de controle da malária do Ministério da Saúde, existem dois padrões epidemiológicos no Peru: o padrão "Costa Norte" e "Selva" (QUIMPER, 1998; MINSA, 1999). Existem opiniões diferentes, como por exemplo, RUBIO-PALIS E ZIMMERMAN (1997) que propõem a classificação em malária de vales profundos (Piemonte) e, malária de vales elevados, o que seria equivalente à malária de "vales interandinos". Segundo os autores para estudos de malária teria que se considerar que esta zona é geograficamente diversificada (detalhada na metodologia) e que, portanto, a tipificação da malária tenderia às características de local, como já foi mencionado por muitos especialistas. Por esta razão, os serviços de saúde utilizam alguns critérios geográficos e climatológicos no estudo e na vigilância epidemiológica desta doença no Peru, como os representados na figura 8.

Neste país, os Programas de Controle de Doenças Transmitidas por Vetores são considerados "unidades multidisciplinares" com funções técnicas, executivas e normativas. No entanto, a execução das ações se torna extremamente complexas pela e atenção por "ciclos de vida" chamada de Modelo de Atenção Integral de Saúde (MAIS) e de um sistema organizacional dos Comitês Locais de 
Administração Compartilhada (CLAS) ${ }^{2}$, autofinanciado, sendo que a sobrevivência destes dependerá da geração de renda própria.

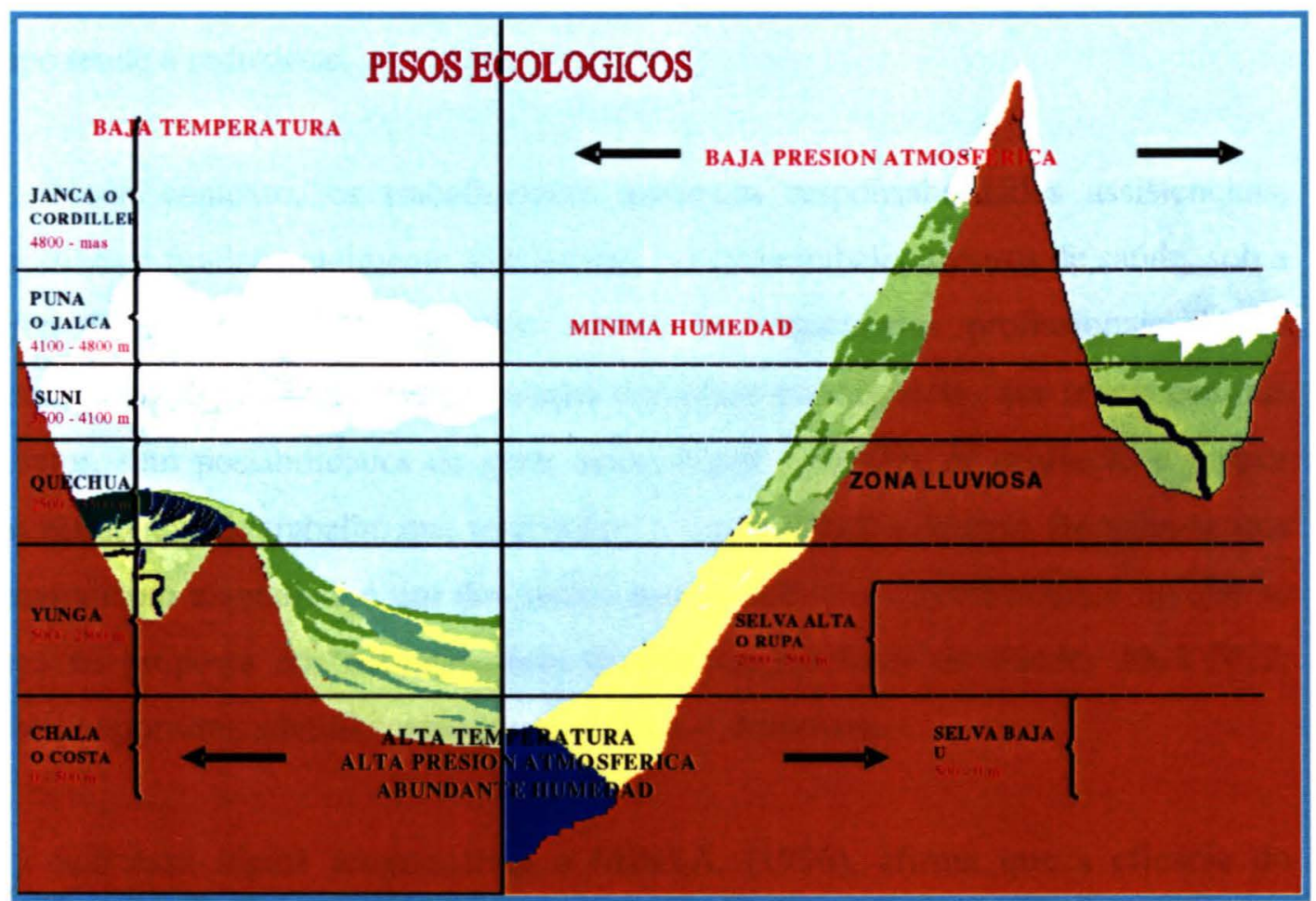

Figura 8. Pisos ecológicos, segundo altura sobre o nível do mar e índices climatológicos.

Fonte: Direção Sub-Região de Saúde Chota- Cajamarca- Perú- 2005

Para facilitar a avaliação da dinâmica do comportamento epidemiológico e das atividades de controle e gerar fontes de dados confiáveis, desde 1994, implementouse uma atenção curativa esquematizada para a malária e um sistema de registro e informação por meio de um sistema em rede (NEYRA et al., 2003). No entanto, os resultados do sistema de registro não são tão satisfatórios, como mostrado adiante.

Este programa de controle tem um protocolo que inclui alguns componentes padronizados, do tratamento, do diagnóstico e das medidas de prevenção e controle. De acordo com as normas estabelecidas, quando o paciente febril acessa aos serviços de saúde, passa primeiramente pelo serviço de triagem (admissão) e posteriormente à

\footnotetext{
${ }^{2}$ Forma de organização administrativa de Serviços de Saúde do Primeiro Nível de Atenção, conformado por um Centro de Saúde, nomeado "cabeça de rede" e Postos de Saúde (acessíveis geograficamente ao Centro de Saúde), administrados por um Comitê Diretivo integrado por um representante da comunidade e trabalhadores dos estabelecimentos.
} 
consulta médica e serviço de enfermaria, onde é coletada uma amostra de sangue (gota espessa), para a análise laboratorial, resultados vão ser entregues depois de uma ou duas horas. Quando se trata de um posto de saúde e havendo pouca demanda o tempo tende a reduzir-se.

Neste contexto, os trabalhadores assumem responsabilidades assistenciais, educativas e fundamentalmente administrativas nos estabelecimentos de saúde, sob a lógica do cumprimento de metas. Assim, as capacidades profissionais desses trabalhadores ficam totalmente limitadas e sujeitas às exigências dos níveis centrais do setor, sem possibilidades de gerar seus próprios padrões de avaliação e propor suas estratégias de trabalho que respondam a sua realidade concreta. Ressalta-se que o centralismo capitalista é um dos males que se mantém, contrariamente ao que se prega na proposta dos delineamentos da Política do Setor de Saúde, 2002-2012, agravado por uma administração burocratizada e desumana.

Sob essa lógica programática o MINSA, (1996), afirma que a eficácia do funcionamento do programa da malária precisa contar com pessoal capacitado e boa implementação. Além disso, deve-se ter esquemas de tratamento completo, material para diagnóstico, registro, controle vetorial, um sistema de supervisão e de investigação epidemiológica, com a participação de toda a equipe de saúde. Mas, nem sempre os estabelecimentos de saúde possuem a implementação e as condições necessárias para prestar a atenção apropriada. Ideal que está muito longe da realidade.

Nas visitas realizadas nos estabelecimentos de saúde desta Sub-Região, observou-se que o pessoal que atende o programa está sobrecarregado de trabalho, tendo que enfrentar uma série de limitações, sendo que um dos aspectos críticos é o sistema de registro, que repercute na sensibilidade da vigilância epidemiológica e na possibilidade de fazer pesquisa. Por outro lado, constatou-se que os esquemas de tratamento não estão disponíveis oportunamente. Esse fato induz ao uso de medicamentos, aos quais o agente já desenvolveu resistência, como no caso do consumo de fansidar. 
$\mathrm{O}$ acesso ao tratamento antimalárico apropriado pode se agravar, diante do anúncio da redução pela metade a elaboração da artemisia, principal medicamento utilizado no tratamento da malária por P. falciparum, em 40 países, (OMS, 2004), devido a escassez de matéria prima, a Artemisia annua. Esta realidade uma vez mais mostra o monopólio da fabricação de certas drogas que são de vital importância para controlar doenças que afetam grandes grupos populacionais

As falhas operacionais, não são anunciadas pelos trabalhadores, já que a maioria dos que trabalham no setor saúde desta área, é contratada por serviços eventuais $^{3}$, sem direito a benefício social, em precárias condições de trabalho e baixa remuneração, e um salário de U\$ 400 para um médico e U\$ 200 para uma enfermeira. Alem disso este pessoal pode ser dispensado a qualquer momento. Esta situação é completamente ignorada na avaliação dos serviços de saúde, convertendose em um aspecto negativo, que tem a ver com a eficiência tão criticada dos serviços de saúde.

Diante estes graves problemas e segundo informações da OMS (2004), existe uma grande possibilidade de redução da incidência da malária pela geração de uma vacina contra a infeção por $P$. falciparum ${ }^{4}$, sendo que a preocupação é a de obter um produto com eficácia de mais de $90 \%$. Mas também deveria considerar-se a possibilidade da população Ter acesso a este produto. Não há dúvida de que muitas vacinas são, no momento, privilégio de alguns, como no caso da vacina para Hepatite B que no Peru tem um custo médio de 10 dólares (segundo lugar em que é administrada), um problema há mais na iniqüidade da saúde em contraposição com os princípios dos direitos a saúde e o estado de bem-estar da população.

\footnotetext{
${ }^{3}$ Empregados do Setor Público que não estão incluídos em planilhas por não constituir parte das vagas orgânicas da instituição, portanto não tem vínculos empregatícios oficial, trabalhando sob a modalidade de trabalhadores eventuais, sem benefícios laborais.

${ }^{4}$ (OMS, 2004). Notícia de primeira página. Aplaude-se resultados de vacina contra malária. http//www.who/malaria/malaria.
} 
O estudo descritivo da malária na DISA-Jaén foi realizado com base na revisão de 50\% (1.458) das fichas de Controle de Assistência e Administração de Tratamento (Anexo 2) de mais de 3000 mil casos registrados entre o ano de 2000 a 2004, nos estabelecimentos de saúde da Jurisdição da DISA que inclui hospitais, centros de saúde, postos e o hospital de Seguridade Social (EsSalud) de Jaén.

A informação coletada a partir destes documentos não é confiável, já que os dados registrados nas fichas são incompletos e de má qualidade, com muitos espaços vazios de informações de muita importância para realizar uma análise apropriada de algumas características dos usuários que foram atendidos com este problema. Isto é evidenciado nos gráficos e tabelas apresentados posteriormente. Alem disso muitas fichas de anos anteriores estavam como "não existentes", situações esta "justificada" pelas constantes trocas de pessoal responsável na área de riscos e danos, que inclui a atenção e execução das atividades dos programas de bartonelose, dengue, raiva, peste e tuberculose, além de atender o correspondente a malária. Por esta razão se pode observar que muitos dos quadros não contêm dados da totalidade de fichas revisadas.

Tabela 2. Distribuição dos casos de malária segundo faixa etária e espécie infectante. 2000-2004. Disa-Jaén. Cajamarca-Peru.

\begin{tabular}{|c|c|c|c|c|c|c|c|c|c|c|}
\hline \multirow{4}{*}{$\begin{array}{l}\text { Grupo } \\
\text { Etário }\end{array}$} & \multicolumn{8}{|c|}{ Espécie infectante } & \multicolumn{2}{|c|}{ TOTAL } \\
\hline & \multicolumn{4}{|c|}{ P.Vivax } & \multicolumn{4}{|c|}{ P. Falciparum } & \multirow{3}{*}{$\mathrm{N}^{\circ}$} & \multirow{3}{*}{$\%$} \\
\hline & \multicolumn{2}{|c|}{ Masculino } & \multicolumn{2}{|c|}{ Feminino } & \multicolumn{2}{|c|}{ Masculino } & \multicolumn{2}{|c|}{ Feminino } & & \\
\hline & $\mathrm{n}^{\circ}$ & $\%$ & $\mathrm{n}^{\circ}$ & $\%$ & $\mathrm{~N}^{\circ}$ & $\%$ & $\mathrm{~N}$ & $\%$ & & \\
\hline$<\operatorname{de} 1$ & 1 & 20,0 & 2 & 40,0 & 1 & 20 & 1 & 20,0 & 5 & 0,3 \\
\hline $1-4$ & 31 & 35,6 & 37 & 42,5 & 9 & 10,4 & 10 & 11,5 & 87 & 6,1 \\
\hline $5-9$ & 66 & 32,5 & 73 & 35,8 & 29 & 14,4 & 36 & 17,6 & 204 & 14,3 \\
\hline $10-19$ & 129 & 33,4 & 84 & 21,8 & 96 & 24,9 & 77 & 19,9 & 386 & 27,0 \\
\hline $20-50$ & 156 & 24,2 & 146 & 22,7 & 179 & 27,8 & 163 & 25,3 & 644 & 45,0 \\
\hline $51 a+$ & 30 & 28,6 & 10 & 9,5 & 34 & 32,4 & 31 & 29,5 & 105 & 7,3 \\
\hline TOTAL & 413 & 28,9 & 352 & 24,6 & 348 & 24,3 & 318 & 22,2 & 1431 & 100,0 \\
\hline
\end{tabular}

Fonte: Dados das Fichas de Controle da Assistência e Administração do Tratamento da Malária dos Serviços de Saúde. DISA-JAEN- Cajamarca. Peru. 2004 ( $p=0.003$ ). 
Os dados da tabela mostram que, o grupo etário mais atingido com esta enfermidade tem entre 20 e 50 anos de idade (45\%). Não obstante, observa-se que os grupos entre 0 a 9 e de 10 a 19 anos somam 47,7\%, por ambas espécies infectantes, dado que reverte a incidência que freqüentemente era mais elevada na população adulta. Assim também se observa que a relação $P$. vivax e $P$. falciparum estão é quase de 1 para 1. Em conseqüência, por tratar-se de populações jovens estáveis e expostas continuamente ao risco de adquirir malária podem estar desenvolvendo certo grau de resistência à infecção (FORATTINI, 2002).

O MINSA (2000), também indica que na Amazônia do Peru, os menores de 14 anos são os mais atingidos por esta doença, ligado à inserção da população infantil ao mercado ocupacional, tornando-os mais vulneráveis. Mesmos resultados foram encontrados por GUTHMANN et al. (2002), na costa norte peruana onde mais de $40 \%$ dos casos de malária tinham menos de 15 anos de idade sendo atingidos principalmente pelo P. vivax. Entanto que ROPER (2000), estudando os fatores de risco na Amazônia peruana encontrou que a incidência da malária aumentava com a idade. Assim também, CAMARGO (1996), em Candeias (Brasil), diz que o grupo etário entre 11 e 15 anos de idade, especialmente as mulheres, seria o grupo de risco, pelas atividades fora da aula, como jogar bola e fazer esportes à beira do rio.

Não existe muita diferença na proporção de mulheres afetadas em relação ao sexo masculino tanto por malária por $P$. vivax como por $P$. falciparum, mas observase um incremento conforme aumenta a idade. Existe associação significativa entre idade e malária segundo espécie infectante $(\mathrm{p}=0.000)$.

Em uma zona com as características geográficas e econômicas como Jaén, se espera que as pessoas mais afetadas por malária sejam os agricultores. Porém, neste estudo, (tabela 3), observou-se que são os estudantes, tanto homens como mulheres, os mais afetados por malária $(25,7 \%)$, com predomínio da doença por $P$. falciparum em 53,4\% destes. Seguindo em ordem de importância, as donas de casa e em terceiro lugar os agricultores, aparecendo na seqüência outros com ocupações diversas como "mototaxistas", carpinteiros, entre outros. E, como se pode notar, 29,6\% das fichas 
revisadas não têm registrado o dado de ocupação. No caso da ocupação de agricultor, a proporção segundo espécie infectante (relação malária por $P$. falciparum e $P$. vivax), também é de quase 1para1. No caso das donas de casa predomina a primeira.

Tabela 3. Casos de malária segundo ocupação e espécie infectante. 2000 - 2004. Disa-Jaén. Cajamarca. Peru.

\begin{tabular}{|c|c|c|c|c|c|c|c|c|c|c|}
\hline \multirow[t]{4}{*}{ Ocupação } & \multicolumn{8}{|c|}{ Espécie infectante } & \multicolumn{2}{|c|}{ TOTAL } \\
\hline & \multicolumn{4}{|c|}{ P. falciparum } & \multicolumn{4}{|c|}{ P. vivax } & \multirow{3}{*}{$\mathrm{N}^{\circ}$} & \multirow{3}{*}{$\%$} \\
\hline & \multicolumn{2}{|c|}{ Homem } & \multicolumn{2}{|c|}{ Mulher } & \multicolumn{2}{|c|}{ Homem } & \multicolumn{2}{|c|}{ Mulher } & & \\
\hline & $\mathrm{n}^{\circ}$ & $\%$ & $\mathrm{n}^{\circ}$ & $\%$ & $\mathrm{n}^{\mathrm{o}}$ & $\%$ & $\mathrm{n}$ & $\%$ & & \\
\hline Estudante & 107 & 28,7 & 92 & 24,7 & 91 & 24,4 & 83 & 22,2 & 373 & 25,7 \\
\hline $\begin{array}{l}\text { Dona de } \\
\text { casa }\end{array}$ & --- & -- & 170 & 60,7 & --- & --- & 110 & 39,3 & 280 & 19,3 \\
\hline Agricultor & 113 & 45,9 & 8 & 3,3 & 117 & 47,5 & 8 & 3,3 & 246 & 17,0 \\
\hline Obreiro & 28 & 77,8 & 3 & 8,3 & 5 & 13,9 & 0 & --- & 36 & 2,5 \\
\hline $\begin{array}{l}\text { Mão de obra } \\
\text { qualificada }\end{array}$ & 18 & 72,0 & 2 & 8,0 & 5 & 20,0 & 0 & -- & 25 & 1,7 \\
\hline Profissional & 10 & 50,0 & 3 & 15,0 & 6 & 30,0 & 1 & 5,0 & 20 & 1,4 \\
\hline Comerciante & 13 & 76,4 & 2 & 11,8 & 2 & 11,8 & 0 & -- & 17 & 1,1 \\
\hline Empregado & 4 & 33,3 & 3 & 25,0 & 4 & 33,3 & 1 & 8,34 & 12 & 0,8 \\
\hline Mototaxista & 6 & 75,0 & 0 & --- & 2 & 25,0 & 0 & --- & 8 & 0,6 \\
\hline $\begin{array}{l}\begin{array}{l}\text { Pessoal de } \\
\text { serviço }\end{array} \\
\end{array}$ & 2 & 50,0 & 0 & --- & 0 & --- & 2 & 50,0 & 4 & 0,2 \\
\hline Não referido & 41 & 9,6 & 42 & 4,8 & 187 & 43,5 & 159 & 37,1 & 429 & 29,6 \\
\hline TOTAL & 348 & 24,0 & 320 & 22,1 & 423 & 29,2 & 359 & 24,7 & 1450 & 100,0 \\
\hline
\end{tabular}

Fonte: Dados das Fichas de Controle da Assistência e Administração do Tratamento da Malária dos Serviços de Saúde. DISA-JAEN- Cajamarca. Peru. $2004(\mathrm{p}=0,000)$.

A análise estatística evidencia uma associação altamente significativa entre a ocupação e a espécie infectante.

Segundo FORATTINI (2002) o sexo e o grupo etário na epidemiologia da malária são indicadores das atividades principais. No primeiro caso concernente ao ambiente onde ocorrerá a transmissão e que determinará que este seja intra ou extradomiciliar. Contudo, a ocupação destes não necessariamente tem a ver com 
labores que os expõem ao vetor da malária, mas com outras atividades relativas às costumes ou hábitos. Isso ocorre na zona urbana e na periferia da cidade de Jaén.

Com os resultados obtidos se pode inferir que o vetor desta doença pode estar muito próximos da moradia, do centro educativo ou dos locais de esporte e lazer, atividades muito comuns nessa zona tanto dos estudantes como as donas de casa. Outros lugares prováveis de exposição à infecção, tanto na cidade de Jaén como na de San Ignacio, pode ser os restaurantes e centros de diversão que são abundantes e concorridos, sobretudo em horários crepusculares, cuja ambientação favorece a presença de mosquitos. Situação não considerada na indagação dos antecedentes epidemiológicos dos casos atendidos.

A busca passiva, a automedicação com antimaláricos e os resultados do diagnóstico baseado no exame da gota espessa, que tem sensibilidade limitada (FERREIRA \& ÁVILA, 1996; KIRCHGATTER et al. (1997) nesta Sub-Região, faz suspeitar que há potenciais fontes de infecção da doença nessa zona).

Entretanto as inúmeras pesquisas realizadas mostram que em áreas de baixa endemia encontram-se pacientes com leituras elevadas de gametócitos em gota espessa (GENTON, 1995; BELIZARIO, 1997; GONZALES et al. (1997) GUTHMANN et al. 2002). Embora HOFFMAN (1986); Mc GREGOR, (1987); REY, (2002), indicam que a imunidade protetora da malária é específica e gradual, precisando entre três a seis anos de exposição numa área de alta endemicidade, sendo que o grupo com maior chance é entre os 5 e 9 anos de idade. Mas também esta imunidade pode ser precursora da doença sintomática; e, por sua vez, ser reservatório de transmissão, reintroduzindo a doença para outras zonas (MARTENS \& HALL, 2000; NJAMA, 2004; CIIFEN, 1995).

De acordo com o MINSA, a simplicidade do procedimento permitiu a capacitação de pessoal técnico para realizar os exames no primeiro nível de atenção e assim poder garantir a captação dos casos de maneira oportuna. Esse método permite identificar a espécie, o estágio em que se encontra e ainda quantificá-la. Mas como já 
labores que os expõem ao vetor da malária, mas com outras atividades relativas às costumes ou hábitos. Isso ocorre na zona urbana e na periferia da cidade de Jaén.

Com os resultados obtidos se pode inferir que o vetor desta doença pode estar muito próximos da moradia, do centro educativo ou dos locais de esporte e lazer, atividades muito comuns nessa zona tanto dos estudantes como as donas de casa. Outros lugares prováveis de exposição à infecção, tanto na cidade de Jaén como na de San Ignacio, pode ser os restaurantes e centros de diversão que são abundantes e concorridos, sobretudo em horários crepusculares, cuja ambientação favorece a presença de mosquitos. Situação não considerada na indagação dos antecedentes epidemiológicos dos casos atendidos.

A busca passiva, a automedicação com antimaláricos e os resultados do diagnóstico baseado no exame da gota espessa, que tem sensibilidade limitada (FERREIRA \& ÁVILA, 1996; KIRCHGATTER et al. (1997) nesta Sub-Região, faz suspeitar que há potenciais fontes de infecção da doença nessa zona).

Entretanto as inúmeras pesquisas realizadas mostram que em áreas de baixa endemia encontram-se pacientes com leituras elevadas de gametócitos em gota espessa (GENTON, 1995; BELIZARIO, 1997; GONZALES et al. (1997) GUTHMANN et al. 2002). Embora HOFFMAN (1986); Mc GREGOR, (1987); REY, (2002), indicam que a imunidade protetora da malária é específica e gradual, precisando entre três a seis anos de exposição numa área de alta endemicidade, sendo que o grupo com maior chance é entre os 5 e 9 anos de idade. Mas também esta imunidade pode ser precursora da doença sintomática; e, por sua vez, ser reservatório de transmissão, reintroduzindo a doença para outras zonas (MARTENS \& HALL, 2000; NJAMA, 2004; CIIFEN, 1995).

De acordo com o MINSA, a simplicidade do procedimento permitiu a capacitação de pessoal técnico para realizar os exames no primeiro nível de atenção e assim poder garantir a captação dos casos de maneira oportuna. Esse método permite identificar a espécie, o estágio em que se encontra e ainda quantificá-la. Mas como já 
referido durante a coloração da gota espessa, segundo Bruce-Chwatt (1985) referido por KIRCHGATTER et al. (1997) pode ocorrer perda de $66 \%$ dos trofozoítas e de $80-90 \%$ de gametócitos. Cabe ressaltar que os estabelecimentos de saúde do primeiro nível de atenção desta zona contam com um laboratório e pessoal para realizar diagnóstico do nível primário.

Tabela 4. Distribuição dos casos de malária segundo espécie infectante e ano de registro. 2000-2004. Disa-Jaén. Cajamarca- Peru.

\begin{tabular}{|c|c|c|c|c|c|c|c|c|c|c|c|c|}
\hline \multirow{3}{*}{$\begin{array}{l}\text { Espécie } \\
\text { Infectante }\end{array}$} & \multicolumn{10}{|c|}{ ANO } & \multicolumn{2}{|c|}{ TOTAL } \\
\hline & \multicolumn{2}{|c|}{2000} & \multicolumn{2}{|c|}{2001} & \multicolumn{2}{|c|}{2002} & \multicolumn{2}{|c|}{2003} & \multicolumn{2}{|c|}{2004} & \multirow[t]{2}{*}{$\mathbf{N}^{\circ}$} & \multirow[t]{2}{*}{$\%$} \\
\hline & $\mathrm{n}^{0}$ & $\%$ & $\mathrm{n}^{\circ}$ & $\%$ & $\mathrm{n}^{0}$ & $\%$ & $\mathrm{n}^{0}$ & $\%$ & $\mathrm{n}^{\circ}$ & $\%$ & & \\
\hline P. falciparum & 18 & 2,9 & 17 & 2,7 & 79 & 12,8 & 285 & 46,3 & 217 & 35,2 & 616 & 44,7 \\
\hline P. vivax & 87 & 11,4 & 111 & 14,6 & 62 & 10,1 & 223 & 29,3 & 275 & 38,8 & 761 & 55,3 \\
\hline TOTAL & 105 & 7,6 & 128 & 9,3 & 141 & 10,2 & 508 & 36,9 & 492 & 35,7 & 1377 & 100,0 \\
\hline
\end{tabular}

Fonte: Dados das Fichas de Controle da Assistência e Administração do Tratamento da Malária dos Serviços de Saúde. DISA-JAEN Cajamarca. Peru. 2004 ( $p=0,000)$.

Os dados da Tabela 4 mostram a tendência da relação entre malária por $P$. vivax e $P$. falciparum nos cinco anos de observação. Assim vemos que do total de fichas revisadas, 55,3\% corresponde a malária por $P$. vivax e as restantes por $P$. falciparum, notando-se que para o ano de 2003, a freqüência deste último aumenta em quase quatro vezes em relação ao ano anterior, evidenciando associação altamente significativa entre espécie de $P$. falciparum y os anos de apresentação.

Esta situação é alarmante por se tratar de uma forma grave da doença que evolui com marcada redução de hemoglobina. Se a terapêutica não é específica e oportuna pode provocar transtornos da coagulação, insuficiência renal hepática, encefalopatia aguda e coma, como se descreve em outros países. Nesta zona, em todos os anos de estudo, não foram registrados casos fatais e são poucos os pacientes com malária por $P$. falciparum que apresentaram complicações severas. Assim vê-se que no livro de registro de internação do Hospital de Apoio de Jaén,(HAP) nos últimos dois anos $(2003,2004)$ foi registrado apenas 15 internações com diagnóstico de malária, sendo que a maioria fora grávidas que, como é obvio, devem ter sido hospitalizadas para tratamento antimalárico respectivo. 
As pesquisas realizadas na região da Amazônia Peruana com imunofluorescência indireta para a detecção de anticorpos contra Plasmodium mostraram que as crianças menores de 10 anos tiveram parasitemia circulante mais elevada do que os adultos. A isto se agrega a desnutrição, alta prevalência de parasitose ou grávidas que desenvolvem complicações com o dobro de freqüência comparado com as que não estão, tais como abortos, parto prematuro e baixo peso ao nascer (EBRAHIM, 1996; SUAREZ, 2004)

Neste sentido existe outro vazio de informação, já que não há registros de casos de malária e abortos ou partos prematuros, como também não tem estudos do estado nutricional relacionados com malária. Deve-se considerar que neste meio o sub-registro de casos é um assunto bastante grave, que segundo alguns trabalhadores do setor saúde ${ }^{5}$ é calculado em uma média de $40 \%$, para tanto não houve seguimento dos pacientes que tiveram malária, especialmente as gestantes e menores de cinco anos. Desconhecem-se quais foram suas condições finais, passados 14 dias do tratamento, já que são pouquíssimos os pacientes que regressaram para fazer o terceiro controle (vide tabela 8 )

Tabela 5. Casos de malária segundo espécie infectante e origem da doença. 2000 2004. Sub-Região de Jaén. Cajamarca. Peru.

\begin{tabular}{lcccccc}
\hline \multirow{2}{*}{$\begin{array}{l}\text { Infećcie } \\
\end{array}$} & \multicolumn{3}{c}{ Origem da infecção } & \multicolumn{2}{c}{ TOTAL } \\
\cline { 2 - 5 } & \multicolumn{2}{c}{ Autóctono } & \multicolumn{2}{c}{ Importado } & \multirow{2}{*}{$\mathbf{N}^{\mathbf{a}}$} & \multirow{2}{*}{$\%$} \\
\cline { 2 - 5 } & $\mathrm{n}^{\circ}$ & $\%$ & $\mathrm{n}^{\circ}$ & $\%$ & & \\
\hline P. falciparum & 516 & 92,8 & 40 & 7,2 & 556 & 43,8 \\
$P$. vivax & 586 & 82,3 & 126 & 17,7 & 712 & 56,2 \\
\hline Total & $\mathbf{1 1 0 2}$ & $\mathbf{8 6 , 9}$ & $\mathbf{1 6 6}$ & $\mathbf{1 3 , 1}$ & $\mathbf{1 2 6 8}$ & $\mathbf{1 0 0}$ \\
\hline
\end{tabular}

Fonte: Dados das Fichas de Controle da Assistência e Administração do Tratamento da Malária dos Serviços de Saúde. DISA-JAEN Cajamarca. Peru. 2004 ( $p=0,000)$.

Os dados da tabela 5 mostram que a malária por $P$. falciparum em quase a sua totalidade $(86,9 \%)$ é registrada como autóctone. Apenas $13 \%$ para ambas as espécies

\footnotetext{
${ }^{5}$ Comentário do chefe de Epidemiologia do Hospital de Apoio de Jaén
} 
são importadas, e destas, a maioria $(75,9 \%)$ são por $P$. vivax. Entende-se por autóctone, segundo as normas do Programa de Controle da Malária, a pessoa que não saiu da cidade nos 15 dias anteriores à manifestação dos primeiros sinais e sintomas.

Os casos importados são qualificados de acordo com a zona onde se apresentam, ou seja, cada estabelecimento considera como "caso importado" todo paciente que de acordo com os seus antecedentes epidemiológicos esteve 15 dias antes do início dos sintomas em lugares considerados como endêmicos e que não pertence a sua área de responsabilidade, ainda que esta zona se encontre dentro da jurisdição da DISA-Jaén. Portanto, a definição de importado tem caráter de local.

Deve-se considerar que neste caso, tratando-se de uma zona endêmica de outras enfermidades febris, o exame clínico do paciente deveria ser completo, visto que se podem omitir outras infecções semelhantes à malária (OMS, 2000), recomendação difícil de cumprir considerando que o médico, do serviço público deve atender seis pacientes por hora, para tanto não se pode garantir um apropriado diagnóstico clínico.

Como mencionado, na primeira parte do presente trabalho, esta zona é de intenso fluxo comercial, com uma circulação permanente de pessoas, o que gera alta probabilidade de exposição à infecção, cabendo a possibilidade de que também se trate de indivíduos já portadores assintomáticos e, portanto, estão veiculando ou reintroduzindo a doença em áreas potencialmente receptivas. Um exemplo são os trabalhadores das rodovias que se estão sendo construídas. Estes provêm de outras zonas altamente endêmicas de malária, como alguns lugares de Piura e Chimbote, mas se desconhece o estado imunológico destes em relação á malária. Nesse sentido BERTOLI (2001), indica que o potencial malarígeno é mantido pela presença de anofelinos transmissores que conserva a capacidade vetorial em áreas restritas, onde as condições climáticas e a pressão exercida pela chegada de doentes de malária e de portadores assintomáticos são os responsáveis pela reintrodução constante do agente etiológico. 
Importante ressaltar que nesta Sub-Região, diante de um surto epidêmico, se realiza uma investigação epidemiológica, baseada em exame de gota espessa nos habitantes que vivem na área onde foram detectados os casos de malária, com a finalidade de descobrir a presença de outros casos autóctones na zona. Na prática, em muitas moradias não se consegue obter informação, já que os habitantes não estão presentes. Quando se faz o pedido aos habitantes para submeter-se a exames de gota espessa em estudos exploratórios, muitas pessoas se recusam, convertendo-se em um obstáculo à obtenção de informações fidedignas. Para as pessoas, o significado de estar enfermo está subentendido no fato de que "não sentem nada e por isso não estão doentes e em conseqüência não precisam ser submetidos a exames".

Para tanto, é desconhecida a provável existência de assintomáticos, como relatada por GUTHMANN et al. (2002), em uma zona limítrofe do lugar do presente estudo, tendo observado que em um surto de malária ocorrido neste lugar, a maioria dos examinados eram assintomáticos, o que não é comum, tratando-se de uma área de baixa transmissão. Esse resultado deve servir como referência para estudos posteriores.

As fichas de Assistência e Administração de tratamento seriam documentos muito valiosos para a vigilância e investigação epidemiológica se fossem consignados apropriadamente os dados que estas registram. A informação de caso autóctone ou importado poderia ajudar, no primeiro caso, a quantificar a possibilidade de propagação da enfermidade nos lugares onde reside o caso. Outrossim, fazer um busca ativa dos que convivem com o caso (colaterais), bem como determinar a existência de anofelinos vetores e seus criadouros. Em consequiência, nesta zona é impossível realizar este tipo de ação, já que, como referido, a qualidade do registro da malária é muito deficiente.

Outros registros, como a ficha de investigação epidemiológica da malária (registro de responsabilidade do médico) (anexo 2) é preenchido principalmente com informações burocráticas correspondentes ao paciente atendido, sendo que muitas vezes é feito pelo pessoal técnico (em três vias). Pelo fato de não existir informação 
correspondente à provável fonte de infecção e o mecanismo de transmissão, não se poderá definir se é uma primeira infecção, uma recaída ou se teve histórico de malária.Com relação à zona de residência, esta não é anotada como urbana ou rural, e sim por localidades, o que faz impossível sua localização como tal, para quem não conhece esse lugar.

Tabela 6. Casos de malária segundo densidade parasitária e espécie infectante. 20002004. DISA-Jaén. Cajamarca. Peru.

\begin{tabular}{|c|c|c|c|c|c|c|c|c|c|c|}
\hline \multirow{4}{*}{$\begin{array}{l}\text { Densidade } \\
\text { parasitária }\end{array}$} & \multicolumn{8}{|c|}{ Espécie infectante } & \multicolumn{2}{|c|}{ TOTAL } \\
\hline & \multicolumn{4}{|c|}{ P. falciparum } & \multicolumn{4}{|c|}{ P. vivax } & & \\
\hline & \multicolumn{2}{|c|}{$\mathbf{H}$} & \multicolumn{2}{|c|}{$\mathbf{M}$} & \multicolumn{2}{|c|}{$\mathbf{H}$} & \multicolumn{2}{|c|}{$\mathbf{M}$} & \multirow[b]{2}{*}{$\mathbf{N}^{0}$} & \multirow[b]{2}{*}{$\%$} \\
\hline & $\mathrm{n}^{\circ}$ & $\%$ & $\mathrm{n}^{\circ}$ & $\%$ & $\mathrm{n}^{\circ}$ & $\%$ & $\mathrm{~N}$ & $\%$ & & \\
\hline$+/ 2$ y Fg & 72 & 27,2 & 56 & 21,1 & 83 & 31,3 & 54 & 20,4 & 265 & 19,2 \\
\hline+ & 132 & 24,1 & 130 & 23,7 & 137 & 25,0 & 149 & 27,2 & 548 & 39.6 \\
\hline++ & 113 & 22,2 & 110 & 21,7 & 161 & 31,7 & 124 & 24,4 & 508 & 36,7 \\
\hline+++ & 26 & 44,1 & 15 & 25,4 & 12 & 20,3 & 6 & 10,2 & 59 & 4,3 \\
\hline++++ & 0 & --- & 3 & 100,0 & 0 & --- & 0 & --- & 3 & 0,2 \\
\hline TOTAL & 343 & 24,8 & 314 & 22,7 & 393 & 28,4 & 333 & 24,1 & 1383 & 100,0 \\
\hline
\end{tabular}

Fonte: Dados das Fichas de Controle da Assistência e Administração do Tratamento da Malária dos Serviços de Saúde. DISA- JAEN- Cajamarca. Peru. 2004 ( $p=0,001)$.

A tabela mostra que nos casos atendidos com diagnóstico de malária confirmada, nos estabelecimentos estudados predominava uma carga parasitária entre uma $(39,6 \%)$ e duas cruzes $(36,7 \%)$, seguindo em ordem de importância $+/ 2$ cruzes $(19,2 \%)$, em alguns deles foi registrado somente o encontro de gametócitos, sendo mais freqüente na espécie $P$. vivax $(51,7 \%)$. Existe associação significativa entre a densidade parasitaria e a espécie infectante de malária $(\mathrm{p}=0,001)$. Além disso, os resultados explorados mostram que o percentual de distribuição da densidade segundo espécie infectante e sexo dos casos não varia, mantendo-se em torno de 22 a $24 \%$, com exceção dos homens com $P$. vivax, nos quais $31,3 \%$ destes mostram baixas parasitemias e naqueles com malária por $P$. falciparum $44,1 \%$ informam altas parasitemias com três cruzes.

Assim também algumas fichas tinham registrado o encontro de 10 a 100 gametócitos, clara evidência de que pode tratar-se de potenciais fontes de infecção da 
doença. Embora NEVES et al. (1998) asseguram que para que o mosquito se infecte, é necessário que o paciente apresente 300 gametócitos por $\mathrm{mm}^{3}$ de sangue, quando a proporção é menor de 50 gametócitos por $\mathrm{mm}^{3}$, a infecção do inseto tende a não ocorrer, de acordo com esta versão esses pacientes não representariam risco para a população em área endêmica de malária.

A entrevista realizada com o laboratorista do Hospital de Apoio de Jaén 6 indica que segundo a sua experiência as altas densidades parasitárias tem sido encontradas em pessoas que não são da zona, assim como também a densidade parasitária muito baixa de $+/ 2 \mathrm{~F}$ ou $2 \mathrm{Fg}$ ou $4 \mathrm{Fg}$, em pacientes que se automedicam com Fansidar. Fato que neste lugar não tem sido estudado. Para tanto, podem existir grupos na população que estariam atuando como principal reservatório da infecção, como o encontrado por BELIZARIO (1997) em um estudo nas Filipinas, área de baixa endemia, tendo que o grupo de indivíduos do sexo masculino entre os 10 e 39 anos, tiveram leituras mais elevadas de gametócitos em gota espessa, que as mulheres.

É difícil determinar a relação entre a sintomatologia e a carga parasitária verdadeira nos pacientes que se automedicam com fansidar e outros antibióticos, porque o efeito desses medicamentos é de mais ou menos 21 dias. Tais medicamentos encontram-se disponíveis nas farmácias e ainda os pacientes em geral não estão dispostos a se submeter a exames de gota espessa seriada, processos necessários para esgotar a possibilidade de positividade. Esta é uma das grandes limitações encontradas em outros estudos. Assim, KAGANI (1992) diz que em áreas de baixa endemia o diagnóstico negativo pode levar a erros, pois a potência é influenciada pelo estado imune do indivíduo e a ação de antimaláricos usados na profilaxia ou na terapia.

Quando essas situações se apresentam, os especialistas falam de seqüestro parasitário que tem sido determinado somente nos estudos post mortem em humanos e nos modelos animais, revelando que este fenômeno se dá principalmente no baço e

\footnotetext{
${ }^{6}$ José Arias. Microbiólogo laboratorista do Hospital de Apoio de Jaén. 2005
} 
na medula óssea. Recentemente se tem encontrado que as moléculas ICAM-1, CD49c, CD166 e CD164 atuam como possíveis receptores de células da medula óssea para adesão dos gametócitos (SMALLEY et al., 1981; ROGERS et al., 2000; CONTRERAS-OCHOA e RAMSEY, 2004).

Cabe ressaltar que os trabalhos de investigação que incluem exames de ELISA (Enzyme-linked inmunosorbent assay), cultura do agente etiológico, taxonomia de vetores, imunologia e métodos biomoleculares, somente são realizados em nível central, ou seja, está centralizado na capital do país. Além do mais, os custos destes são muito elevados.

As normas para registrar as leituras de densidade parasitária das lâminas das amostras obtidas são as padronizadas pela OMS. Mas o registro também inclui outras características como que a espécie de plasmódio identificada é informada por suas iniciais: Plasmodium vivax (V); Plasmodium falciparum (F); Plasmodium malariae (M). Entanto que as formas sexuais do parasito, os gametócitos de P. falciparum se indicam como: F: somente aneles; Fg: somente gametas; F e Fg: aneles e gametas. Essas normas são utilizadas para facilitar a leitura pelos técnicos, porém ainda encontradas dificuldades no bom desempenho dos mesmos.

A avaliação da qualidade das lâminas deve ser feita trimestralmente em 100\% das lâminas informadas como positivas e de $10 \%$ das registradas como negativas (MINSA, 1996). Segundo o responsável pelo laboratório do Hospital de Apoio de Jaén, é um serviço que funciona a contento.

A tabela 7 mostra os resultados da densidade parasitária dos exames dos pacientes atendidos nos estabelecimentos de saúde da DISA-Jaén. É evidente que a densidade parasitária predominante é de uma ou duas cruzes, condição que se apresenta com mais freqüência nos menores de nove anos $(44,0 \%)$. Nota-se que $37,4 \%$ dos registros de pessoas com carga parasitária de uma a duas cruzes teriam idades entre um a 19 anos. Foram registrados somente $4,5 \%$ de densidades parasitárias com três cruzes ou mais. A distribuição percentual destas densidades 
parasitárias é quase homogênea nos outros grupos etários por cada classificação de densidade.

Tabela 7. Casos de malária segundo grupo etário e densidade parasitária. 2000-2004. Sub-Região de Jaén. Cajamarca. Peru.

\begin{tabular}{|c|c|c|c|c|c|c|c|c|c|c|}
\hline \multirow{3}{*}{$\begin{array}{l}\text { Grupo } \\
\text { etário }\end{array}$} & \multicolumn{8}{|c|}{ Densidade Parasitária } & \multicolumn{2}{|c|}{ TOTAL } \\
\hline & \multicolumn{2}{|c|}{$+/ 2$} & \multicolumn{2}{|c|}{+} & \multicolumn{2}{|c|}{++} & \multicolumn{2}{|c|}{+++} & \multirow[b]{2}{*}{$\mathbf{N}^{\circ}$} & \multirow[b]{2}{*}{$\%$} \\
\hline & $\mathrm{n}^{\circ}$ & $\%$ & $\mathrm{~N}^{\circ}$ & $\%$ & $\mathrm{~N}^{\circ}$ & $\%$ & $\mathrm{n}$ & $\%$ & & \\
\hline$>1$ & 3 & 60,0 & 1 & 20,0 & 1 & 20,0 & --- & ---- & 5 & 0,4 \\
\hline 1 a 9 & 50 & 18,1 & 95 & 34,3 & 122 & 44,0 & 10 & 3,6 & 277 & 20,2 \\
\hline 10 a 14 & 33 & 17,8 & 84 & 45,4 & 65 & 35,1 & 3 & 1,6 & 185 & 13,5 \\
\hline 15 a 19 & 32 & 17,3 & 76 & 41,1 & 71 & 38,4 & 6 & 3,2 & 185 & 13,5 \\
\hline 20 a 29 & 55 & 22,9 & 94 & 39,2 & 80 & 33,3 & 11 & 4,6 & 240 & 17,5 \\
\hline 30 a 39 & 43 & 19,5 & 96 & 43,4 & 69 & 31,2 & 13 & 5,9 & 221 & 16,1 \\
\hline 40 a 49 & 24 & 16,6 & 61 & 42,1 & 50 & 34,5 & 10 & 6,8 & 145 & 10,6 \\
\hline $50 a+$ & 24 & 21,4 & 40 & 35,7 & 39 & 34,8 & 9 & 8,1 & 112 & 8,2 \\
\hline TOTAL & 264 & 19,3 & 547 & 39,9 & 497 & 36,3 & 62 & 4,5 & 1370 & 100,0 \\
\hline
\end{tabular}

Fonte: Dados das Fichas de Controle da Assistência e Administração do Tratamento da Malária dos Serviços de Saúde. DISA-JAEN. Cajamarca. Peru. 2004 ( $p=0,108)$.

Está confirmado que na medida que a população convive com a malária vai crescendo em suas defesas. REY (2002) sugere que a imunidade protetora da malária é específica e gradual, e sua aquisição por pessoas expostas em áreas de alta endemicidade é dirigida contra a fase sangüínea, requerendo de três a seis anos de exposição para assegurar nos indivíduos uma larga proteção dos efeitos mórbidos da doença e eliminação do risco de mortalidade devido a malária. É provável que os moradores de algumas regiões da Amazônia peruana, tenham desenvolvido alguns graus de imunidade, já que num estudo realizado nestas regiões no ano de 1978, mostrou que os habitantes desse lugar apresentaram anticorpos contra a malaria (SULZER, et al, 1981).

No presente estudo se observa que mais de $20 \%$ dos casos são menores de 9 anos de idade. Dentro desse grupo, os afetados entre cinco e nove anos são os que têm maior possibilidade de resposta imunitária mais eficiente e uma sintomatologia mais discreta, com parasitemia elevada (NEVES et al., 1998). 
Tabela 8. Casos de malária segundo número de controles realizados e espécie infectante. 2000-2004. Sub-Região de Jaén. Cajamarca. Perú.

\begin{tabular}{|c|c|c|c|c|c|c|}
\hline \multirow{3}{*}{ Controles } & \multicolumn{4}{|c|}{ Espécie infectante } & \multicolumn{2}{|c|}{ TOTAL } \\
\hline & \multicolumn{2}{|c|}{ P. falciparum } & \multicolumn{2}{|c|}{ P. vivax } & \multirow{2}{*}{$\mathbf{N}^{\mathrm{a}}$} & \multirow{2}{*}{$\%$} \\
\hline & $\mathrm{n}^{\mathrm{o}}$ & $\%$ & $\mathrm{n}^{0}$ & $\%$ & & \\
\hline 1 & 257 & 85,0 & 45 & 15,0 & 302 & 24,7 \\
\hline 2 & 68 & 11,0 & 551 & 89,0 & 619 & 50,7 \\
\hline 3 & 130 & 51,0 & 125 & 49,0 & 255 & 20,9 \\
\hline 4 & 45 & 97,8 & 1 & 2,2 & 46 & 3,7 \\
\hline AAL & & & & & 22 & 0,0 \\
\hline
\end{tabular}

Fonte: Dados das Fichas de Controle da Assistência e Administração do Tratamento da Malária dos Serviços de Saúde. DISA-JAEN. Cajamarca. Peru. 2004 ( $p=0,02)$.

Realizar os controles dos casos de malária tratados nos estabelecimentos é parte fundamental do processo de controle desta doença. Neste caso, apenas $83,8 \%$, das fichas, possuem o registro de controle realizado nos diferentes estabelecimentos de saúde do MINSA e EsSalud entre os anos de 2000 e 2004. Destes, 24,6\% realizaram entre três e quatro controle, em 50,7\% figuram somente dois controles e em $24,7 \%$ foram registrados apenas um controle. Por tanto apenas uma quinta parte dos pacientes atendidos consegue realizar os controles obrigatórios ao qual deve submeter-se cada paciente que recebeu o tratamento antimalárico. Além do exposto observa-se que mais de $16 \%$ não realizaram controle algum.

Segundo os depoimentos dos trabalhadores dos serviços de saúde desse lugar, o acompanhamento dos casos que não retornam para os seus controle é impossibilitado por principalmente pela falta de pessoal ou a distância entre o estabelecimento e o domicílio do caso de malária. Observa-se que quando os responsáveis do programa da malária, marcam as datas ou exigem aos casos para que realizem o controle ou levem os seus familiares para fazer o exame de gota espessa, estes reagem com agressividade porque dizem "não tenho tempo, devo trabalhar para comer" 
Alguns trabalhadores conseguem este objetivo quando atuam com rigidez e autoritarismo, tentando convencer os pacientes a cumprirem com todos os seus controles, do contrário são poucos os que aceitam. Recomenda-se como prática corrente no manejo de casos tratados, repetir o exame de gota espessa nos três, sete e 14 dias posteriores ao começo do tratamento.

Este problema da não assistência aos controles também se apresentou nos casos que participaram no estudo, dos quais apenas 35,6\% completaram seus controles regularmente e $43,3 \%$ chegaram a fazer apenas um controle.

O abandono do tratamento principalmente se produz nos casos atingidos por $P$. vivax, probabelmente porque o tratamento é prolongado. Não entanto esse vão procurar a cura "pelos entendidos que moram nos arredores. Pode-se constatar que alguns dos casos foram levados para outros lugares, como a cidade de Chacapoyas, a 200 Km de Jaén, para se curarem”.

É provável que esta situação também seja um problema a mais em outras zonas, precisando estabelecer acordos que permitam melhorar estes impasses, fato que possibilitaria prever o aparecimento de resistência aos esquemas de tratamento implementado, como acontecido na década passada nesta mesma área do estudo, na costa norte e na Amazônia peruana, onde devido aos altos níveis de resistência do $P$. falciparum (PF), tanto à cloroquina (CQ) como à sulfadoxina-pirimetamina (SP) na região amazônica, o MINSA substituiu seu esquema de tratamento de primeira linha para infecção por $P$. falciparum não complicada a sete dias de quinina mais tetraciclina.

$\mathrm{Na}$ Costa Norte esta foi trocado por SP. Porém estes dois esquemas fracassaram porque teriam muitas desvantagens: primeiro porque o tempo de sete dias era difícil de aplicar na selva e segundo porque leva à resistência quando se usa como monoterapia (NEYRA et al., 2003). 
Vale ressaltar que, nesta Sub-Região, o tratamento dos casos de malária por $P$. falciparum, também esteve baseado em SP, acompanhado com estudos de coorte com a finalidade de garantir a eficácia desses medicamentos, observando-se resistência em mais de $25 \%$ dos casos tratados, resultados considerado também como referência para assumir o tratamento com o esquema atual.

Atualmente, e desde de junho de 2003, no Peru, foi instaurado um novo esquema de tratamento supervisionado como opção de primeira linha para malária por $P$. falciparum não complicada para maiores de seis meses de idade, que consiste em uma combinação de mefloquina (MQ) mais artesunato (AS) na Selva e de SP mais AS na Costa Norte (MINSA, 2003), os quais devem ser administrados sob supervisão do programa. Este tratamento combinado tem como objetivo diminuir a probabilidade de selecionar parasitos resistentes, problema comum com medicamentos de tempo de vida média prolongado, como a sulfadoxinapirimetamina (SP) e a mefloquina (MQ) que são eliminadas lentamente pelo sangue (NOSTEN et al., 2000).

Esta opção de terapia combinada teve início como estudo prévio entre março e agosto do ano 2000, no Hospital de Apoio de Iquitos e no Centro de Saúde Moronacocha, utilizando MQ e MQ-AS, (MARQUINO et al., 2003), baseados nos resultados das observações na Tailândia, já que neste país a adição de AS a MQ para a terapia de infecções por $P$. falciparum foi associada à estabilização e redução da resistência a MQ, observada durante a monoterapia (WHITE, 1999;NOSTEN et al., 2000).

No caso das gestantes e os menores de seis meses de idade devem ser hospitalizados para receber o tratamento, sendo este supervisionado, com administração de quinina e clindamicina por sete dias. $\mathrm{O}$ tratamento para malária por $P$. vivax se mantém com a cloroquina e primaquina como esquema de primeira linha.

Os comentários feitos acima se justificam devido a que o Peru é o primeiro país na América a iniciar o uso destes esquemas (MAGILL et al. 1999). Isto o coloca em 
alerta para o risco de seleção de cepa resistente aos últimos esquemas, se não for implantado um sistema apropriado de vigilância do impacto.

Tabela 9. Casos de malária segundo colaterais registrados. 2000-2004. Sub-Região de Jaén. Cajamarca. Peru.

\begin{tabular}{|c|c|c|c|c|c|c|c|c|c|c|c|c|}
\hline \multirow[t]{3}{*}{ COLATERAIS } & \multicolumn{10}{|c|}{ AÑOS } & \multicolumn{2}{|c|}{ TOTAL } \\
\hline & \multicolumn{2}{|c|}{2000} & \multicolumn{2}{|l|}{2001} & \multicolumn{2}{|l|}{2002} & \multicolumn{2}{|l|}{2003} & \multicolumn{2}{|l|}{2004} & \multirow[b]{2}{*}{$\mathrm{N}^{\circ}$} & \multirow[b]{2}{*}{$\%$} \\
\hline & $\mathrm{n}^{\circ}$ & $\%$ & $\mathrm{~N}^{\circ}$ & $\%$ & $\mathrm{n}^{\circ}$ & $\%$ & $\mathrm{n}^{\circ}$ & $\%$ & $\mathrm{n}^{\circ}$ & $\%$ & & \\
\hline 0 & 67 & 16,7 & 92 & 22,9 & 22 & 5,5 & 137 & 34,1 & 84 & 20,9 & 402 & 32,6 \\
\hline $1-2$ & 4 & 2,3 & 8 & 4,6 & 15 & 8,7 & 73 & 42,4 & 74 & 43,0 & 172 & 13,9 \\
\hline $3-4$ & 7 & 2,2 & 9 & 2,9 & 27 & 8,6 & 123 & 39,3 & 147 & 47,0 & 313 & 25,3 \\
\hline $5-6$ & 4 & 1,8 & 7 & 3,2 & 31 & 13,8 & 82 & 36,6 & 100 & 44,6 & 224 & 18,2 \\
\hline $7 y+$ & 5 & 4,0 & 8 & 6,5 & 18 & 14,5 & 47 & 37,9 & 46 & 37,1 & 124 & 10,0 \\
\hline Total & 86 & 7,0 & 124 & 10,0 & 113 & 9,1 & 460 & 37,2 & 451 & 36,5 & 1235 & 100,0 \\
\hline
\end{tabular}

Fonte: Dados das Fichas de Controle da Assistência e Administração do Tratamento da Malária dos Serviços de Saúde. DISA-JAEN. Cajamarca. Peru. 2004

Os dados mostram que $32,6 \%$ da fichas revisadas não têm registro de familiares, em conseqüência não há registros de exames destes. De acordo com as normas, as pessoas que convivem com o caso confirmado de malária devem ter uma amostra de gota espessa, a fim de descartar a existência de outro caso de malária presente na família. Situação que se complica quando se trata de pacientes do sexo masculino, pois além de se recusarem a retornar para realizarem os seus controles, esses dificilmente aceitam levar a família para descartar possíveis novos casos de malária.

No trabalho de campo foi observado que é difícil para os casos de malária levarem seus familiares para que seja descartada a presença de outro caso da doença na família. Esta situação ficou evidente nas visitas domiciliares quando se constatou a existência de outros membros da família que não estavam consignados nas fichas de acompanhamento da malária. Se for considerada uma média de cinco pessoas por família, somente $40 \%$ teriam registrado o número real de familiares. 
Na prática ocorre que após o inicio do tratamento do primeiro caso, chega ao serviço de saúde o familiar deste em estado febril para ser atendido, confirmando-se como caso por meio do exame laboratorial.
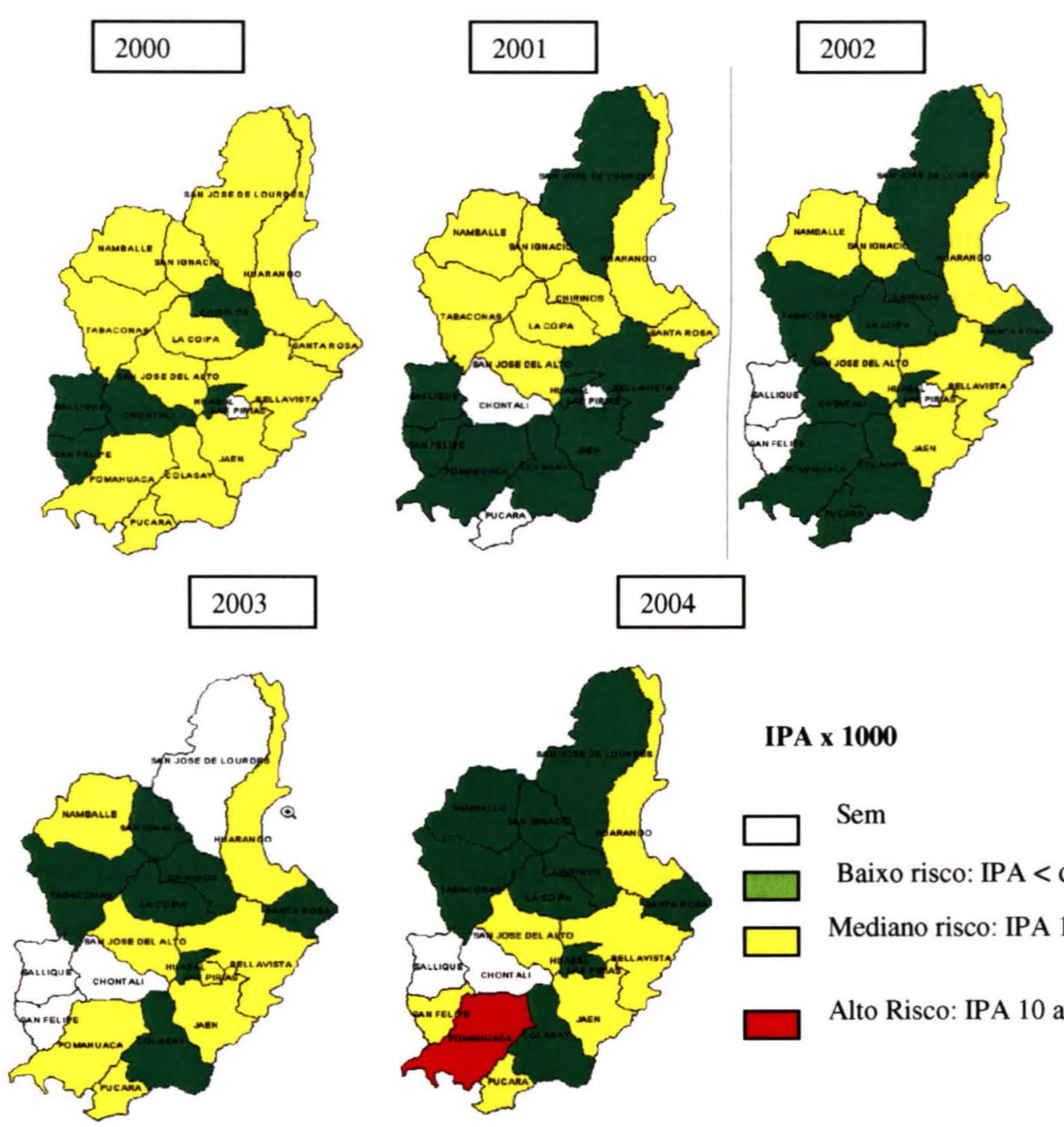

IPA x 1000

\section{Sem}

Baixo risco: IPA $<$ de 1

Mediano risco: IPA 1-9

Alto Risco: IPA 10 a más

Figura 9. Risco de malária, segundo IPA 2000 - 2004, Sub- Região de Jaén.

Cajamarca. Peru-

Fonte: Dados de registros de DISA-JAEN. Cajamarca. Peru. 2004

Em relação à qualificação de risco da malária nesta área, é utilizado o IPA que é equivalente ao número de casos confirmados por mil habitantes. Esse índice mede a intensidade da transmissão da doença que permite estratificar a zona segundo risco alto quando o IPA é de dez ou mais; risco médio de um a nove; risco baixo menor de um e sem risco igual a zero. 
Este indicador padronizado do enfoque de risco substituiu a concepção de erradicação (BARATA, 1998), pela redução significativa da incidência da malária, como conseqüência da campanha de controle de vetores com inseticidas baseados no uso de Dicloro-Difenil-Tricloroetano (DDT), nas décadas de 40 e 50 (ROBERTS, 1997). Considera-se que este indicador pode ser modificado pelo acesso aos serviços de diagnóstico e tratamento adequado (OPS, 2000b)

Os mapas mostram (figura 9) o comportamento da malária, calculado com base no (IPA) entre os anos 2000 e 2004, evidenciando-se que a dinâmica da intensidade de transmissão dessa doença é oscilante e que se mantêm em quase toda a área geográfica desta Sub-Região, com exceção dos distritos Las Pirias, Chontalí, San Felipe e Sallique, lugares que por dois ou três anos não registraram casos. No ano 2004, o distrito de Pomahuaca, consigna uma elevada incidência de malária por P. vivax, sendo considerado como zona de "alto risco".A análise global desta dinâmica indica que 50\% da Jurisdição se encontra como área de "baixo risco" para malaria.

O IPA tem como desvantagem o fato de expressar a situação global da malária em qualquer área geográfica. Por esta razão, o distrito de Jaén não aparece como zona de alarme ou de alto risco, afirmação sustentada nos últimos acontecimentos, onde foi observado um aumento de malária por P. falciparum em quase 7 vezes entre 2003 e 2004.

A tabela 10, mostra com detalhe o número de casos de malária entre 2000 e 2004. Destaca-se o comportamento da malária por $P$. falciparum, a mesma que vem aumentando proporcionalmente em relação à malária por $P$. vivax. Assim observa-se que nestes três últimos anos aumentou de $22,9 \%$ a $53,5 \%$ superando a magnitude registrada da malária por $P$. vivax. Essa tendência pode ser observada com mais objetividade na figura 11. No entanto, a incidência total de malária mostra um notório decréscimo como se aprecia no quadro geral da DISA-Jaén. 
Tabela 10.Casos de malária por $P$. falciparum e $P$. vivax. Sub-Região de Jaén. Cajamarca. Perú. 2000 - 2004

\begin{tabular}{|c|c|c|c|c|c|c|c|c|c|c|}
\hline \multirow{3}{*}{$\begin{array}{l}\text { Provincias / } \\
\text { distritos }\end{array}$} & \multicolumn{10}{|c|}{ ANOS } \\
\hline & \multicolumn{2}{|c|}{2000} & \multicolumn{2}{|c|}{2001} & \multicolumn{2}{|c|}{2002} & \multicolumn{2}{|c|}{2003} & \multicolumn{2}{|c|}{2004} \\
\hline & $\begin{array}{l}P . \\
\text { falciparum }\end{array}$ & P. vivax & $\begin{array}{l}P . \\
\text { falciparum }\end{array}$ & $P$ vivax & $\begin{array}{l}P . \\
\text { falciparum }\end{array}$ & P. vivax & $\begin{array}{l}P . \\
\text { falciparum }\end{array}$ & $\begin{array}{l}P \\
\text { vivax }\end{array}$ & $\begin{array}{l}P . \\
\text { falciparum }\end{array}$ & $\begin{array}{l}P . \\
\text { vivax } \\
\end{array}$ \\
\hline $\begin{array}{l}\text { PROVINCIA } \\
\text { JAEN }\end{array}$ & 132 & 183 & 31 & 126 & 89 & 103 & 210 & 334 & 292 & 180 \\
\hline JAEN & 81 & 62 & 13 & 29 & 72 & 28 & 40 & 315 & 250 & 15 \\
\hline BELLAVISTA & 22 & 12 & 6 & 9 & 14 & 12 & 13 & 16 & 40 & 7 \\
\hline CHONTALI & ---- & 7 & --- & --- & --- & 1 & --- & --- & ---- & $--\cdot-$ \\
\hline COLASAY & 2 & 16 & --- & 3 & --- & 2 & 4 & $-\cdots$ & --- & 2 \\
\hline HUABAL & --- & 2 & --- & 1 & ---- & 1 & 2 & 1 & ---- & 4 \\
\hline LAS PIRIAS & ---- & 0 & --- & ---- & ---- & $-\cdots$ & 8 & --- & -.-. & 1 \\
\hline POMAHUACA & 12 & 23 & --- & 3 & --- & 1 & 64 & 1 & & 109 \\
\hline PUCARA & 11 & 4 & --- & --- & 1 & --- & 50 & 1 & 1 & 23 \\
\hline SALLIQUE & -..-- & 4 & --- & 1 & --- & --- & --- & --- & & --- \\
\hline $\begin{array}{l}\text { SAN FELIPE } \\
\text { SAN JOSE DEL }\end{array}$ & 1 & 2 & --- & 3 & --- & --- & --- & --- & & 11 \\
\hline ALTO & 2 & 30 & 12 & 44 & 2 & 51 & 28 & ---- & 1 & 7 \\
\hline $\begin{array}{l}\text { SANTA ROSA } \\
\text { PROVINCIA } \\
\text { SAN }\end{array}$ & 1 & 21 & ---- & 33 & --- & 7 & 1 & ---- & & 1 \\
\hline IGNACIO & 9 & 581 & 25 & 326 & 6 & 217 & 73 & 6 & 4 & 77 \\
\hline SAN IGNACIO & 1 & 284 & 2 & 110 & --- & 46 & 25 & --- & & 21 \\
\hline CHIRINOS & 4 & 9 & 14 & 3 & 4 & 4 & 1 & 1 & 1 & 3 \\
\hline HUARANGO & 1 & 109 & 6 & 144 & 2 & 46 & 24 & 5 & 2 & 35 \\
\hline LA COIPA & 1 & 32 & 1 & 19 & --- & 3 & 2 & --- & 1 & 6 \\
\hline $\begin{array}{l}\text { NAMBALLE } \\
\text { SAN JOSE DE }\end{array}$ & --- & 80 & 1 & 21 & --- & 105 & 20 & --- & & 2 \\
\hline LOURDES & 1 & 29 & 1 & 14 & ---- & 6 & $-\cdots$ & $--\cdot$ & & 7 \\
\hline TABACONAS & 1 & 38 & --. & 15 & --.- & 7 & 1 & --.-- & & 3 \\
\hline TOTAL DISA & 141 & 764 & 56 & 452 & 95 & 320 & 283 & 340 & 296 & 257 \\
\hline
\end{tabular}

Fuente: Datos de Dirección de Epidemiología DISA. Jaén. Cajamarca. Perú

Considerando que a cidade de Jaén é o centro do movimento comercial desta sub-região, seria lógico deduzir que a dispersão da malária por $P$. falciparum se produz a través das pessoas que se deslocam em toda esta jurisdição. No entanto, como se observa no quadro, são pouquíssimos os casos de malária por $P$. vivax em Jaén, assim como são escassos os casos de malária por $P$. falciparum nos demais distritos que não o de Jaén.

A incidência total de malária na Sub-região de Jaén, não parece tão significativa, quando comparada com a totalidade de casos informados em outras zonas como a Região de Loreto que registra mais de $50 \%$ do total dos casos no país 
(QUIMPER, 1998). No entanto, o aumento progressivo na Sub-região de Jaén deve ser considerado, já que pode significar um risco maior.

Contrário ao sucedido com o problema da malária, o MINSA, no ano de 2005, se pronuncia em relação a esta alarmante re-emergência das metaxênicas “...o êxito na redução dos níveis de transmissão nas áreas mais afetadas, se deve a capacidade organizacional dos serviços e a articulação com o trabalho de colaboradores voluntários, o que permite controlar de maneira eficiente reservatórios humanos em tempo adequado". Apoio que na prática é de caráter virtual.

No entanto, é alegados que para reduzir o nível de transmissão e a morbidade causada pela malária, evitar e controlar epidemias no futuro é necessário contar com maior informação em relação ao hospedeiro, o vetor, a transmissão, a epidemiologia e as medidas de controle no país. Assim como ter pessoal de saúde treinado para implementação dessas medidas.

A Figura 10 mostra que o IPA por 1000 da província de Jaén em relação ao de San Ignacio se inverteu, evidenciando um aumento da incidência de malária nos últimos anos na primeira.

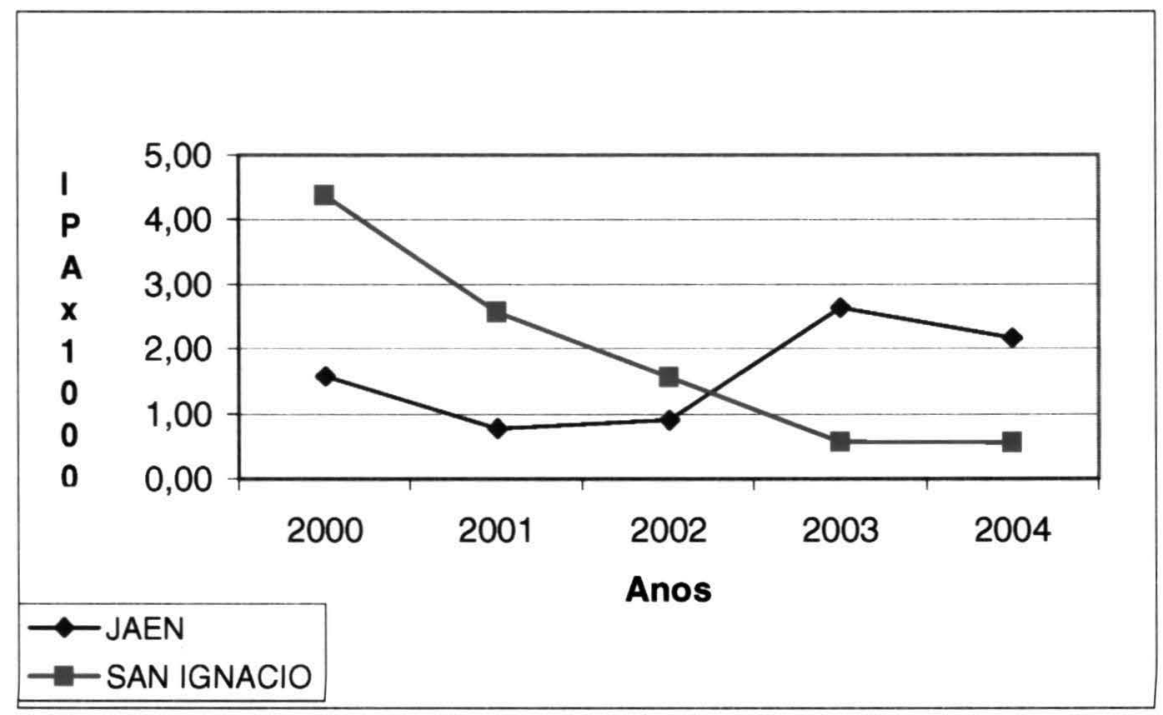

Figura 10.- IPA da malária. 2000-2004. Sub-Região de Jáen Cajamarca. Perú Fonte: Dados da Direção de Epidemiologia. Disa-Jaén. Cajamarca. Peru. 2004 
Esta tendência também se evidencia segundo espécie infectante, com uma sobreposição da malária por $P$. falciparum nestes três últimos anos. Ainda que esses valores sejam inferiores ao valor médio nacional, nota-se uma clara tendência ao aumento (figura 11). Até a última semana epidemiológica 20, do presente ano, foi registrado nesta Sub-Região, um total de 621 casos, dos quais $342(55,0 \%)$ são casos de malária por $P$. falciparum, sendo que a quase totalidade são casos autóctones da cidade de Jaén.

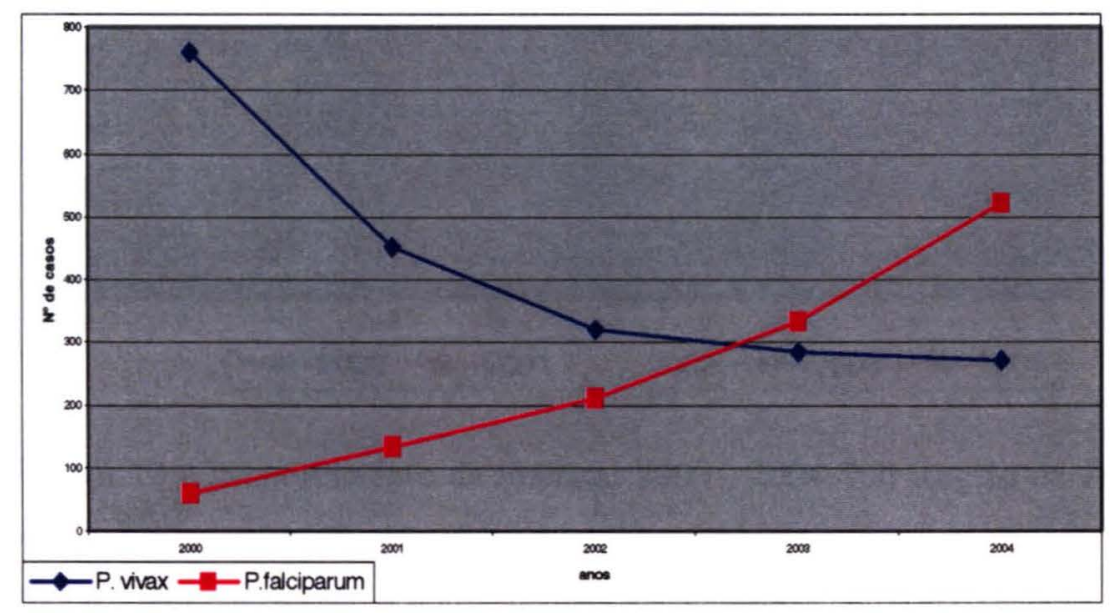

Figura 11. Casos de malaria P.vivax e P. falciparum, 2000 - 2004. Sub-Região de Jaén. Cajamarca. Peru .

Fonte: Dados da Direção de Epidemiología d Sub- Região de Jaén. Cajamarca. Peru

A tendência desta doença por ambas as espécies infectantes, pode ser observada de maneira mais detalhada na figura 12 nos cinco anos de estudo. É evidente que a incidência é maior no primeiro semestre destes últimos cinco anos, mostrando una queda no segundo semestre, época em que as chuvas também diminuem. O comportamento desta doença é ondulante, sendo que esta foi qualificada pelo Ministério da saúde como zona em alarme, juntamente com Cutervo (Região de Cajamarca) e a Região de San Martin, e particularmente a cidade de Jaén (MINSA, 2005).

Essas referências mostram uma vez mais que os serviços de saúde precisam avaliar suas estratégias implementadas. Observou-se ainda um sério problema na 
convocação da população para como agente chave no processo de prevenção e controle dos problemas de saúde, especialmente da malária.

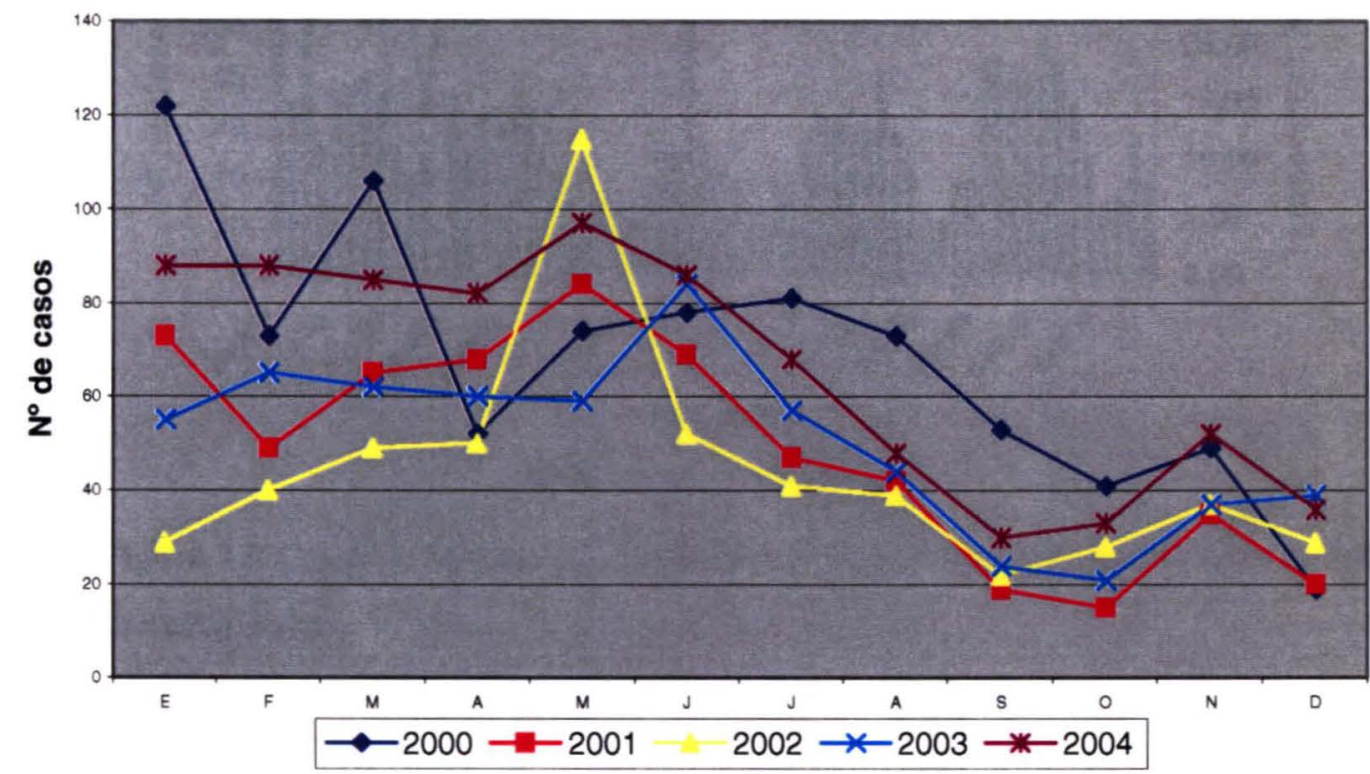

Figura 12 .Comportamento da malária. 2000 - 2004 Sub-Região de Jaén. Cajamarca. Perú

Fonte: Dados da Direção de Epidemiología d Sub- Região de Jaén. Cajamarca. Peru.

A seqüência histórica da malária nos cinco anos de estudo mostra com clareza a presença de picos nos meses de maio e junho entre 2000 e 2002, evidenciando-se uma freqüência constante entre março e setembro nos anos seguintes. Portanto, se pode afirmar que a malária neste lugar é hipoendêmica, instável e estacional. Resultados similares foram encontrados por CAMARGO et al. (1996) e GUTHMANN et al. (2002), em estudos realizados em Brasil (Candeias do Jamary) e na costa norte do Peru, onde encontraram que a malária é estacional com surtos na época seca (junho-agosto) e que os casos autóctones aumentam na época de estiagem. Fato que é mais bem explicitado com as informações climatológicas a seguir.

As condições climáticas como temperatura e precipitação pluviométrica considerados como fatores contribuintes no aumento da malária, variaram substancialmente, apresentando picos irregulares. Conforme os dados fornecidos pelo SENAMHI (Anexo 3 e 4). 


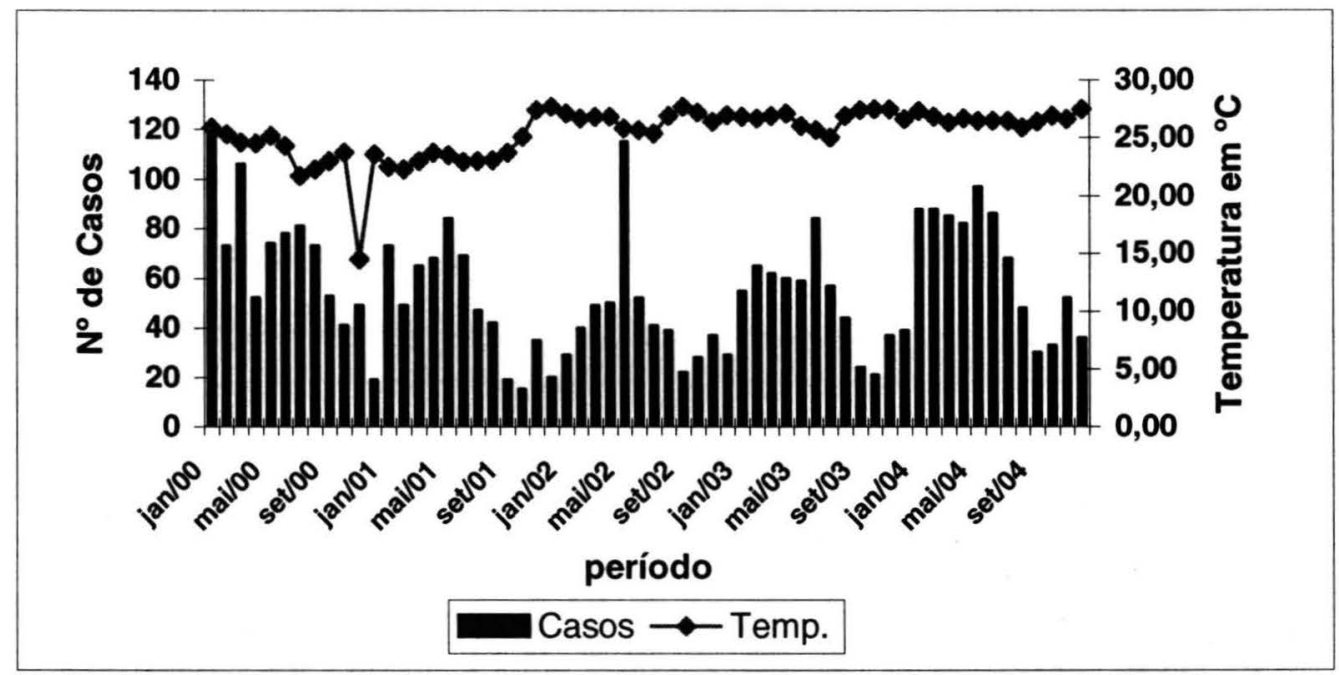

Figura 13. Casos de Malária e Temperatura Média. 2000-2004. Sub-Região de Jaén. Cajamarca. Peru

Fonte:dados da Oficina de Informação Agrária. Ministério da Agricultura, Sub-Região

Em relação os registros da temperatura e precipitação média mensal entre 2000 e 2005. Na figura 13, pode-se observar que as médias de temperatura nos últimos cinco anos não apresentaram variações muito acentuadas, tendo registrado médias que oscilam entre $23^{\circ} \mathrm{C}$ e $28^{\circ} \mathrm{C}$, com exceção do ano 2000 , onde as temperaturas desceram a limites muito baixos entre $9^{\circ} \mathrm{C}$ e $11^{\circ} \mathrm{C}$, nos meses de outubro a novembro. A análise das temperaturas em todos esses anos (anexo 3) mostram que a partir do ano 2002 , as temperaturas variaram entre $30^{\circ} \mathrm{C}$ como temperatura máxima e um pouco mais de $20^{\circ} \mathrm{C}$ como temperatura mínima. Esses níveis de temperaturas segundo (ARAMBURU (1999), são ideais para a reprodução dos vetores. De acordo com os dados existe associação significativa entre os casos e a temperatura $(\mathrm{p}=0.008)$.

Sobre as precipitações pluviométricas nesta zona e no mesmo período percebese que foram bastante irregulares (anexo 4). Nos meses considerados como de intensas chuvas, especialmente no mês de janeiro e nos últimos quatro anos diminuíram notoriamente a uma média de $27,5 \mathrm{~mm}^{3}$. Foram registradas precipitações muito baixas de $2,3 \mathrm{~mm}^{3}$ no mês de agosto de 2002 e muito altas para o lugar de até 
$152,8 \mathrm{~mm}^{3}$ no mês de março de 2005 . Não existe associação entre pluviometria e número de casos $(\mathrm{p}=0.253)$.

A figura 14 mostra o comportamento das precipitações pluviométricas em relação ao número de casos registrados entre Janeiro 2000 e dezembro 2004, observa-se o caráter oscilatório das chuvas neste período.

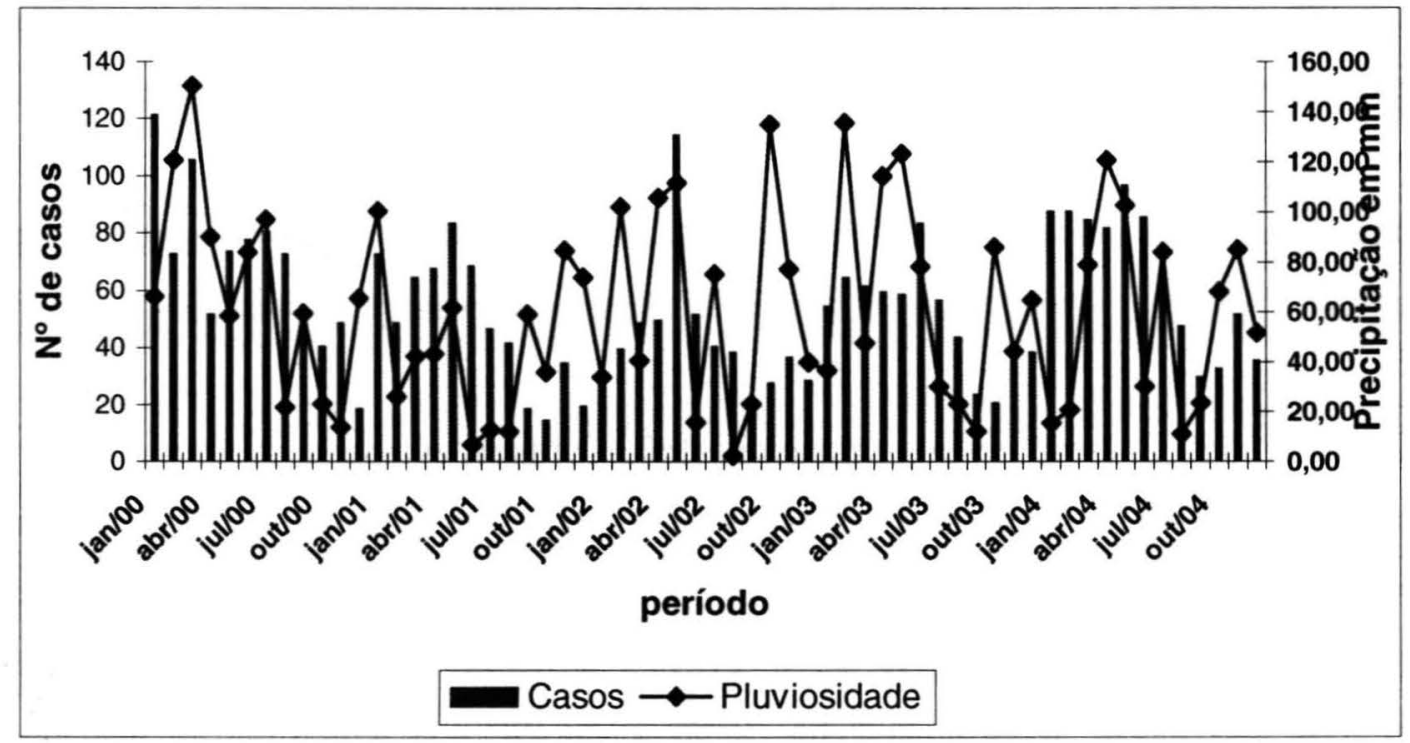

Figura 14. Casos de Malária e Pluviosidade. 2000- 2004. Sub-Região Jaèn. Cajamarca. Perú

Fonte:dados da Oficina de Informação Agrária. Ministério da Agricultura, Sub-Região Agrária de Jaén.

Outros estudos realizados por GUTHMANN et al., (2002) e GONZALES et al., (1997), na costa do Pacífico, na Colômbia, encontraram uma correlação negativa entre incidência de malária e precipitação pluviométrica. E, CAMARGO et al. (1994) em Urupa (Brasil) observou que entre 1992 e 1993, houve aumento de casos de malária com chuvas de baixa intensidade. Entretanto GIL (2003) afirma que a relação das precipitações pluviais com o aumento de casos de malária precisa em média de 30 dias, considerando que é o tempo mínimo necessário para concluir com as fases no processo de infecção do parasita da malária.

Contudo o aumento da densidade vetorial nem sempre significa que a efetividade destes seja elevada. Neste sentido, SMALL (2003), a partir de um estudo de 80 anos de malária na África, recomenda uma ampla análise da relação da malária 
e clima, incluindo outros fatores não climáticos, considerando os resultados de outros estudos, os quais revelam o aumento significativo da malária durante os meses secos (BARRERA et al., 1999; ROSENBERG et al.1990).

De outro lado os estudos epidemiológicos da malária mostraram que em áreas de intensa transmissão com elevadas taxas de incidência propiciam na população o desenvolvimento de níveis de resistência contra esta doença, possibilidades que diminuem em áreas hipoendémicas e com taxas de incidência pouco significativas (CELIS, et al., 2003: FELGER et al., 1999) Por tanto as características epidemiológicas da malária nesta zona não estariam facilitando o desenvolvimento de proteção imunitária para esta doença.

Porem, as inúmeras pesquisas feitas mostram que em áreas de baixa endemia encontram-se pacientes com leituras elevadas de gametócitos em gota espessa (BELIZARIO, 1997; GONZALES et al. 1997; GUTHMANN et al. 2002). Embora HOFFMAN (1986); Mc GREGOR, (1987); REY, (2002), indicam que imunidade protetora da malária é específica e gradual, precisando entre três a seis anos de exposição numa área de alta endemicidade, sendo que o grupo com maior chance é entre os cinco e nove anos de idade. Mas também esta imunidade pode ser precursora da doença sintomática e, por sua vez, ser reservatório de transmissão, re-introduzindo a doença para outras zonas (MARTENS \& HALL, 2000; NJAMA, 2004; CIIFEN, 2005)

É indiscutível que o conhecimento da dinâmica de transmissão do vetor é importante. Mas, não é o único aspecto que deve ser discutido. No enfoque bioecológico se enfatiza a interação entre parasitos, vetores e hospedeiros. Não obstante outros afirmam que a força de transmissão da infecção palúdica requer a interação de quatro fatores epidemiológicos: o hospedeiro humano, o parasito palúdico, o vetor Anopheles e os ambientes físicos, biológicos e socioeconômicos CELIS et al. (2003). Conforme discutido anteriormente, o risco de contrair a malária também está associado às características sociais, econômicas e ecológicas do local 
onde as pessoas residem, as que, em combinação, favorecem distintas intensidades de transmissão da doença.

Alem disso, esta problemática é entendida de maneira reduzida e às vezes errada pelos funcionários dos serviços de saúde. Assim uno deles manifestou que “ $A$ malária representa mais gasto para o Estado e descuido de outros programas" (Maria 'nome fictício'. Enfermeira da DISA-Jaén), a mesma considera que " $A$ promoção à saúde pode contribuir a reduzir os casos". Contudo, outros trabalhadores indicam que "Se quer fazer muito, mas faltam recursos humanos $e$ materiais. A idiossincrasia da população é outro problema muito difícil de lidar...”.

Enfim, a análise dos dados coletados das fichas de controle de Assistência e Administração de Tratamento, mostra que a endemia da malária, na Sub-Região de Jaén se da como um problema não considerado prioridade do lugar e não necessariamente porque a zona seja qualificada como pobre, mas porque existem aspectos de maior significância, que tem a ver com especificidades socioculturais e políticos de cada região. Neste sentido GALLUP \& SACHS (2000) afirmam que elevados níveis de malária em países pobres não são a principal consequiência da pobreza, mas pelas condições ecológicas que sustentam a maior eficiência dos vetores da malária e que em primeiro lugar determinam a distribuição e intensidade da doença.

Nota-se que se trata de uma afirmação feita a partir das análises de regressão realizadas com base em variáveis como pobreza, política econômica, localização geográfica e expectativa de vida. Sabe-se que os dados quantitativos muitas vezes não são suficientes para explicar situações relativas aos aspectos socioculturais que definitivamente podem sustentar os fatores de risco da malária. 


\section{2 Fatores de risco da malária por P.falciparum}

O estudo objetiva realizar uma abordagem não somente de caráter bioecológico, como também considera alguns aspectos políticos, culturais, socioeconômicos, psicológicos, ambientais e éticos como fatores de risco da malária em uma zona geográfica caracterizada por uma forte dinâmica econômica comercial, que deriva em um movimento migratório estável.

Neste sentido o enfoque de risco como metodologia pode ajudar a determinar alguns dos fatores com maior significância estatística (OPS, 1986), que estariam contribuindo no processo saúde-doença da malária, nos distritos de Jaén e Bellavista, tendo sido usada a regressão logística. Nesta pesquisa, de todas as variáveis analisadas 21 mostraram ter associação. Não obstante, quando se realizou a análise através da regressão, apenas 11 mantiveram o nível de significância (tabela 22). Em conseqüência, o número por si só não explica a complexidade do problema, sendo necessário fazer mais uma análise qualitativa a partir das observações realizadas na população desta zona.

Por tanto, os dados foram complementados com as testemunhas dos participantes dos grupos focais e as entrevistas dos trabalhadores de saúde e observações realizadas nos diferentes estabelecimentos do setor público e com a população em geral desta área geográfica, com a convicção de que assim se poderia ter uma idéia mais clara do problema da malária. Neste sentido GALLUP \& SACHS (2000), asseveram que "existe muita dificuldade para medir o impacto da malária, por sua amplitude e complexidade".

Esta proposta de análise está baseada nas afirmações de AYRES (1995), respeito do enfoque de risco, o qual diz que, "ainda tenha um sentido "analíticoadministrativo" não rompe com o caráter objetivista, que marca os saberes técnicocientíficos, já que trata aos constructos de maneira fragmentária”. 
As entrevistas realizadas nas unidades de estudo: controles e casos permitiram captar alguns dos efeitos qualitativos da malária para este último, assim como para a família destes e as formas como tentam neutralizá-los. Foram obtidos alguns dados relacionados com os custos econômicos e psicológicos percebidos pelos afetados por essa doença, sendo estes considerados impossíveis de serem quantificados com os métodos de medição convencionais.

Tabela 11. Casos e controles segundo características, ocupacional, educativa e de residência. Jaén. Cajamarca. Peru. 2004.

\begin{tabular}{lllll}
\hline \multicolumn{1}{c}{ Ocupação } & \multicolumn{3}{c}{ Casos } & \\
\cline { 2 - 5 } & $\mathbf{n .}^{\mathbf{0}}$ & $\mathbf{\%}$ & $\mathbf{n .}^{\mathbf{0}}$ & Controles \\
\hline Dona de casa & 29 & 32,2 & 70 & 38,9 \\
Estudante & 32 & 35,6 & 22 & 12,2 \\
Agricultor & 10 & 11,1 & 23 & 12,8 \\
Mão de obra qualificada & 8 & 8,9 & 18 & 10,0 \\
Comerciante & 4 & 4,4 & 12 & 6,7 \\
Empregado & 1 & 1,1 & 13 & 7,2 \\
Obreiro & 3 & 3,3 & 11 & 6,2 \\
Pessoal de serviço & 2 & 2,2 & 5 & 2,8 \\
Sem ocupação & 1 & 1,1 & 6 & 3,3 \\
\hline Total & $\mathbf{9 0}$ & $\mathbf{1 0 0 , 0}$ & $\mathbf{1 8 0}$ & $\mathbf{1 0 0 , 0}$ \\
\hline Grau de Instrução & \multicolumn{5}{c}{} \\
\hline Secundário & 36 & 40,0 & 72,0 & 40,0 \\
Fundamental & 39 & 43,3 & 69 & 38,3 \\
Superior & 9 & 10,0 & 24 & 13,3 \\
\hline Analfabeto & 6 & 6,7 & 15 & 8,3 \\
\hline Total & $\mathbf{9 0}$ & $\mathbf{1 0 0 , 0}$ & $\mathbf{1 8 0}$ & $\mathbf{1 0 0 , 0}$ \\
\hline Zona de Residência & \multicolumn{5}{c}{} \\
\hline Periurbana & $\mathbf{5 5}$ & 61,1 & 87 & 48,3 \\
\hline Urbano & 25 & 27,8 & 64 & 35,6 \\
\hline Rural & 10 & 11,1 & 29 & 16,1 \\
\hline Total & $\mathbf{9 0}$ & $\mathbf{1 0 0 , 0}$ & $\mathbf{1 8 0}$ & $\mathbf{1 0 0 , 0}$ \\
\hline Fon & & & & \\
\hline
\end{tabular}

Fonte: questionário utilizado para o estudo

A caracterização sócio-demográfica dos casos e dos controles do presente estudo permite fazer uma comparação de algumas especificidades de ambos os grupos pouco possíveis de serem modificadas, mas que poderiam estar atuando como fatores de risco para adquirir malária por P. falciparum.

Quanto à ocupação, 36,6\% dos casos são estudantes, entanto que 12,2\% dos controles têm esta condição, sendo que em média 35,5\% para ambos os grupos, indicaram ser donas de casa. Caso similar ocorre com as ocupações de agricultor (em 
média 12\%), e mão-de-obra qualificada, ainda que em proporções um pouco maiores para os controles. Outras ocupações menos freqüentes para ambos os grupos são as de comerciante, pessoal de serviço e obreiro. Não ouve associação significativa entre ocupação e risco em adquirir malária. A esse respeito, GUTHMAN et al (2001), estudando a costa peruana encontrou que a atividade de agricultor e o nível educativo em relação a malária, aparecem como fatores protetores contra esta doença, situação que poderia estar acontecendo nesta área geográfica onde se realizou esta pesquisa.

Em Jaén, como no resto do país, o problema do emprego é preocupante, mas não existe oficial dos níveis de desemprego nesta área, por tanto se adota como referência os dados em nível nacional. Assim, segundo INEI (2003), o desemprego da população do PEA jovem entre os 14 e 24 anos no Peru é de 14,6\% e na Serra, para esse mesmo grupo, é de $10,1 \%$. Na realidade, esses dados não refletem a grave situação de desemprego no país, onde o que predomina é o trabalho informal.

Para enfrentar esse grave problema, a população do Peru apela a múltiplas estratégias de sobrevivência, sendo uma delas a criação de microempresas de mobilidade pública como o moto-táxis, tendo-se convertido em uma fonte de renda grande no país. No caso de Jaén, este é o único meio utilizado como transporte público urbano. Segundo alguns habitantes da zona existem aproximadamente 3.000 unidades na cidade de Jaén e Bellavista ${ }^{7}$. Observa-se que algumas famílias que possuem essas unidades móveis constituem a única fonte de renda, sendo pilotada por todos os homens jovens da família, combinando estudos com trabalho.

Existem outras atividades ocupacionais eventuais, tal como indicado no quadro anterior, como os bóias-frias nas plantações de arroz, café ou cacau que são os principais produtos agrícolas da região, ou seja, trata-se de trabalhos temporários de acordo com o movimento econômico do lugar. Assim vemos que quando se fala de mão de obra qualificada se refere a trabalho como técnico em refrigeração, motorista, soldador, artesão, padeiro, técnico em computação, técnico eletrônico, construtor civil, modista, maquinista, garçom e outras atividades de comércio como

\footnotetext{
${ }^{7}$ Goicochea Bernal Armando, periodista e ex-presidente da Câmara de Comercio de Jaén..
} 
camelôs, concentrando suas atividades durante os dias de mercado, no final da semana.

As ocupações são diferenciadas entre homens e mulheres, tal como diarista para estas últimas e motorista, lavrador ou construtor civil na condição de obreiro para os homens. Poucos são os que exercem trabalhos relacionados com o nível educativo.

A ocupação de agricultor ou de operário na construção de estradas é reconhecida pela população como um fator de risco para adquirir doenças infecciosas, como a malária, no entanto eles indicam que "não há outra opção e pela necessidade de ter que trabalhar". Ainda que para eles "o mosquito da lavoura não é tão bravo quanto o que tem lá em casa" (expressão de um entrevistado de 52 anos).

Em relação com o grau de instrução, os níveis educativos alcançados por os grupos de estudo são baixos. Assim, em média $40 \%$ declaram ter estudos secundários e outros $40 \%$ estudo primário. Apenas $12 \%$ de ambos os grupos indicaram ter estudos superiores. Em relação à proporção de analfabetos, tanto os casos assim como os controles $(6,7$ e $8,3 \%$ respectivamente) apresentam una condição similar às médias nacionais que é de 9,2\% (INEI, 2003).

Esta condição de educação se converte em uma desvantagem no mercado de trabalho, dada as poucas oportunidades que vão ter para desenvolver-se como cidadão. Em conseqüência a oportunidade de ter uma expectativa de vida longa e saudável, um maior conhecimento e acesso a bens materiais e serviços para alcançar um nível decente de vida, fica de lado, aumentando a possibilidade de passar a ser parte dos grupos excluídos social e economicamente, sem liberdade política, econômica e social, assim como também sem oportunidade para uma vida criativa e produtiva, tendo o respeito dos outros e de si mesmo e exercer plena cidadania, características próprias de um modelo econômico discriminante, como do Peru.

Por tanto o nível educativo que tem dos grupos em estudo permite deduzir que nesta zona tem analfabetos absolutos (aqueles que não tem nenhum ano de 
escolaridade) e analfabetos funcionais (SOUZA, 1999), já que se trata de pessoas com educação de má qualidade (situação que predomina em nosso meio) e que não permite empreender atividades em que a alfabetização é necessária para a atuação eficaz e funcional ao serviço de seu próprio desenvolvimento e ou da comunidade.

Quando se fala de pobreza de rendas e pobreza de capacidades é muito importante considerar, por exemplo, que, deve-se melhorar a educação básica e assistência sanitária, que não somente vem a melhorar a qualidade de vida de maneira direta, mas também a capacidade da pessoa para ter uma renda e livrar-se da pobreza (SEN, 1998).

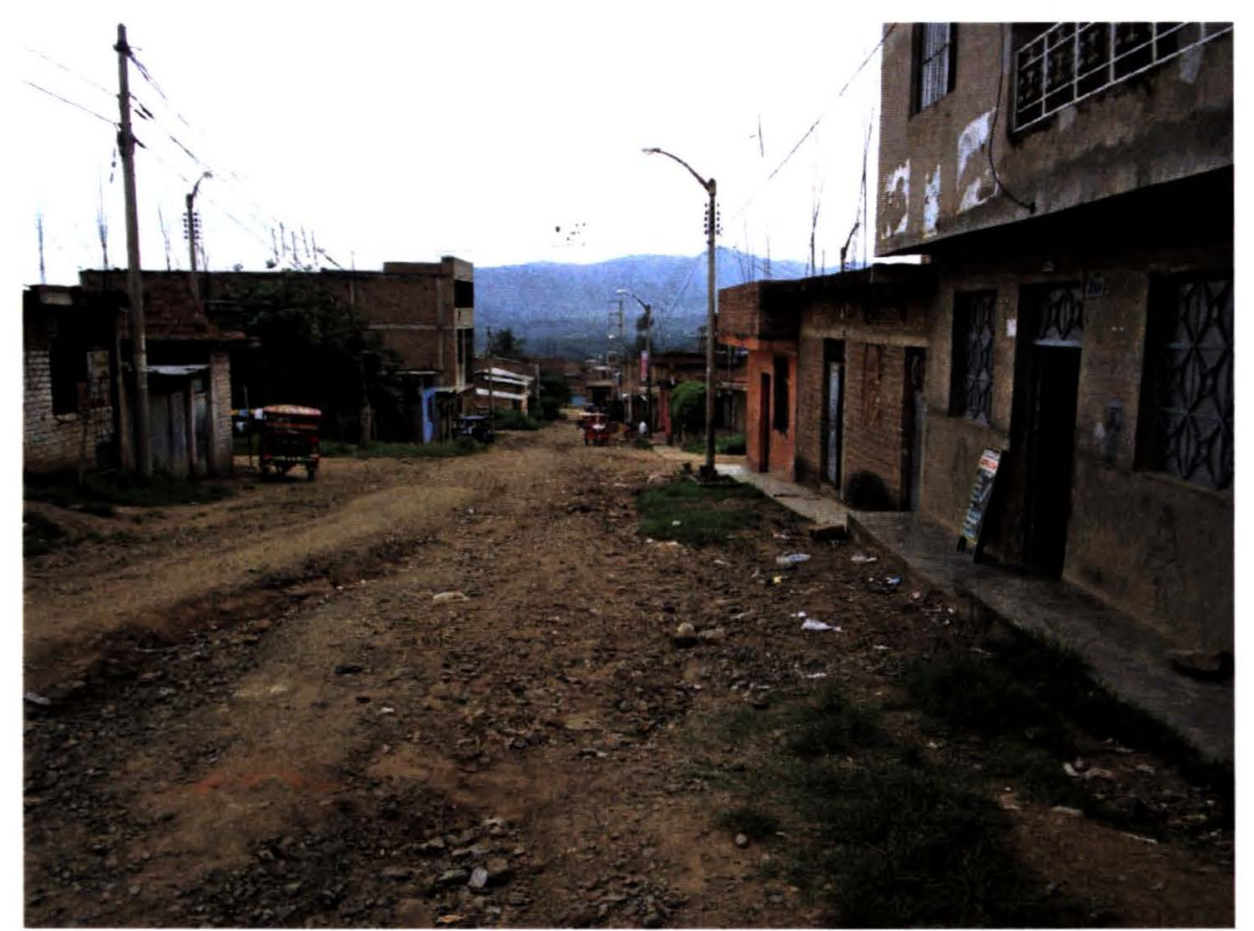

Figura 15.Rua na zona periurbana da cidade de Jaén. Cajamarca, Peru. 2005

Fonte: própria autora

A residência dos casos e dos controles no presente estudo se constitui em um elemento de muita importância, já que teoricamente quem vive em melhores condições seriam os que residem em zona urbana. Neste caso, os que vivem em zona periurbana correspondem à populações imigrantes de outras zonas e da zona rural. Assim vemos que $27,8 \%$ dos casos e $35,6 \%$ dos controles residem na zona urbana. Contudo uma proporção muito significativa de $61,1 \%$ de casos e $48,3 \%$ dos controles 
residem em zona denominada periurbana que em Jaén é claramente diferenciada, já que constitui uma zona de expansão urbana com áreas de muita vegetação e ruas não asfaltadas (figura 15)

Os efeitos do processo de urbanização como fenômeno dos últimos séculos deixaram marcas na história social, política e cultural de todas as populações do mundo, principalmente os relacionados com a formação dos sindicados cinturões de pobreza. Como já referido; esses são constituídos, maiormente por grupos que migram para as grandes cidades, estabelecendo-se nas periferias, gerando graves problemas sociais, como a falta de emprego, de serviços básicos, educativos, de saúde, entre outros. Nas visitas domiciliares nesta zona constatou-se que se trata de moradias ao redor das quais tem vegetação ou pelo menos tem uma horta.

Neste sentido, FILHO (1999) afirma que lugares densamente povoados prestam condições menos favoráveis para a reprodução de mosquitos, situação que se dá como conseqüência da limitação do número de criadouros provocada pelo aumento dos níveis de poluição das coleções de água e dos níveis de alteração antrópico do ambiente natural que dificultam a sobrevivência dos vetores. No entanto, outros investigadores como FORATTINI (2002) afirma que não é tão certo que a urbanização reduz o processo de transmissão da malária e que facilite o controle, uma vez que a expansão periférica se faz de forma precária dos serviços de saúde e preservação do solo, portanto, contribui para a permanência da doença entre os moradores. Além disso, parece ser que a variabilidade genética inerente a cada espécie vai condicionar a adaptabilidade às novas condições do meio (FORATTINI, 1998). 


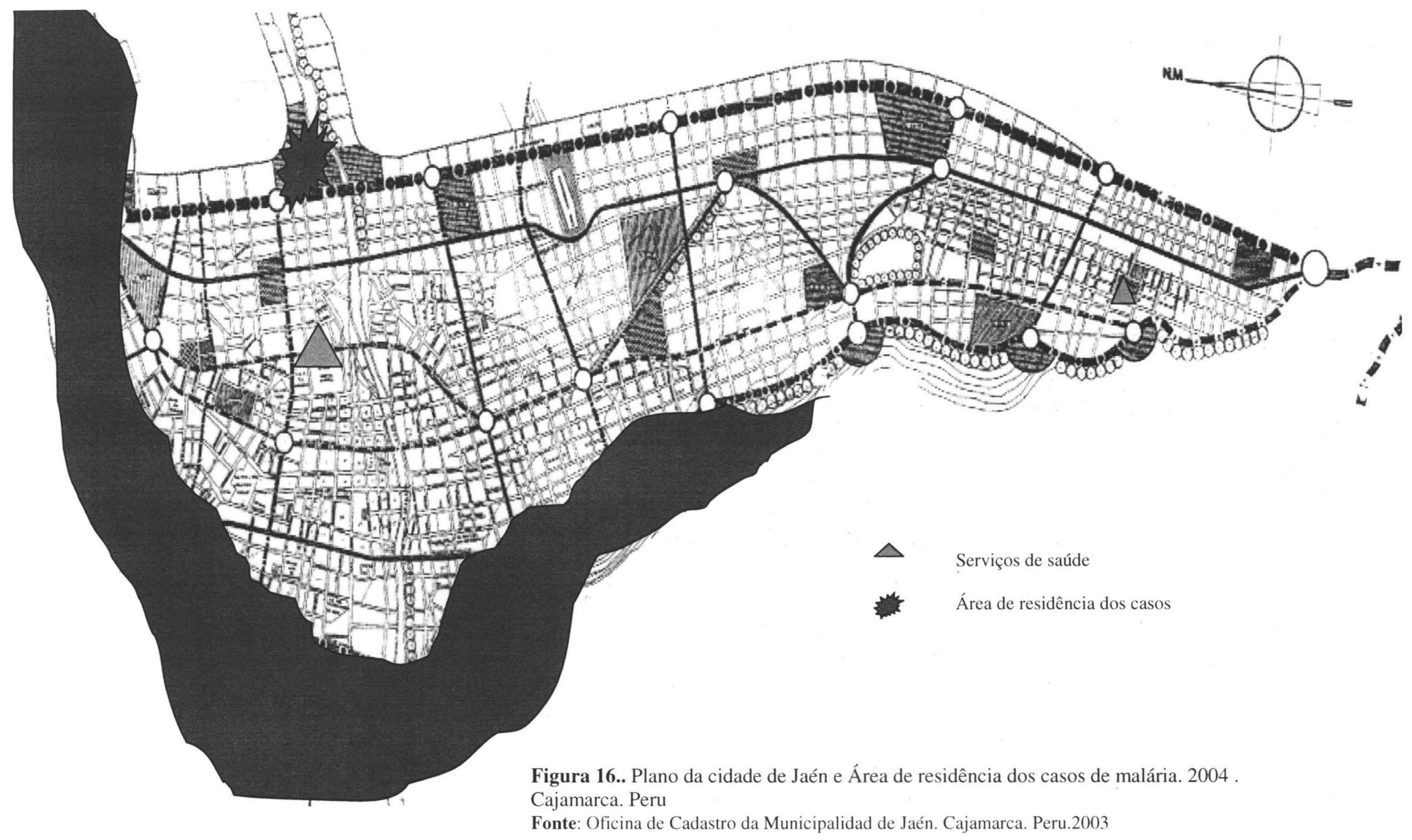


Tabela 12. Casos e controles segundo condição da moradia. Jaén. Cajamarca. Peru. 2004

\begin{tabular}{lllll}
\hline \hline \multirow{2}{*}{ Condição de moradia } & \multicolumn{3}{l}{ Casos } & \multicolumn{3}{c}{ Controles } \\
\cline { 2 - 6 } & $\mathbf{n} .^{\mathbf{0}}$ & $\mathbf{\%}$ & n. $^{\mathbf{0}}$ & $\mathbf{\%}$ \\
\hline \hline Própria & 77 & 85,6 & 117 & 65,0 \\
Alugada & 7 & 7,8 & 49 & 27,3 \\
Emprestada, encarregada ou cuida. & 6 & 6,7 & 14 & 7,8 \\
\hline \hline Total & $\mathbf{9 0}$ & $\mathbf{1 0 0 , 0}$ & $\mathbf{1 8 0}$ & $\mathbf{1 0 0 , 0}$ \\
\hline \hline \multicolumn{1}{c}{ Fonte: questionário utilizado para o estudo: } & \multicolumn{3}{c}{ p-Value $=\mathbf{0 , 0 0 1}$}
\end{tabular}

A moradia como necessidade básica deve ser satisfeita, porém esta deve ter condições apropriadas que permitam viver com dignidade. No presente estudo, se pode observar que $85,6 \%$ dos casos e $65 \%$ dos controles dizem ter casa própria. Contudo, muitas delas têm apenas uma habitação como se verá mais adiante, sendo que estas estão divididas em dois ou três ambientes, isso incide nas moradias localizadas na zona periurbana, que como indicada $43,8 \%$ dos entrevistados residem neste lugar.

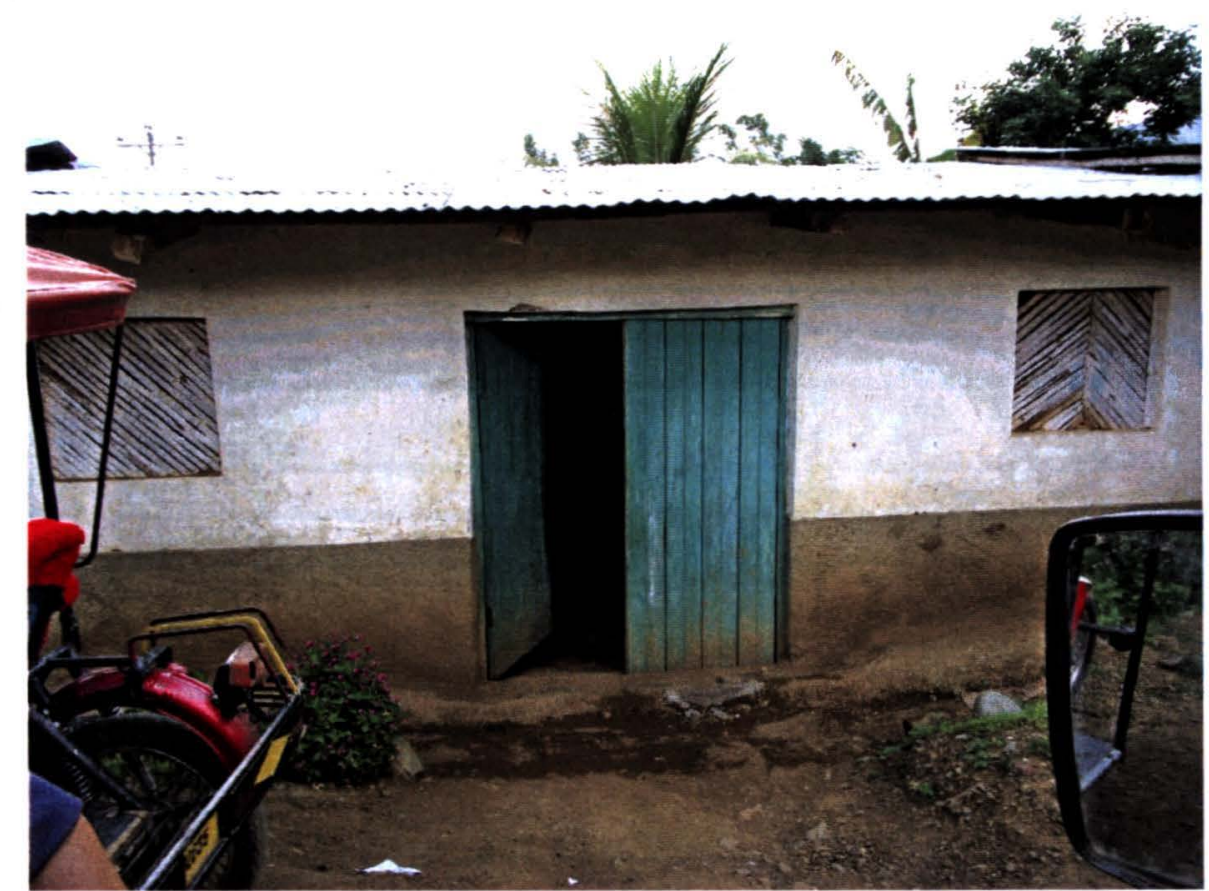

Figura 17. Moradia na zona periférica da cidade de Jaén. Cajamarca. Peru.2005. Fonte: a própria autora 
$\mathrm{O}$ conceito de migração se associa às cidades Latino-americanas, onde o rápido processo de urbanização faz com que os grupos mais desfavorecidos economicamente, minorias étnicas ou imigrantes, abandonem o campo e se estabeleçam na periferia da cidade. Assim como no caso dos entrevistados, que migram até a cidade de Jaén e vão se instalar na periferia desta ou agregam-se a outras famílias, já estabelecidas, alguns deles passam a formar parte de grupos de excluídos sociais morando em condições de vida precárias, expondo-se aos perigos existentes neste lugar, que já foram mencionadas anteriormente.

Tabela 13. Casos e controles segundo material e condições da moradia. Jaén. Cajamarca. Peru. 2004.

\begin{tabular}{|c|c|c|c|c|c|}
\hline $\begin{array}{l}\text { Material e condições de construção } \\
\text { de moradia }\end{array}$ & & asos & & troles & p-value \\
\hline Material da moradia & $\mathrm{n.}^{0}$ & $\%$ & n. ${ }^{\circ}$ & $\%$ & $=0,04$ \\
\hline Adobe & 58 & 64,4 & 103 & 57,2 & \\
\hline Tijolo não concluído & 15 & 16,7 & 45 & 25,1 & \\
\hline Tijolo concluído & 17 & 18,9 & 22 & 12,2 & \\
\hline Taipa & --.-- & $-\cdots$ & 10 & 5,5 & \\
\hline Total & 90 & 100,0 & 180 & 100,0 & \\
\hline Condições das Janelas & & & & & 0,000 \\
\hline Com vidros & 48 & 53,3 & 62 & 34,4 & \\
\hline Com rede ou tela & 13 & 14,4 & 46 & 25,6 & \\
\hline Sem janela & 12 & 13,3 & 23 & 12,8 & \\
\hline Sem proteção & 17 & 18,9 & 49 & 27,2 & \\
\hline Total & 90 & 100,0 & 180 & 100,0 & \\
\hline Condições das paredes & & & & & 0,077 \\
\hline Revestidas & 60 & 66,7 & 135 & 75,0 & \\
\hline Não revestidas & 30 & 33,3 & 45 & 25,0 & \\
\hline Total & 90 & 100,0 & 180 & 100,0 & \\
\hline Material teto & & & & & 0,278 \\
\hline Lata & 61 & 67,8 & 136 & 75,6 & \\
\hline Concreto & 29 & 32,2 & 44 & 24,5 & \\
\hline Total & 90 & 100,0 & 180 & 100,0 & \\
\hline Portas da moradia & & & & & 0,001 \\
\hline Com portas & 79 & 87,8 & 174 & 96,7 & \\
\hline Com portas deterioradas & 9 & 10,0 & 1 & 0,6 & \\
\hline Sem portas & 2 & 2,2 & 5 & 2,8 & \\
\hline Total & 90 & 100,0 & 180 & 100,0 & \\
\hline
\end{tabular}

Fonte: questionário utilizado para o estudo 
Em relação ao material da moradia, tanto os casos quanto os controles $(64,4 \%$ e $5,2 \%$ ) vivem em casa feita com adobe (figura 17); $35,6 \%$ dos casos e $37,3 \%$ dos controles têm casa de tijolo que não foi concluída. As características das moradias condizem com as condições sanitárias das mesmas, já que esse podem favorecer a invasão ou reprodução de vetores, insetos ou roedores dentro da casa.

. Observou-se que 53,3\% dos casos e $34,4 \%$ dos controles têm janelas com vidros. As casas de 13,3\% dos casos e 12,8\% dos controles não têm janelas (figura 17). Esta omissão é substituída por um espaço livre feito de propósito baixo do teto, que vai fazer as vezes de janela, permitindo a circulação do ar. As casas que têm essas características, maiormente são de adobe. Apenas $14,4 \%$ dos casos e $25,6 \%$ dos controles têm janelas protegidas com redes ou com telas. Assim mesmo se observa que 18,9\% dos casos e $27,2 \%$ dos controles não protegem as suas janelas.

A tabela 13 mostra que em média $70 \%$ das habitações dos casos e controles tem revestimento, porém quase a totalidade daquelas que estão pintadas, apresentam estado de conservação deficiente, condição que favorece a camuflagem dos vetores, existentes na casa. Além disso, o piso em quase todas as casas que são de adobe, é de terra e outros têm os chamados "falso piso".

Outra característica das moradias feitas adobe é terem o teto de calamina (figura 17) tanto das casas da zona urbana quanto da zona rural. Neste caso, $67,8 \%$ dos casos e $75,6 \%$ dos controles têm estas características, principalmente porque se trata de materiais mais acessíveis a economia da população de escassos recursos. Igualmente as habitações de $12,2 \%$ dos casos e 3,4\% dos controles têm portas em péssimo estado de conservação ou não têm portas, em especial aquele utilizado como dormitórios.

As condições das moradias em relação à incidência da malária, também tem sido motivo de múltiplos estudos e discussões. Assim vemos que GUNAGUARDENA et al. (1998), estudando uma área endêmica ao sul de Sri Lanka, encontraram que o risco de 
ter malária foi 2,5 vezes maior naqueles que viviam em casas de construção pobre do que os que viviam em casas de boa construção, aumentando este risco quando a moradia estava próxima a fonte de água.

Para tanto, consideram que o simples fato de melhorar a construção das casas e localizá-las em lugares com potencial menor de ter criadouros de mosquitos, se alcançaria uma redução entre 25 a $36 \%$ a incidência da malária, demonstrando que o tipo de construção da casa por si só constitui fator de risco para malária e não tem a ver com fatores ambientais, ainda que consideram que as condutas de seus habitantes são fundamentais. No presente estudo o material da moradia, as condições da janela e as condições das paredes, tem associação significativa com a malária, mas não representam fator de risco.

Segundo GUTHMANN et al. (2001), na costa peruana, habitar uma casa com mais de quatro anos de ter sido construída e habitada, com presença de frestas nas paredes dos dormitórios, permitiria a entrada de mosquitos dentro de esta e permaneceram ali escondidos, para entrar em atividade durante a noite. KORAM (1995) também encontrou associação entre malária e o tipo de construção pobre da casa (paredes revestidas com barro sem pintado), má higiene da moradia e status socioeconômico baixo, especialmente nas crianças de Gambia.

Quanto ao abastecimento de água $77,8 \%$ dos casos e $81,1 \%$ dos controles têm água da rede pública. Aparentemente esta população estaria em vantagem porque segundo o INEI (2003), a média nacional que tem este serviço é de 73,7\%. Quanto os outros entrevistados de ambos os grupos se abastecem de água de poço, córrego ou rio, especialmente aqueles que vivem na zona rural.

O problema mais grave é a eliminação de excretas. Como observado $60 \%$ dos casos e 48,9\% dos controles possuem serviço de deságüe com arraste hidráulico, e $35 \%$ dos casos e $48,9 \%$ dos controles têm fossa negra ou poço cego ou latrina. 
Tabela 14. Casos e controles segundo serviços de saneamento básico. Jaén. Cajamarca. Peru. 2004.

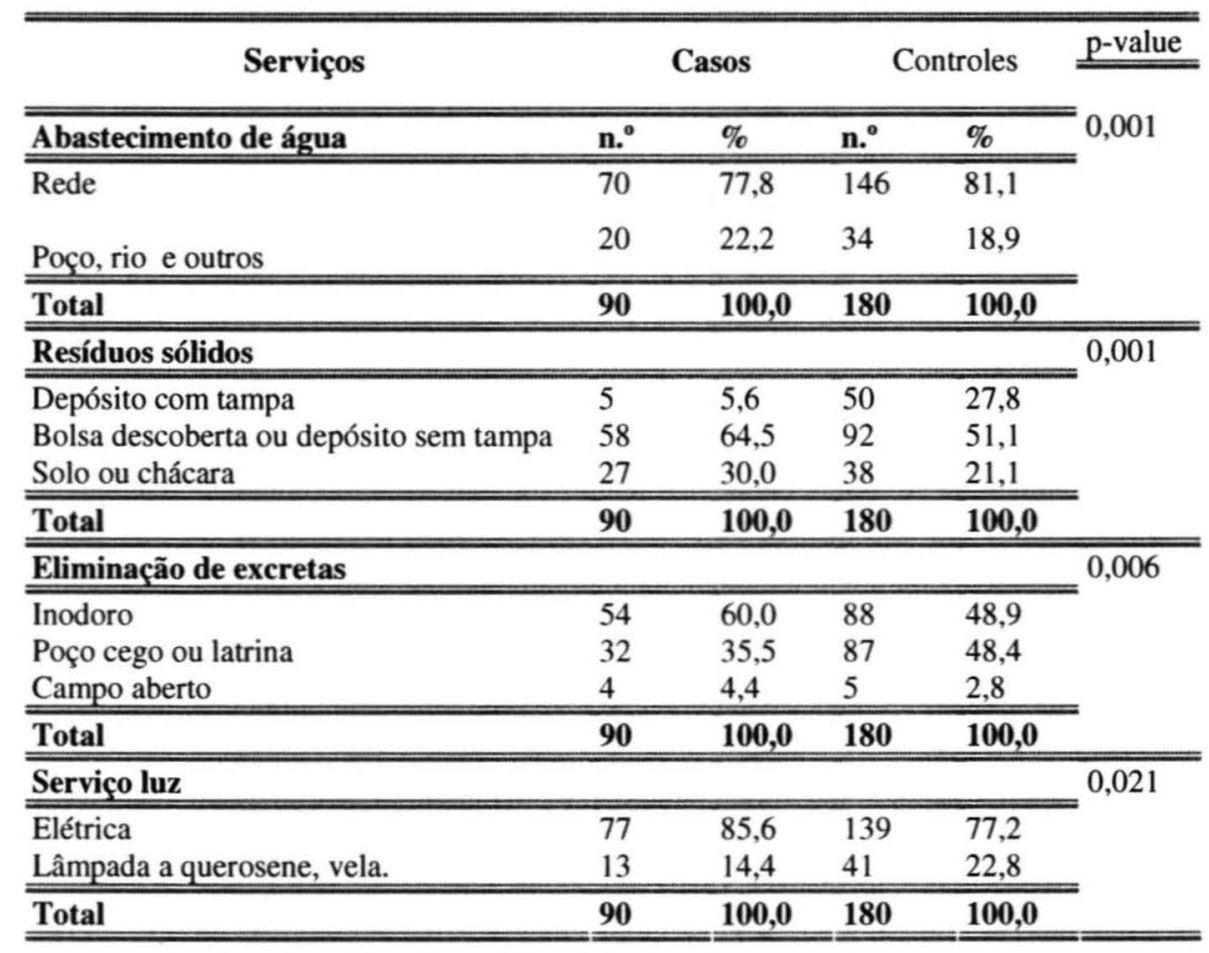

Fonte: questionário utilizado para o estudo

Segundo o INEI (2003), a carência do serviço de deságüe no Peru, é a necessidade que afeta em maior proporção, os distintos estratos de pobreza, maiormente por efeito da urbanização, da industrialização e outros. Essa insalubridade reflete indiretamente as estatísticas fornecidas pela Oficina de Epidemiologia da Sub-Região de Jaén. Esta indica que a primeira causa de morbidade atendida nos serviços de saúde é a parasitose intestinal (Tabela 1).

Em relação aos resíduos sólidos, esses são coletados em bolsas descobertas, chamados de "sacola de plástico", isso acontece mais com os casos $(55,6 \%)$ do que com os controles $(41,7 \%)$. Apenas alguns deles guardam os resíduos em depósitos de plástico. Observou-se que uma importante porcentagem tanto nos casos quanto nos controles (30\% e $21,1 \%$ respectivamente) elimina o lixo em chácaras ou no campo aberto. Assinala-se a presença de muitas casas com acúmulo de lixo, representando um foco de atração para insetos e roedores. Em quanto ao serviço de luz elétrica, 85,6\% dos 
casos e $77,2 \%$ dos controles, têm esse serviço, sendo que $14,4 \%$ dos casos e $22,8 \%$ dos controles utilizam lâmpada com querosene (lampião) ou vela.

A análise de regressão revela que a carência de serviços básicos, especialmente a de água, a disposição de resíduos sólidos e o serviço de luz elétrica, seriam fatores de risco para adquirir malária. Assim se observa que quem não tem água potável, teria quatro vezes mais possibilidades $(\mathrm{OR}=4,16 \mathrm{p}=0,02)$ de se infectar com o agente da malária que os que têm esses serviços. Contudo, neste lugar a qualidade da água para abastecimento público, na maioria dos casos, não têm a garantia o consumo humano, na cidade de Jaén e Bellavista (anexo 6), sendo que apenas as casas que estão no centro da mesma, consumem água potável.

Em conseqüência, ter água de rede não é garantia de consumir água de qualidade. Este fato é referido nos informes da Direção Geral de Saneamento Ambiental (DIGESA) do Ministério da Saúde e Água de Consumo Humano de Jaén, indiciando que este elemento, tem uma carga bacteriana acima dos níveis permissíveis, assim como $\mathrm{pH}$ em geral muito alcalino (anexo 6). Este problema tem a ver com a resistência da população para aceitar a instalação à planta principal de tratamento, já que o preço do serviço aumentaria em 15 vezes o pagamento mensal. A qualidade de este líquido elemento explicaria em parte a elevada incidência de febre tifóide já referida antes.

Além disso, quem tem uma disposição inadequada dos resíduos sólidos teria duas vezes mais possibilidades de se infetar com malária $(\mathrm{OR}=2,12 \mathrm{p}=0,01)$ do que aqueles que tem uma adequada disposição. E quem não conta com o serviço de luz elétrica teria três vezes mais chance $(\mathrm{OR}=3,13 \mathrm{p}=0,03)$ em adquirir malária que os que têm este benefício. Aspectos que já foram discutidos em parágrafos anteriores.

A ausência desses serviços considerados fatores de risco constituem uma manifestação insatisfação das necessidades básicas dos moradores nesta Sub-Região, especialmente os aqueles da zona periurbana e da rural, carência que por sua vez podem 
originar alguns problemas sanitários, constituindo apenas uma parte da problemática, já que se o morador tem praticas promotoras aceitáveis, bem pode tornar-se agente da promoção em saúde da própria família e estabelecer estratégias para superar as limitações como por exemplo o tratamento caseiro da água.

As condições ambientais ao redor das vivendas têm muita importância como fatores que podem favorecer a circulação e reprodução dos mosquitos. Neste caso, se refere à existência de riscos ambientais arredor de 50 metros de distância da casa. Assim vemos que $10 \%$ das vivendas dos casos e $23,9 \%$ dos controles continham depósitos com água parada, o que condiciona a presença de criadouros de mosquitos. Tendo sido constatado a existência de depósitos que abrigavam larvas de mosquitos em algumas das casas visitadas. E ainda, em 38,9\% das moradias dos casos e 33,9\% dos controles têm córregos de água contaminada que passam perto.

Tabela 15. Casos e controles segundo cercania de potenciais fontes de reprodução dos vetores no peridomicilio. Jaén. Cajamarca. Peru. 2004

\begin{tabular}{|c|c|c|c|c|c|}
\hline \multirow{2}{*}{$\begin{array}{l}\begin{array}{l}\text { Características } \\
\text { peridomiciliares }\end{array} \\
\begin{array}{l}\text { Lugares com água } \\
\text { parada }\end{array}\end{array}$} & \multicolumn{2}{|c|}{ Casos } & \multicolumn{2}{|c|}{ Controles } & \multirow{2}{*}{$\begin{array}{l}\text { p- valor } \\
=0,006\end{array}$} \\
\hline & n. ${ }^{0}$ & $\%$ & $\mathbf{n .}^{0}$ & $\%$ & \\
\hline$\overline{\text { Sim }}$ & 9 & 10,0 & 43 & 23,9 & \\
\hline Não & 81 & 90,0 & 137 & 76,1 & \\
\hline Total & 90 & 100,0 & 180 & 100,0 & \\
\hline \multicolumn{6}{|l|}{ Córregos } \\
\hline$\overline{\mathrm{Sim}}$ & 35 & 38,9 & 61 & 33,9 & \\
\hline Não & 55 & 61,1 & 119 & 66,1 & \\
\hline Total & 90 & 100,0 & 180 & 100,0 & \\
\hline Rio & & & & & 0,034 \\
\hline$\overline{\text { Sim }}$ & 10 & 11,1 & 39 & 21,7 & \\
\hline Não & 80 & 88,9 & 141 & 78,3 & \\
\hline Total & 90 & 100,0 & 180 & 100,0 & \\
\hline Vegetação & & & & & $=0,000$ \\
\hline Sim & 81 & 90,0 & 118 & 65,6 & \\
\hline Não & 9 & 10,0 & 62 & 34,4 & \\
\hline Total & 90 & 100,0 & 180 & 100,0 & \\
\hline
\end{tabular}


Em relação à presença de potenciais fontes de reprodução de vetores, 11,1 dos casos e $21,7 \%$ dos controles moram em casas localizadas próximo do rio. Dentre todas essas exposições a proximidade da vegetação é a mais freqüente, em $90 \%$ dos casos e $65,6 \%$ dos controles.

Quase $3 / 4$ das vivendas dos casos possuem curral, com a presença de animais domésticos, aves, gado, suínos e outros e tipos de animais que constituem fonte de renda para a família, sendo que $40 \%$ destes currais, especialmente nas moradias dos controles $(62,2 \%)$ estão em péssimas condições de higiene e conservação, convertendo-se em focos para reprodução de vetores, especialmente em locais aonde se criam os porcos.

Tabela 16. Casos e controles segundo condições de distribuição da moradia. Jaén. Cajamarca. Peru. 2004

\begin{tabular}{|c|c|c|c|c|c|}
\hline \multirow{2}{*}{$\begin{array}{l}\text { Distribuição } \\
\text { da moradia }\end{array}$} & \multicolumn{2}{|l|}{ Casos } & \multicolumn{2}{|c|}{ Controles } & \multirow{2}{*}{$\begin{array}{l}\text { P-value } \\
0,000\end{array}$} \\
\hline & n. ${ }^{\circ}$ & $\%$ & $n^{0}{ }^{0}$ & $\%$ & \\
\hline 1 & 6 & 6,7 & 49 & 27,2 & \\
\hline $2-3$ & 67 & 74,4 & 84 & 46,7 & \\
\hline $4-5$ & 14 & 15,6 & 26 & 14,4 & \\
\hline 6 ou Mais & 3 & 3,3 & 21 & 11,7 & \\
\hline Total & 90 & 100,0 & 180 & 100,0 & \\
\hline \multicolumn{2}{|c|}{$\begin{array}{l}\text { Pessoas que } \\
\text { moram na casa }\end{array}$} & & & & 0,000 \\
\hline 1-2 Pessoas & 5 & 5,6 & 11 & 6,1 & \\
\hline 3-4 Pessoas & 25 & 27,8 & 77 & 42,8 & \\
\hline 5- 6 pessoas & 43 & 47,8 & 65 & 36,1 & \\
\hline 7 ou más & 17 & 18,8 & 27 & 15,0 & \\
\hline Total & 90 & 100,0 & 180 & 100,0 & \\
\hline \multicolumn{2}{|l|}{$\mathrm{N} .^{\circ}$ dormitórios } & & & & 0,141 \\
\hline 1 & 69 & 76,7 & 121 & 67,2 & \\
\hline 2 & 20 & 22,2 & 37 & 20,6 & \\
\hline 3 ou mais & 1 & 1,1 & 22 & 12,2 & \\
\hline Total & 90 & 100,0 & 180 & 100,0 & \\
\hline
\end{tabular}

Fonte: questionário utilizado para o estudo 
Além dos aspectos extradomiciliares e dos serviços que a morada deve ter, as condições de distribuição desta são características que devem considerar-se como referência das condições de vida que tem uma população. No presente estudo, quanto ao número de habitações que tem as moradias, $74,4 \%$ dos casos e $46,7 \%$ dos controles têm entre dois e três. Uma média de $15 \%$ de ambos os grupos e contam com quatro ou cinco habitações, observando-se que uma proporção muito importante dos controles $(27,2 \%)$ vivem em casas com apenas uma habitação. Estas últimas pertencem a irmãos ou parentes jovens ou recém-casados que moram na qualidade de encarregados da casa de familiares ou de seus pais.

Em relação ao número de pessoas que vivem na casa, se observa que em $47,8 \%$ dos casos, a família está constituída por cinco ou seis pessoas, situação similar para $36,1 \%$ dos controles; sendo que $42,8 \%$ destes e $27,8 \%$ dos casos têm entre três ou quatro pessoas. A importância deste dado se baseia no fato de que para o Peru, a média de pessoas por família está calculada em cinco para a zona urbana (INEI, 2003), sendo que no Distrito de Jaén estaria quase esse nível. No entanto, se podem encontrar proporções importantes de lares com uma grande carga familiar. Neste caso, se observa que em média $16 \%$ de ambos os grupos, a família é composta por sete pessoas.

Esta situação é discordante com o número de dormitórios, que tem as vivendas, já que uma grande maioria, em média $70,4 \%$ de ambos grupos apenas tem apenas um dormitório. Estatisticamente, quem tem uma família com mais de sete integrantes tem quatro vezes $(\mathrm{OR}=3,78 \mathrm{p}=0,02)$ mais possibilidades de ter malária. Provavelmente isto tenha que ver com o risco agregado da precariedade na alimentação familiar, já que quem os resultados do estudo mostram que consome uma dieta "não balanceada" tem 3 vezes maior possibilidades $(\mathrm{OR}=3,21 \mathrm{p}=0,03)$ de ficar doente com malária.

Resultados similares foram encontrados por NAWAZ et.al. (2001) em estudo sobre a Amazônia peruana, indicando que famílias numerosas e condições sanitárias 
deficientes estariam contribuindo com a elevada prevalência de doenças transmissíveis como a malária.

É sabido que o problema alimentar e nutricional é determinado pela desigualdade no acesso a alimentos de qualidade e outros bens e serviços básicos por parte de grande parcela da população, situação que se vai complicar, quando se trata de uma família numerosa. Assim, neste caso quando os membros de uma família são atingidos pela malária, o estado nutricional destes também é seriamente afetado, tornando-os mais suscetíveis a outras doenças, agravando ainda mais a situação socioeconômica da família, pelas implicâncias já mencionadas antes. Situação que apenas é importante para aqueles que são afetados, já que para o Estado somente importa o gasto que determina o controle da doença.

Tabela 17. Casos e controles segundo condições de salubridade da moradia. Jaén. Cajamarca. Peru. 2004

\begin{tabular}{|c|c|c|c|c|}
\hline \multirow{2}{*}{$\begin{array}{l}\text { Condições } \\
\text { salubridade }\end{array}$} & \multicolumn{2}{|c|}{ de Casos } & \multicolumn{2}{|c|}{ Controles } \\
\hline & n. ${ }^{\circ}$ & $\%$ & n. ${ }^{\circ}$ & $\%$ \\
\hline Boa & 15 & 16,7 & 56 & 31,1 \\
\hline Regular & 51 & 56,7 & 50 & 27,8 \\
\hline Ruim & 24 & 26,7 & 74 & 41,1 \\
\hline Total & 90 & 100,0 & 180 & 100,0 \\
\hline
\end{tabular}

Fonte: questionário utilizado para o estudo

$$
\mathrm{p} \text {-Value }=0,000
$$

Os verdadeiros indicadores das condições de salubridade da moradia são referidos pela higiene e a presença ou não de organização que constituem parte das práticas promotoras de saúde, sendo que o papel principal tradicionalmente neste lugar é desempenhado pela dona de casa. Para $83,4 \%$ das moradias dos casos e 68,9\% dos controles as condições de salubridade das casas são qualificadas de regular ou ruim. 
Nas visitas domiciliares realizadas, constatou-se que algumas das casas que têm uma ou duas habitações, essas são divididas por plástico ou telas para poder organizar os diferentes ambientes que tradicionalmente tem em comum as casas de acordo aos padrões estabelecidos pela "modernidade", ou seja, sala, sala de jantar, cozinha, dormitórios e serviços higiênicos.

Essas condições da vivenda podem caracterizar parte do processo de favelização das áreas onde estas estão localizadas, que vem expressar as precárias condições de vida, que neste caso não é somente pela falta ou baixa renda, mas pelas limitações que segundo SEN (1998) dependem de outras circunstâncias, como a idade, sexo, papel social, responsabilidades especiais, lugar de residência, a situação epidemiológica e outros fatores que uma pessoa pode ou não controlar.

Nesta perspectiva, não se pode falar de qualidade de vida, já que a disponibilidade de recursos no âmbito das necessidades básicas como o alimento, casa, saneamento básico e a seguridade alimentar tem a ver com a acessibilidade e o bom uso destes. Assim, é contraditório referir-se a comunidades saudáveis, lema adotado pelo setor de saúde uma vez que o próprio pessoal de saúde tem suas limitações para abordar o tema com a simplicidade e claridade que necessita a fim de promover "condutas saudáveis na população para melhorar sua qualidade de vida”.

A esse respeito, esse lema se torna em discurso contraproducente onde existem populações cujo problema prioritário é satisfazer a fome.

De acordo com HEGGENHOUGEN et al. (2003), em regiões maláricas pode ser alegado que a redução e o controle da enfermidade deve ser um pré-requisito para o desenvolvimento econômico, proposta que neste meio tem caráter de urgência, já que nas propostas de desenvolvimento da Direção Regional de Cajamarca, a malária não faz parte da agenda de discussões. Portanto, não é considerada como problema prioritário na população. É importante ressaltar que as diferentes organizações oficiais e comunitárias 
existentes no meio há anos se reúnem nas "mesas de acordos", a fim de discutir e buscar “alternativas de solução" aos problemas mais graves nos diferentes lugares, reuniões que após de 10 anos não deram resultados.

Assim também a limitada capacidade administrativa estatal para patrocinar a prestação de serviços públicos, especialmente aos menos favorecidos, se confirma com um dos problemas mais palpáveis deste lugar, como no caso da água de consumo humano, que já foi indica acima.

Tabela 18. Casos e controles segundo uso de meios de informação. Jaén. Cajamarca. Peru. 2004

\begin{tabular}{lccccc}
\hline Uso de & meios & de Casos & \multicolumn{3}{c}{ Controles } \\
\cline { 2 - 6 } informação & & $\mathbf{n .}^{\mathbf{0}}$ & $\mathbf{\%}$ & $\mathbf{n .}^{\mathbf{0}}$ & $\mathbf{\%}$ \\
\hline \hline Rádio & 25 & 27,8 & 51 & 28,3 \\
Rádio eTv & 63 & 70,0 & 119 & 66,1 \\
Nada & 2 & 2,2 & 10 & 5,6 \\
\hline \hline Total & $\mathbf{9 0}$ & $\mathbf{1 0 0 , 0}$ & $\mathbf{1 8 0}$ & $\mathbf{1 0 0 , 0}$ \\
\hline \hline \multicolumn{1}{c}{ Fonte: questionário utilizado para o estudo } & p-Value $=\mathbf{0 , 0 0 0}$
\end{tabular}

A tabela mostra que, a maioria dos casos $(70 \%)$ e $66,1 \%$ dos controles têm rádio e televisão e uma média de $27,5 \%$ teriam somente rádio. No entanto, quando se realizou a visita domiciliar, se constatou que quase a totalidade dos entrevistados contava com equipamentos de som, refrigerador e outros, pelo menos estavam dentro da casa, mas não se constatou se esses aparelhos funcionavam.

A idéia de qualidade de vida entendida como a satisfação de necessidades e possibilidades de consumo do que o mercado oferta, dentro da lógica capitalista e o consumista, promovida pelos meios de comunicação, se vê refletida na necessidade de adquirir os meios necessários para entrar no mundo da virtualidade. A "propriedade" de aparelhos tais como rádio, televisão, equipamentos de som, computador, internet, entre 
outros poderiam expressar as possibilidades econômicas da família ou a preocupação dos indivíduos em gozar certos benefícios que a modernidade e a tecnologia lhes oferece.

Neste sentido o lucrativo negócio do entretenimento e a publicidade se constituem em um setor de grande efetividade como mecanismo inconsciente e informal de controle, moldando padrões de consumo e vendendo a idéia de contar com "bom nível de vida" (TELLO, 1995). Para o caso, no Peru, os programas da TV se tem transformado num meio muito discutido pela qualidade de mensagens emitidas e que bem poderia ser uma excelente forma de poder brindar informações sobre os chamados "estilos de vida saudáveis" que poderiam incluir mensagens relacionadas com medidas de prevenção e controle das enfermidades que predominam no meio, especialmente da malária, estratégia que é adotada em caso de surtos epidêmicos

RODRÍGUEZ (1997) expressa de maneira mais clara a implicância desta situação: "A educação e a solidariedade se baseiam mais, por exemplo, no que aparecem na TV, que nos problemas concretos e reais dos nossos vizinhos, o que com certeza desconhecemos ou não valorizamos, porque não é dito precisamente por esse deus universal que todos temos em nossas casas. Esta realidade virtual é recreada a partir da tecnologia de modo que os fatos da convivência, as experiências coletivas criativas, desde as bases sociais, se vêem desprezadas por ser demasiadas artesianas e vivas".

O trabalho com uma remuneração digna que possibilite o sustento para a satisfação das necessidades básicas, na realidade é privilégio de alguns. No presente estudo em média $63 \%$ tanto dos casos quanto dos controles, apenas um dos integrantes da família tem trabalho, entretanto quase a terceira parte de ambos grupos tem dois ou mais com trabalho. 
Tabela 19. Casos e controles segundo características econômicas. Jaén. Cajamarca. Peru. 2004

\begin{tabular}{|c|c|c|c|c|c|}
\hline \multirow{2}{*}{$\begin{array}{l}\text { Características } \\
\text { econômicas } \\
\text { Pessoas que trabalham }\end{array}$} & \multicolumn{2}{|c|}{ Casos } & \multicolumn{2}{|c|}{ Controles } & P-value \\
\hline & $\bar{n} .^{\circ}$ & $\%$ & n. $^{\circ}$ & $\%$ & -..- \\
\hline 1 & 55 & 61,1 & 117 & 65,0 & \\
\hline 2 & 26 & 28,9 & 53 & 29,4 & \\
\hline 3 & 9 & 10,0 & 8 & 4,4 & \\
\hline 4 a mais & --- & --- & 2 & 1,2 & \\
\hline Total & 90 & 100,0 & 180 & 100,0 & \\
\hline Sustenta a familia & & & & & 0,087 \\
\hline Pai & 32 & 35,6 & 95 & 52,8 & \\
\hline Mãe & 17 & 18,9 & 29 & 16,1 & \\
\hline Pai e Mãe & 18 & 20,0 & 23 & 12,8 & \\
\hline Pai e filhos & 16 & 17,8 & 20 & 11,1 & \\
\hline Agregados & 7 & 7,8 & 13 & 7,2 & \\
\hline Total & 90 & 100,0 & 180 & 100,0 & \\
\hline Renda média familiar & & & & & 0,000 \\
\hline < 1 S.M. & 37 & 41,1 & 132 & 73,3 & \\
\hline $1-2$ & 50 & 55,6 & 41 & 22,8 & \\
\hline $3 \mathrm{e}$ mais & 3 & 3,3 & 7 & 3,9 & \\
\hline Total & 90 & 100,0 & 180 & 100,0 & \\
\hline
\end{tabular}

Estes resultados são discutíveis, porque o fato de trabalhar, não significa que se trata de uma ocupação digna, mas de ocupações pouco qualificadas, com remunerações precárias e em condição eventual, os que muitas vezes não chegam a ter uma renda de mais de U\$ 40 mensais. Aqueles que referem que mais de três integrantes da família trabalham, corresponde a grupos familiares de trabalho coletivo já referido anteriormente. 
De outro lado, $35,6 \%$ dos casos e $52,8 \%$ dos controles quem sustenta a família é o pai. E, em $20 \%$ dos casos e $12,8 \%$ dos controles são pai e mãe os que mantêm a casa. Ainda em $18,9 \%$ dos casos e $16,1 \%$ dos controles quem sustenta a casa é somente a mãe.

Assim, quando um dos membros de casa adoece, quem da atenção logicamente é a mãe. Mas, se ela também deve trabalhar fora do lar para manutenção da família, esta deverá suspender essa ocupação. Para numerosas famílias esse fato vai comprometer a alimentação, porque quem trabalha em alguns casos o salário que recebe é por dia efetivo trabalhado, o que significa a redução da renda mensal ou semanal. Essa pressão determinará com que a mãe deva decidir entre a saúde do seu filho e o trabalho, situação que pode resultar em problemas de saúde para a própria mulher ou agravar-se em caso seja a mãe quem adoeceu. No cenário da malária a mãe assume o papel fundamental do cuidado, onde estará em jogo sua capacidade promotora de saúde.

Nessas condições, a relação entre renda e capacidade de sobrevivência faz cair as possibilidades de controle que a mulher possa ter e que também dependerá da experiência que tenha para superar esse impasse. Assim, SEN (1998) diz que “...a pobreza real', entendida como a privação de capacidades, pode ser, em um importante sentido, maior do que parece no cenário das rendas. Esta questão pode ser fundamental quando se avalia as medidas públicas para ajudar as pessoas de idade avançada e a outros grupos que têm dificuldades de conversão“, além de uma baixa renda”.

Sob este aspecto, as desigualdades de gênero têm sido exaustivamente discutidas e a partir destas que se têm realizado múltiplas propostas e compromissos de proteção ás mulheres e crianças por parte dos governos, emitindo-se uma série de normas que não têm sido aplicadas, pois as condições não melhoraram. Se for analisado o papel da mulher em nosso meio, dentro da simplicidade da sua vida cotidiana, poderiam ser ressaltadas características que ajudariam a entender como a inexistência de assistência sanitária justa deteriora a qualidade de vida e a capacidade das pessoas, como no caso da mulher, para ganhar uma renda e superar a pobreza em que vive. 
A obtenção dos dados referentes à renda familiar foi complicada, já que quando perguntados sobre esse aspecto, os entrevistados mudavam de atitude. Foram poucos os que deram dados aproximados do nível de renda familiar. Não é possível fazer um cálculo destas a partir das ocupações, já que são eventuais e algumas duram apenas uns dias, denominada por algumas pessoas como de "cachuelo". Isto se observa tabela 19 , na qual $41,1 \%$ dos casos e $73,3 \%$ dos controles referem que sua renda é menor a um salário mínimo, o que equivale a 450,00 "novos soles" (U\$130). Entretanto que 55,6\% dos casos e $22,8 \%$ dos controles dizem ter entre um e dois salários mínimos.

Neste sentido SEN (1998) afirma que a renda é somente uma opção do que se desejaria ter, e ainda que seja importante, não é tudo na vida. A renda é também um meio, e o fim é o desenvolvimento humano. Em nível coletivo, o desenvolvimento pode ser entendido como um fator de crescimento no nível de vida, o "bem-estar" dos seres humanos. Este conceito é um termo que nestas últimas décadas tem sido bastante utilizado, não somente nos meios políticos e econômicos de quase todos os países industrializados, como também na América Latina ou em países denominados pobres, subdesenvolvidos ou de terceiro mundo.

Tabela. 20. Casos e controles segundo benefício de programa social. Jaén. Cajamarca. Peru. 2004

\begin{tabular}{lllll}
\hline \hline \multirow{2}{*}{ Programa social } & \multicolumn{2}{c}{ Casos } & \multicolumn{3}{c}{ Controles } \\
\cline { 2 - 6 } & \hline $\mathbf{n .}^{\mathbf{0}}$ & $\mathbf{\%}$ & $\mathbf{n .}^{\mathbf{0}}$ & $\mathbf{\%}$ \\
\hline \hline Vaso de Leite & 3 & 3,3 & 10 & 5,6 \\
Sistema Integrado de Saúde & 23 & 25,6 & 42 & 23,3 \\
Comedores Populares & 4 & 4,4 & 7 & 3,9 \\
Não beneficiários & 60 & 66,7 & 121 & 67,2 \\
\hline \hline Total & $\mathbf{9 0}$ & $\mathbf{1 0 0 , 0}$ & $\mathbf{1 8 0}$ & $\mathbf{1 0 0 , 0}$ \\
\hline \hline Fonte: questionário utilizado para o estudo & \multicolumn{3}{c}{ p value $=0,212$}
\end{tabular}


A tabela indica que $25,6 \%$ dos casos e $23,3 \%$ dos controles dizem que os filhos menores de 18 anos são beneficiários do Programa Integrado de Saúde e 7,7\% dos casos e 9,5\% dos controles se beneficiam com o Vaso de Leite e Comedores Populares.

Os programas sociais constituem uma estratégia do Estado para "reduzir" os efeitos das condições de pobreza em que vivem grandes massas da população", oferecendo "apoio em saúde e alimentação", a través de programas como o Vaso de Leite, o Sistema Integral de Saúde e os Comedores Populares, sendo que esses programas oferecem principalmente alimentação complementar e assistência básica de saúde a grupos considerados vulneráveis e em condições de pobreza.

Assim, se estes programas cumpriram com a finalidade para qual foram criados, não teria elevada mortalidade e desnutrição infantil na região em questão Estes, por sua vez, poderiam suportar o desgaste corporal que ocasiona neste caso algumas enfermidades febris, como a malária. Doença que tem repercussões orgânicas desgastantes, deixando o indivíduo mais vulnerável em adquirir outra enfermidade ou afetando seu estado nutricional.

No obstante, esses programas protecionistas, não fazem mais que reforçar o paternalismo do estado e a dependência da população, especialmente os pais de família, já que com freqüência se observa que quem na realidade se beneficia com os alimentos fornecidos pelo Vaso de Leite ou Comedores Infantis ou Populares são os adultos, especialmente o pai de família, que por tradição é quem consome a maior parte da comida da família, ainda que não trabalhe. Fato que probabelmente tem a ver com o desinteresse desses pais para procurar trabalho, situação que é observada com muita freqüência nestes grupos populacionais. 
Tabela 21. Casos e controles segundo alimentação consumida. Jaén. Cajamarca. Peru. 2004

\begin{tabular}{|c|c|c|c|c|c|}
\hline \multirow[b]{2}{*}{ Alimentos consumidos regularmente } & \multicolumn{2}{|c|}{ Casos } & \multicolumn{2}{|c|}{ Controles } & \multirow{2}{*}{ p-value } \\
\hline & n. ${ }^{\circ}$ & $\%$ & n. ${ }^{\circ}$ & $\%$ & \\
\hline Alimentação "balanceada" & 27 & 30,0 & 69 & 38,3 & \\
\hline Alimentação "não balanceada" & 63 & 70,0 & 111 & 61,7 & \\
\hline Total & 90 & 100,0 & 180 & 100,0 & \\
\hline Vezes que consomem & & & & & ----- \\
\hline \multicolumn{6}{|l|}{ Alimentos } \\
\hline 1 & 5 & 5,6 & 3 & 1,7 & \\
\hline 2 & 19 & 21,1 & 28 & 15,6 & \\
\hline 3 & 66 & 73,3 & 149 & 82,8 & \\
\hline Total & 90 & 100,0 & 180 & 100,0 & \\
\hline
\end{tabular}

Fonte: questionário utilizado para o estudo

A observação realizada nas visitas domiciliares aos grupos de estudo, permitiu determinar que a alimentação para $30 \%$ dos casos e $49,4 \%$ dos controles é "balanceada", sendo que contém cereais, verduras, frutas e outros produtos com importante conteúdo nutritivo. Quase a quarta parte dos casos e dos controles dizem ter entre uma ou duas refeições por dia.

Esta é uma realidade própria de grupos humanos que vivem em condições precárias, qualificadas como de pobre e extremamente pobre, onde a desnutrição crônica dos menores de cinco anos é o fiel reflexo da qualidade de vida desta população (INEI, 2003). Vale ressaltar que a Região de Cajamarca é considerada como a segunda região mais pobre do Peru, ironicamente aqui se exploram uma das minas de ouro mais ricas do mundo como a mineira "Yanacocha" Não obstante, as taxas de desnutrição na sub-região de Jaén, segundo PRONAA (2005), está entre 19,6\% e 31,9\%, proporções menores que as informadas em nível da região que supera os $40 \%$. 
Tabela 22. Odds Ratio (OR), Intervalos de Confiança de 95\% (IC) e Valor P dos fatores associados à infecção com malária por P. falciparum. Jaén. Cajamarca. Peru. 2004.-

\begin{tabular}{|c|c|c|c|}
\hline VARIAVEIS & $\mathbf{O R}$ & I. C. (OR) & P. valor \\
\hline Não sabe como se transmite a malária & 8,26 & $3,08-13,67$ & 0,00 \\
\hline $\begin{array}{l}\text { Não faz nada para se proteger da picada dos } \\
\text { zancudos }\end{array}$ & 6,12 & $1,72-18,92$ & 0,01 \\
\hline Não acredita que a malária seja perigosa & 4,66 & $1,62-13,41$ & 0,00 \\
\hline Não tem água potável & 4,16 & $1,58-12,58$ & 0,02 \\
\hline & 3,93 & $1,46-15,15$ & 0,00 \\
\hline $\begin{array}{l}\text { Não sabe qual é o tratamento da malária } \\
\text { Ter de } 7 \text { a } 11 \text { integrantes na família. }\end{array}$ & 3,78 & $1,71-11,85$ & 0,02 \\
\hline Alimentação não balanceada & 3,21 & $1,13-9,41$ & 0,03 \\
\hline Não ter luz elétrica & 3,16 & $1,10-7,41$ & 0,03 \\
\hline Mosquito não é problema para a saúde & 2.53 & $1,32-6,98$ & 0.05 \\
\hline Zancudo se reproduz no monte & 2,53 & $1,16-7,06$ & 0.06 \\
\hline Não sabe quais são os sintomas da enfermidade & 2.17 & $1,43-3,92$ & 0.05 \\
\hline Mal acondicionamento de resíduos sólidos & 2,12 & $1,12-6,88$ & 0.01 \\
\hline Ter grau de instrução médio & 2.53 & $0,47-13,64$ & 0.28 \\
\hline Não sabe aonde se cria o zancudo & 2.06 & $0,40-10,51$ & 0.38 \\
\hline Tratamento de malária por vários dias & 1.30 & $0,31-4,06$ & 0.86 \\
\hline Ser analfabeto & 1.59 & $0,06-11,85$ & 0.92 \\
\hline Viver em zona rural & 1,62 & $0,21-5,01$ & 0.98 \\
\hline
\end{tabular}

$\mathrm{O}$ cálculo de $\mathrm{OR}$ permitiu determinar que existe associação entre presença e ausência de malária e saber como se transmite esta doença. Aqueles que não sabem como ocorre a transmissão teriam oito vezes $(\mathrm{OR}=8,62 \mathrm{p}=0,000)$ mais chance de adquirir a enfermidade que aqueles que sabem como se produz. Esta associação foi encontrada nos múltiplos estudos realizados, mostrando que o conhecimento sobre malária é uma deficiência quase comum, apesar de que existem campanhas de prevenção 
e controle há várias décadas. Assim, por exemplo, MENDEZ et al. (2000) em um estudo realizado em Buenaventura (Colômbia) foi encontrados que a incidência da doença decrescia com a idade e com o conhecimento e as medidas de prevenção para eliminar os lugares de reprodução dos mosquitos transmissores de malária, porém não houve associação com o uso de mosquiteiros. No entanto, nesse mesmo estudo foi observado uma associação muito significativa com a malária, quando havia exposição com a floresta e a automedicação contra esta doença em meses anteriores.

Alguns investigadores como GREENWOOD (1989) asseguram que o conhecimento da causa da malária, as condutas tradicionais, a educação em saúde, a disponibilidade de antimaláricos nas tendas e farmácias, o acesso aos trabalhadores de saúde e ao setor privado são fatores que podem contribuir para uma variação local da forma de apresentação da malária. Afirmações que podem ser muito discutidas desde que muitos outros elementos interagem neste problema. Outros estudos como o realizado por o MINSA (2001), em estudo realizado na costa e selva do Peru, encontrou que o desconhecimento que tinham a população sobre a malária era um fator de risco para os moradores desta zona. Do mesmo modo ELZUBIER 1(997) em Sudão encontrou que nas escolas do nível secundário tinham informação limitada da malária em grávidas e que a cloroquina poderia produzir aborto.

Para tanto, a situação se repete em outros lugares como ao sul do México aonde DANIS-LOZANO et al., (1999) determinaram que unicamente a metade da população tem conhecimento sobre malária e alguma forma de prevenção, e a mesma proporção reconhece alguns sintomas da doença. Caso similar dos encontros de AIKINS et al. (1994) no oeste africano, onde houve baixo nível de conhecimentos sobre malária, sendo que a população se preocupava mais com a moléstia das picadas do que com a enfermidade. Neste lugar, utilizam também medicina tradicional para o tratamento da malária. 
Nas respostas relativas à pergunta "você sabe o que é malária ou paludismo?", pode-se perceber que para quase $53 \%$ dos casos e controles, a malária ou paludismo "é uma enfermidade" y $20 \%$ de ambos os grupos a relacionam com o vetor da doença. Para alguns o conceito deste dano tem como referência o quadro clínico, já que para eles "é uma enfermidade que dá febre e dor nos ossos".

Quando foi realizada a entrevista, em ambos os grupos se constatou que as pessoas sabiam o que era paludismo, mas não sabiam o que era malária. Isso é uma situação contraditória, já que no Peru, o material educativo do setor de saúde, utilizado nas atividades de prevenção da doença, contém mensagens denominando-a como malária. Constituindo num fator de confusão na população, especialmente para aquelas que tem poucas oportunidades de acessar a este tipo de material ou de ler os grandes murais existentes em lugares estratégicos.

Contudo, nem todos os que sabem ler têm informação apropriada acerca desta enfermidade. Assim, por exemplo, ELZUBIER et al. (1997) no estudo realizado ao leste do Sudão dizem que os escolares e mestres das escolas não conheciam nada da doença em relação às grávidas e crianças e tinham informações distorcidas do tratamento antimalárico, considerando que este medicamento produzia aborto e que consumindo vitaminas podia-se prevenir a malária.

Esses resultados fazem lembrar que para garantir a eficácia dos programas educativos em saúde, necessitam ser expressos no vocabulário da região, e entender que somente a mensagem não é suficiente para transformar ações e relações. Uma mostra de que os programas educacionais até hoje não alcançam os resultados esperados. Assim, KORAM et al. (1995) em um estudo em Gâmbia, encontrou que a mães, ainda, não entendem a causa da doença e a atitude que deveriam tomar quando uma criança tem febre, ressaltando que apenas $10 \%$ delas assistiram à escola. Entretanto, a mulher tem um papel fundamental na motivação, organização e educação em saúde previamente às campanhas de saneamento ambiental e controle vetorial (HAMID et al., 1996). 
Esse fato, neste país constitui uma das grandes debilidades da chamada Educação em Saúde, que tem a ver com o material utilizado para transferir as mensagens de acordo com o tema que se quer tratar. Com freqüência se observa que este problema da informação para a saúde tem relação com imagens e mensagens que são pouco claras para a população alvo. Outras vezes se trata de mensagens sobrecarregados para o interesse de quem lê. Isto pode ser constatado com alguns dos "materiais educativos" do programa de malária, uma vez que apenas a metade das lâminas que continham o álbum seriado da malária era do interesse dos entrevistados.

Neste sentido, SÁEZ et al. (1995), indicam que quando se fala em educação para a saúde, se deve considerar que não se trata de ter muito conhecimento $\mathrm{e}$, sim de dispor de capacidades e habilidades que permitam um novo comportamento. Mas nesse processo tem muito a ver o modo de agir do pessoal de saúde, o mesmo que nesta área de estudo geralmente adota uma atitude de imposição frente ao usuário, atitude que, ainda não seja intencional, pode determinar que quem recebe a mensagem assuma uma posição subalternidade, já que supostamente quem "tem a verdade" sobre o seu problema de saúde é quem trabalha no estabelecimento de saúde, especialmente se quem proporciona a informação é o médico.

De outro lado, em média $56,5 \%$ de casos e controles dizem que a doença se produz "porque os mosquitos picam e transmitem a doença" e o restante afirma que "porque a casa não está saneada" ou "quando se toma água não tratada ou "pelo desordem no ambiente". Praticamente a quarta parte dos casos e $16,1 \%$ dos controles dizem "não saber". Algo parecido sucede quando se pergunta se "é uma doença contagiosa?", em média $64,5 \%$ indicam que sim. No entanto, 1/3 dos controles indicam que não é, mostrando uma certa confusão quando este grupo afirma que quem transmite a malária é o mosquito.

A esse respeito, ESPINO et al. (1997), em um estudo realizado nas Filipinas, encontrou que a população não tem clara a relação entre ser humano-vetor-parasito, já 
que uma parte desta acredita que a malária se adquire tomando água contaminada. Assim também, não tem claro o papel do mosquito como vetor desta doença. Estas expressões evidenciam por um lado o conhecimento limitado da população desta SubRegião, da relação que existe entre a malária e os mosquitos e de outro a confusão com as condições sanitárias das vivendas que favorecem a presença de vetores; mensagens que foram difundidas ante a presença de epidemia de dengue.

Igualmente, os termos contágio e transmissão, para a população (inclui alguns profissionais de saúde), sempre levam a confusão. Nesse caso, o sentido que é dado ao primeiro termo é o de "transmissão de pessoa à pessoa", para tanto, em média $64,5 \%$ dos entrevistados afirmam que esta enfermidade "se contagia" nessas condições. Já o termo "transmissão" significa a presencia de um elemento intermediário para a transmissão que neste caso é a certeza de que o mosquito tem esse papel por meio da picada, ainda que, quando é perguntado “por que os mosquitos picam?", respondem "chupam sangue porque têm que comer".

Por outro lado, a referência dos sintomas da malária, tanto dos casos como dos controles, são aceitáveis. Assim vemos que, mais de $90 \%$ de ambos os grupos se referem aos "calafrios ou muita tremedeira, dor de cabeça e febre" como parte do quadro clínico desta enfermidade e podem corresponder as vivências que já tiveram no caso dos primeiros ou também o que têm escutado acerca das enfermidades febris, no caso dos segundos.

Quando se analisou estatisticamente o risco em adquirir malária naqueles que não sabiam quais eram os sinais e sintomas da doença, se determinou que quem não sabia a esse respeito, teria 2,17 vezes $(\mathrm{p}=0,05)$ mais possibilidades que aqueles que conheciam. Esses resultados revelam que, cada lugar tem suas próprias percepções em relação a um dano dependendo das vivencias que produziram maior impacto. 
Assim vemos que ESPINO et al. (1997), na pesquisa realizada nas Filipinas, encontraram que a malária é percebida unicamente com base na intensa febre, intenso frio e severa dor de cabeça. E quando apenas o paciente tem febre não é motivo de consulta e sim quando estão presentes os demais sintomas.

Como mencionado nos parágrafos anteriores, esta zona tem doenças febris que apresentam febre alta, intensa dor de cabeça, dor nas articulações e nos músculos e dor do globo ocular. Nestas circunstâncias também aparece confusão na população, tendo-se gerado um discurso genérico para qualquer doença, sem identificar de que doença se trata. Na realidade, a febre ou "quentura" é o que mais se destaca como manifestação da doença, porém não é relacionada especificamente como malária e sim como a dengue, febre tifóide e até como infecção urinária, condição que às vezes se complica, já que quando acessam à farmácia, são oferecidos medicamentos para estes "prováveis danos", protelando por tempo indefinido a consulta com o médico.

Durante a coleta dos dados, nas declarações dos entrevistados, se percebeu que o quadro clínico narrado corresponde mais para a dengue que para a malária, observandose que em alguns casos, estes acreditam ser a malária e a dengue a mesma doença. $\mathrm{O}$ tipo de informação que esta população tem das enfermidades endêmicas probabelmente contribui para a automedicação, já que foi aprendido que a dengue não tem tratamento específico e para tanto as pessoas se limitam a "tomar paracetamol e um antialérgico, porque "só com isso vão sentir melhora" até que passe a sintomatologia.

No Peru, a população te acesso a toda a classe de produtos farmacêuticos, decorrente da não existência de controle da venda dos medicamentos, tanto nas farmácias quanto nas "boticas". No caso de Jaén tem boticas e farmácias que vão mais além, já que os vendedores tornaram-se "especialistas" para tratar alguns males próprios da zona, neste caso, a malária. Em conseqüência, o tratamento é realizado de acordo a cada sintoma referido. 
Além disso, alguns pacientes que são tratados nos serviços públicos, que já vem com um tratamento medicamentoso prévio, estabelecido pelas farmácias e boticas que inclui: um antipirético, um antiinflamatório, um analgésico e um antibiótico que geralmente é o cloromoycetin, que no dizer dos febris " trata-se de um medicamento específico para febre tifóide". Algo parecido é informado por BAUME et al. (2000) em um estudo realizado em Zâmbia, no qual notaram que as mães tratam a febre de seus filhos com cloroquina e um antipirético e que a maioria destes eram levados depois aos serviços de saúde. Em outros lugares como Ghana AHORLU et al. (1997) encontraram que a malária é tratada principalmente com uma combinação de ervas e medicamentos antimaláricos em doses inadequadas.

Esse fenômeno probabelmente contribui para manter em circulação as fontes de infecção por períodos prolongados e, em lugares onde ocorre má uso de drogas contra a malária, agravando-se o problema. Neste sentido MOTTA, 1992 \& WHO, 2000b, referem que em alguns países a população toma os medicamentos contra a malária como se fossem um antitérmico, interrompendo o tratamento com um simples alívio dos sintomas, com a finalidade de economizar os medicamentos para a próxima vez que apresente febre. Assim é gerado um circulo vicioso: automedicacão-descumprimentoarmazenamento-automedicação.

Esta situação se dá em qualquer parte do mundo onde não existe controle da liberação de medicamentos. No entanto DANIS-LOZANO (1999), estudando o sul do México, observou que a população com um ou mais episódios de febre, já sabe que pode ser malária e que não é letal e, e que o tratamento antimalárico disponível nas farmácias pode não ser efetivo.

A respeito disso, nesta Sub-Região, quando a administração de medicamentos para esta enfermidade é supervisionada, não é freqüente a automedicação do paciente. Mas este problema pode acontecer, no caso da entrega de medicamentos antimaláricos ao paciente para seu consumo em casa. Situação percebida em alguns pacientes 
atendidos no mesmo hospital de Apoio de Jaén, obtendo como justificativa do pessoal que trabalha nesta área: "não conseguimos atender a todos de uma vez. Tem que fazer muito em cada programa e somos apenas duas pessoas, o médico e eu. Então temos que entregar o medicamento para que tomem em casa. A supervisão e o acompanhamento dos pacientes é impossível de realizar, pois para ir até a residência, demora muito e teríamos que fechar o serviço para fazer uma visita domiciliar e ainda o hospital não fornece facilidades para o transporte ${ }^{, 8}$.

O conhecimento da existência dos tipos de malária é limitado. Especialmente para nos casos, somente $18,8 \%$ têm alguma idéia da existência das formas mais comuns, condição que é mais vantajosa nos controles, já que 53,9\% desses fornecem uma resposta aceitável quanto a estas formas. As expressões mais usadas são "tem uma malária que dizem que mata e outra que não", resposta advinda da informação muitas vezes errada recebida de outros que já experimentaram a doença ou por outros meios ou "escutou de algum conhecido". Alguns entrevistados dizem que "já sabem como devem curar-se", pois eles já tiveram malária nos anos anteriores, portanto "já têm conhecimento do tratamento medicamentoso". Esses personagens por sua vez vão "recomendar esse tratamento" a quem tem sintomatologia suspeita de malária.

Diante estes problemas o MINSA coloca algumas justificativas que tem a ver unicamente com aspectos técnicos institucionais do controle da malária. Assim, indica que, os diagnósticos errados, a falta de certeza clínica, as falhas técnicas na coleta de amostras de sangue, falhas no exame laboratorial e a inacessibilidade geográfica seriam explicações dadas em relação ao atraso no diagnóstico e tratamento dos pacientes com malária grave (MINSA, 2001). Situação que segundo estes autores fora reportada pela primeira vez aos peritos da OMS no ano de 1987.

Outra das características que estatisticamente mostra associação significativa, e que estaria atuando como fator de risco é o fato das pessoas que "não acreditam que a

\footnotetext{
${ }^{8}$ Trabalhador dos serviços de saúde.
} 
malária seja perigosa" tem 4,66 $(\mathrm{p}=0,000)$ vezes mais probabilidade de adquirir malária do que aqueles que acreditam que ela é perigosa. E as razões alusivas para ter esta opinião estão indicadas e discutidas nas tabelas e comentários seguintes:

Tabela 23. Casos e controles segundo porque a malaria é perigosa ou não. Jaén, Cajamarca. Peru. 2004.

\begin{tabular}{|c|c|c|c|c|c|}
\hline \multirow{2}{*}{ Razões porque a malária é perigosa } & \multicolumn{2}{|c|}{ Casos } & \multicolumn{2}{|c|}{ Controles } & \multirow{2}{*}{$\begin{array}{l}\text { p-value } \\
0,000\end{array}$} \\
\hline & n. ${ }^{\circ}$ & $\%$ & n. ${ }^{\circ}$ & $\%$ & \\
\hline $\begin{array}{l}\text { Debilita muito, envenena o sangre e pode dar } \\
\text { outras enfermidades }\end{array}$ & 25 & 27,8 & 65 & 36,1 & \\
\hline Debilita e pode matar & 41 & 45,5 & 53 & 29,4 & \\
\hline Sistema* & 24 & 26,7 & 62 & 34,5 & \\
\hline Total & 90 & 100,0 & 180 & 100,0 & \\
\hline Razões porque a malária não é perigosa & & & & & 0,002 \\
\hline Melhoram sem tratamento & 14 & 15,6 & 19 & 10,6 & \\
\hline Mais perigoso é a dengue & 10 & 11,1 & 43 & 23,9 & \\
\hline Sistema* & 66 & 73,3 & 118 & 65,5 & \\
\hline Total & 90 & 100,0 & 180 & 100,0 & \\
\hline
\end{tabular}

A tabela mostra que para $69,4 \%$ dos casos e controles, a malária é perigosa, justificada por "debilita muito, envenena o sangue e pode dar outras doenças" alguns deles acreditam que "a malária ataca a corpo todo, muda de cor, torna-se amarelo, pois a sangue está com veneno, entanto vai-se perder peso". Ou porque a malária "debilita e pode matar". Não obstante, $37,8 \%$ dos casos e $34,5 \%$ dos controles indicam que não é perigosa, já que asseguram que podem melhorar sem tratamento ou consideram que "mais perigosa é a dengue".

No imaginário dos pacientes que foram entrevistados afirmavam que "dizem que quem pega dengue, sai sangue por todos os orifícios do corpo, por isso dá muito

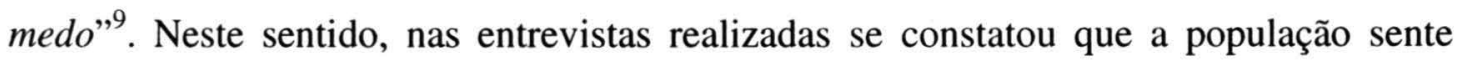
mais temor pela dengue do que pela malária e, segundo a versão do pessoal dos

\footnotetext{
${ }^{9}$ Paciente de 22 anos de idade, gestante, teve malaria por $P$. falciparum.
} 
estabelecimentos de saúde, esta atitude dos pacientes se explicaria porque "a população sabe que tem tratamento para a malária", e o medo de adoecer com a dengue, se sustenta no fato de que "pode matar, porque produz hemorragia

Esses resultados revelam também que, o pessoal de saúde estabelece níveis de gravidade das enfermidades febris, colocando a malária como um dano sem muita importância, afirmando que "a bartonelose é igual a perigo de morte, comparado com a malária, o paciente pode estar vários dias enfermo e não passa nada, não deixa de ser grave, é mais agressiva, avança mais rápido, porém mais fácil de cortar a cadeia e não tem casos graves ou complicados, ... a dengue não tem falecimentos, porém é perigoso, difícil de cortar a cadeia". Expressões que revelam o enfoque biologista da doença que tem os servidos de saúde baseada na cadeia epidemiológica.

Nestas circunstâncias a malária se mantém e está avançando à sombra de outras doenças febris. Essa enfermidade para a população vai ter importância na medida que adquire popularidade quando aumenta a incidência, porém não por sua gravidade e sim pela velocidade de distribuição.

Tabela 24. Casos e controles segundo local procurado em caso de doença. Jaén, Cajamarca. Peru. 2004.

\begin{tabular}{|c|c|c|c|c|}
\hline \multirow{2}{*}{ Local procurado } & \multicolumn{2}{|c|}{ Casos } & \multicolumn{2}{|c|}{ Controles } \\
\hline & n. $^{\circ}$ & $\%$ & $\bar{n} .^{\circ}$ & $\%$ \\
\hline Farmácia & 10 & 11,1 & 27 & 15,0 \\
\hline Minsa & 48 & 53,3 & 105 & 58,3 \\
\hline $\begin{array}{l}\text { Clinicas/consulta } \\
\text { privada }\end{array}$ & 5 & 5,5 & 8 & 4,4 \\
\hline Farmácia e Minsa & 22 & 24,4 & 19 & 10,6 \\
\hline EsSalud & & & 21 & 11,7 \\
\hline Total & 90 & 100,0 & 180 & 100,0 \\
\hline
\end{tabular}


As boticas, as farmácias e as clínicas constituem parte do circuito que percorre muito dos pacientes na procura de assistência, comentário oportuno, já que muitos deles são transferidos do hospital para as clínicas devido a que o estabelecimento público não conta com a implementação necessária para atender todos os pacientes ou como já mencionado, muitos se vêem forçados a solicitar os serviços privados pela incompatibilidade de horários entre o paciente e os serviços públicos. Assim vemos que as pessoas com afecções febris são consideradas como "não urgentes", para tanto devem esperar o atendimento na consulta externa, geralmente entre as oito e às treze horas, sendo que, neste horário, muitos dos que precisam o serviço tem que trabalhar.

Assim, apenas 53,3\% dos casos e 58,3\% dos controles indicam procurar como primeira opção os estabelecimentos de saúde públicos. No entanto, se pode perceber que a maioria destes já tinha se automedicado ou tratado com remédio caseiro e $24,4 \%$ dos casos e 10,6\% dos controles dizem solicitar atenção na farmácia. Para o presente estudo, $11,7 \%$ dos controles têm a vantagem de pertencer a EsSalud, instituição de atendimento a saúde para grupos de assegurados, mas que foram atendidos nos serviços públicos.

Por outro lado, os pacientes febris que são registrados como negativos de malária, vão solicitar os serviços da clínica ou das farmácias e/ou boticas, devido a que o quadro clínico febril continua. Finalmente retornam ao serviço público quando o quadro piora, agravando más a sua economia já que houve desperdício de tempo e de dinheiro. Circunstância que se repete em outros lugares como referido por ERHART et al., (2004) em estudo realizado em Mekong Delta, região do Vietnam encontraram que os pacientes preferem o uso dos serviços de saúde privados para o tratamento da malária, ainda que os serviços teriam acesso livre e, E NAWAZ et al. (2001), estudando o Amazônia peruano, referem que mais de três quartos da população entrevistada não realiza consulta com o médico, porque não necessitam ou por razões econômicas ou pela distância dos serviços de saúde. 
As opções de solicitar os serviços de saúde sejam privadas ou públicas, deriva da impossibilidade de solucionar o problema em casa, após de tentar o tratamento com medidas caseiras, resposta obtida de mais de $60 \%$ dos entrevistados, atitude confirmada nos grupos focais, no qual os participantes indicavam que quando seus familiares adoecem lhes dão "preparados caseiros" e pastilhas que são adquiridas da farmácia ou do próprio estoque, de acordo com sua experiência aos conselhos ou sugestões dos familiares ou dos vizinhos. Em conclusão, o caminho mais comum dos afetados por malária é: casa (automedicação), curandeiro, farmácia e hospital.

Estes resultados vão questionar os delineamentos ou princípios do setor saúde, como o de garantir o acesso aos serviços a toda a população, sob o enfoque de igualdade. Na realidade concreta, a brecha entre o povo e serviços de saúde é grande. Por tanto é uma utopia pensar que é fácil conseguir que ambos confluam esforços para enfrentar os problemas de saúde de maneira conjunta, como no caso do problema da malária.

No dizer dos trabalhadores de saúde, as razões pelas quais os pacientes não acessam os serviços públicos de saúde é porque: "não gostam de esperar. Têm suas crenças, se automedicam, o curandeiro não cobra a consulta, apenas o medicamento, mas é mais caro. A farmácia lhes vende fansidar e lhes passa. Porém acabam retornando ao hospital ou posto de saúde"10.

Outro funcionário de saúde diz, "Os pacientes não gostam da análise de sangue. É a idiossincrasia da população. Têm lugares aonde vendem muitos antimaláricos, são tratamentos desorganizados e isto pode dar complicações. Apesar de que se trata de pessoas que não têm recursos para pagar os exames. E se o tratamento é desorganizado com relação ao número de dias, não será cortada a cadeia, então essa pessoa se

\footnotetext{
${ }^{10}$ Trabalhador de Saúde, participante do grupo focal.
} 
converte em um foco infeccioso. Já tivemos problemas até com a justiça, porque muitos pacientes se recusam a hospitalizar-se e, apesar de estarem graves, chamam á polícia".

Tabela 25. Casos e controles segundo informação de tratamento da malaria. Jaén, Cajamarca. Peru. 2004

\begin{tabular}{|c|c|c|c|c|c|}
\hline Informação de tratamento & & Casos & & troles & p-alue \\
\hline Sabe como se trata & n. ${ }^{\circ}$ & $\%$ & n. & $\%$ & 0,000 \\
\hline Sabe & 66 & $\overline{73,3}$ & 123 & 68,3 & \\
\hline Não Sabe & 24 & 26,7 & 57 & 31,7 & \\
\hline Total & 90 & 100,0 & 180 & 100,0 & \\
\hline Medicamento a dar & n. $^{\circ}$ & $\%$ & n. $^{\circ}$ & $\%$ & 0,000 \\
\hline $\begin{array}{l}\text { Os que são dados no posto ou no } \\
\text { hospital }\end{array}$ & 9 & 10,0 & 60 & 33,3 & \\
\hline Cloroquina & 5 & 5,6 & 49 & 27,2 & \\
\hline Fansidar & 10 & 11,1 & 24 & 13,3 & \\
\hline Não sabe & 66 & 73,3 & 47 & 26,1 & \\
\hline Total & 90 & 100,0 & 180 & 100,0 & \\
\hline
\end{tabular}

Fonte: questionário utilizado para o estudo

Os resultados encontrados indicam que a maioria dos casos $(73,3 \%)$ e controles $(68,5 \%)$, dizem que a malária "se cura com comprimidos". Um terço dos controles menciona que é "com o que dão nos postos de saúde ou no hospital", observando que $16 \%$ dos casos e $30 \%$ dos controles referem que "se cura com a cloroquina" o que também é conhecido pela população como "aralén ou fansidar". No entanto 73,3\% dos casos e $26,1 \%$ dos controles indicam não conhecer qual é o medicamento para curar esta enfermidade. $\mathrm{O}$ tempo de tratamento segundo a maioria dos controles $(42,2 \%)$ deve ser de um dia e de dois dias segundo $46,7 \%$ dos casos. Os demais dizem que deve ser de até 15 dias. E, quem não conhece qual é o tratamento da malária tem 3,93 vezes mais risco em adquirir malária que os que não conhecem. 
Resultados similares foram encontrados nos estudos realizados por MINSA (2001), num estudo realizado na costa norte e na Amazônia do Peru, mostrando que aqueles que "não conheciam quais eram os medicamentos para tratar malária" ou "administravam e ou recebiam medicina tradicional para o caso de febre, teriam alto risco de adquirir malária grave”.

$\mathrm{O}$ direito que tem o paciente do tratamento medicamentoso que recebe, em qualquer serviço de saúde se torna polêmico, considerando que a automedicação é qualificada como um problema de saúde pública. Más, muitas vezes a omissão desta informação vai ocasionar que esses pacientes fiquem assustados com as reações adversas aos medicamentos, como o caso dos que recebem tratamento antimalárico. A maioria deles referiram que, "os efeitos eram horríveis" porque "produzia vômito, mal estar e tontura". Expressões que indicam que os pacientes não recebem orientação sobre a terapia recebida e da doença que tem.

Portanto, o desconhecimento sobre o dano que afeta pode ser um dos fatores que condicionaria o uso irresponsável dos medicamentos que o paciente consome. $\mathrm{O}$ problema é mais complexo quando o acesso aos serviços de saúde se vê limitado por múltiplas razoes.

Em relação a essas reações adversas, o vômito é referido com maior freqüência $(47,7 \%)$ dos casos. Nas declarações de alguns pacientes ou de familiares destes, se constatou que muitos deles vomitavam o medicamento depois de uma hora de haver tomado a dose correspondente, colocando em duvida a eficácia dos medicamentos antimaláricos, considerando ainda o fato de que muitos não retornam após o tratamento para o controle respectivo. Outros pacientes referem que o problema maior depois do tratamento são"problemas no fígado", taquicardia, insônia, agitação, debilidade e fotofobia. Reações que em média duram 15 dias. 
Esses aspectos também não são considerados de importância quando se realizam as avaliações dos programas, omissão que teria que ser encarada, pela probabilidade do agente da malária possa desenvolver resistência ao tratamento antimalárico que se esta utilizando no país, fato que ocasionaria graves problemas no programa de controle da mesma.

Tabela. 26. Casos e controles segundo de quem seria responsável do controle da malária. Jaén, Cajamarca. Peru. 2004.

\begin{tabular}{lllll}
\hline \hline \multirow{2}{*}{ Responsáveis } & \multicolumn{2}{c}{ Casos } & \multicolumn{3}{l}{ Controles } \\
\cline { 2 - 6 } & $\mathbf{N}$ & $\mathbf{\%}$ & $\mathbf{N}$ & $\mathbf{\%}$ \\
\hline \hline Minsa & 16 & 17,8 & 48 & 26,7 \\
Hospital & 12 & 13,3 & 56 & 31,1 \\
Mesma pessoa & 35 & 38,9 & 30 & 16,7 \\
Das pessoas e o setor de saúde & 11 & 12,2 & 39 & 21,7 \\
Não sabe & 16 & 17,8 & 7 & 3,9 \\
\hline \hline Total & $\mathbf{9 0}$ & $\mathbf{1 0 0 , 0}$ & $\mathbf{1 8 0}$ & $\mathbf{1 0 0 , 0}$ \\
\hline \hline \multicolumn{1}{c}{ Fonte: questionário utilizado para o estudo } & \multicolumn{3}{c}{ p-Value $=0,000$}
\end{tabular}

A responsabilidade do controle da malária segundo $31,1 \%$ dos casos e $57,8 \%$ dos controles é do MINSA e do Hospital. Sendo que para 38,9\% dos primeiros a responsabilidade é deles mesmos.

Estes resultados mostram com clareza a dependência da população das ações do Estado assistencialista, mas também julgam o atuar dos responsáveis das atividades de controle da malária. Assim alguns deles dizem “...os da DISA ou do hospital, quando tem muitas pessoas que ficam doentes, com febre, saem a borrificar, como se, com isso, remediassem algo, porque os mosquitos atacam pior à noite e os que borrificam vêm a cada seis meses. Até então, muitas pessoas ficaram doentes"11.

\footnotetext{
${ }^{11}$ Mulher de 40 anos, ensino primário completo. Mora há 3 anos em uma zona periférica de Jaén, natural de Cutervo (província limítrofe com a província de Jaén).
} 
Essas respostas estariam explicando algumas das razões de exposição dos casos de malária. Os resultados das pulverizações, feitas pelos serviços de saúde, são observados como "uma atividade que tem efeito negativo na população", já que depois da borrificação de uma casa o relato foi de que "os mosquitos vêm mais bravos". Essas pessoas têm aprendido a diferenciar que "as pulverizações com bombas não dão resultado" e quando essa atividade é feita com "pressão" os mosquitos desaparecem.

A explicação está no fato de que estas últimas são realizadas com substâncias piretróides, cuja efetividade está demonstrada. As que são realizadas com "bomba" são substâncias de menor efetividade como a deltametrina (Baytroid PM ®). Não é feita a avaliação de impacto, nem estudos entomológicos e de resistência aos inseticidas. Além disso, deve ser considerado que se trata de uma zona de elevada produção de arroz, café e cacau, aonde é utilizado grande quantidade de inseticidas químicos.

Cabe ressaltar que, esse serviço é realizado no caso da ocorrência de surtos ou uma iminente ameaça de epidemia de malária ou de enfermidades adquiridas através de vetores, que, como rotina é realizado trimestral ou semestralmente (quando tem insumos), utilizando maneira rotativa, substâncias organofosforadas, organocloradas e piretróides, com a finalidade de prevenir a resistência dos vetores aos inseticidas, sendo usado pelo setor de Saúde o Lombdaohidrolim ou K-hotrine PM-25\% ${ }^{12}$. Os trabalhadores que se encarregam desse serviço ainda são conhecidos como "os maláricos".

O problema de um Estado assistencialista e intervencionista se vê refletido neste aspecto e que por sua vez os serviços vêm replicá-lo na população, por tanto esta é convicta de que o Estado é quem deve solucionar o problema, neste caso, referindo-se à malária. Esta é uma das formas mais comuns de privar a capacidade resolutiva que tem a população para enfrentar suas próprias dificuldades.

\footnotetext{
${ }^{12}$ Eusebio León, trabalhador da DISA- Jaén. Responsável pelas atividades de fumigação desta jurisdição.
} 
Desta maneira se fala equivocadamente de "participação comunitária" quando a população "aceita ou colabora" na execução das atividades programadas pelo setor, como, por exemplo "limpar a casa, jogar o lixo, aceitar que borrifiquem sua casa, tomar o medicamento". O que na realidade se faz é aperfeiçoar o papel do estado. O Estado pauta e as comunidades executam (PAREDES, 1994)

Contraditoriamente a OPS afirma que os países latino americanos têm muita experiência em matéria de prevenção e controle de enfermidades transmitidas por vetores. Por conseguinte, cabe supor que, nas regiões onde as doenças transmitidas por vetores são endêmicas, os departamentos de saúde realizam atividades de controle. No caso dos serviços de saúde pertencentes ao Ministério da Saúde, faz alguns anos que se está organizando e implementando os serviços de epidemiologia, desde o primeiro nível de atenção. Sabe-se da existência de capacitações permanentes para o pessoal em Saúde Pública e Epidemiologia sobre enfermidades infecciosas prevalentes da zona onde trabalham. Isto tem muito a ver com o perfil de formação dos diferentes servidores nestes serviços. No entanto, este desenvolvimento dos chamados Recursos Humanos em Saúde não tem consistência, já que como se explicou, a condição laboral dos trabalhadores em saúde é eventual.

Quando se objetiva obter uma participação ativa da comunidade nas atividades de prevenção e controle desenvolvidas em relação às doenças endêmicas da zona, é fundamental que estes se informem. Neste caso, a maioria $(78,3 \%)$ dos controles mostra ter uma informação mais clara acerca do mecanismo de transmissão desta enfermidade, sendo a proporção menor em 13 pontos $(65,5 \%)$ para o grupo de casos.

E como é lógico, para mais de $70 \%$ de ambos os grupos, o elemento principal é o mosquito. Termo que em alguns casos, é usado de maneira diferenciada, chamando de "mosquito" os insetos que têm aparência das moscas da família Drosophilidae, ou relacionando-o, por exemplo, com a "manta branca" nome dado a Lutzomia, vetor da bartonelose, ou às vezes para referir-se a qualquer culicídeo ou anofelino, é chamado de 
"zancudo". No dizer de algumas pessoas, o temor é maior quando se trata de um mosquito culicídeo (de tamanho grande), como que para eles é provável transmissor da dengue ou de outra doença, já que paludismo ou malária não é mencionado.

As denominações que dão ao vetor da malária refletem confusão com os apelativos usados com os vetores de outras enfermidades. Assim vemos que alguns dos entrevistados tanto dos casos como dos controles dizem que o vetor da malária se chama "Aedes, manta branca, dengue, mal de malária" ou simplesmente "zancudo de patas negras ou mosquito". Portanto, a população parece acreditar que somente uma espécie de mosquito transmite várias doenças. Porém não sabem o porque.

No presente estudo, para quem afirma que os lugares de reprodução dos mosquitos é no mato e que o mosquito não é problema para a saúde pública teriam duas vezes mais chance $(\mathrm{OR}=2,3 \mathrm{p}=0,06)$ de adquirir malária.

A análise dos dados descritivos evidencia que os controles têm uma opinião mais acertada da forma como se reproduzem os mosquitos, resultados que de alguma maneira estão mostrando o impacto da campanha de informação para a prevenção da dengue, realizada há pouco tempo e, que coincidiu com a época da coleta de dados do presente estudo. Não obstante, esses resultados não são convincentes, já que não tem níveis aceitáveis desses conhecimentos, mostrando maior desvantagem o grupo de casos, porque apenas $34,4 \%$ destes deram uma resposta considerada correta. O restante informou que "o mosquito se reproduz na água suja, pelo lixo". Alguns dos entrevistados disseram que o que observavam em alguns depósitos com água "era a dengue" ${ }^{\prime 13}$, percepção que inda não é correta, mas pode determinar o descarte de potenciais fontes de reprodução dos vetores.

A esse respeito GUTHMANN et al (2001), na região Grau do Peru, encontrou que $55 \%$ da população sabia onde se reproduzia o mosquito, mas não estabeleceram se

\footnotetext{
${ }^{13}$ Entrevistado de 29 anos de idade, com estudo superior, natural de Chiclayo.
} 
existia associação com o risco em adquirir malária. No presente estudo, quase $90 \%$ de ambos os grupos indicaram que "os mosquitos se criam aonde tem vegetação, umidade, água parada, no mato e sujeira” ou também “ aonde tem charcos de água, vegetação e calor".

Tabela 27. Casos e controles segundo medidas para se proteger da picada do mosquito. Jaén, Cajamarca. Peru. 2004

\begin{tabular}{llllll}
\hline \multirow{2}{*}{ Medidas para se proteger } & \multicolumn{3}{l}{ Casos } & \multicolumn{3}{c}{ Controles } \\
\cline { 2 - 6 } & $\mathbf{N}$ & $\mathbf{\%}$ & $\mathbf{n .}^{\mathbf{0}}$ & $\mathbf{\%}$ \\
\hline \hline Uma medida & 35 & 38,9 & 98 & 54,4 \\
Nada 3 medidas & 23 & 25,6 & 68 & 37,8 \\
\hline \hline Total & 32 & 35,6 & 14 & 7,8 \\
\hline \hline Fonte: questionário utilizado para o estudo. & \multicolumn{3}{c}{ p value $=0,000$}
\end{tabular}

Das medidas praticadas para se proteger das picadas dos mosquitos é indicado basicamente o uso de mosquiteiros. Essa medida é referida por $38,9 \%$ dos casos e $54,4 \%$ dos controles. Em menores proporções informaram que, além disso, utilizam repelentes ou defumam as casas. E 35,6\% dos casos dizem não fazer nada, resposta que também é dada por $7,8 \%$ dos controles. Mas apenas a terceira parte dos entrevistados indicam praticar essas medidas como estratégia para prevenir a malária.

Apesar de que a aplicação de medidas de controle dos vetores tem larga data de uso, os resultados mostram que a população parece não estar percebendo a finalidade e a importância da sua utilização. Fato que alguns lugares também parece ser maior, já que VUNDULE (1996) em um estudo realizado na zona rural de Zimbábue, encontrou que $50 \%$ da população não tem entendido a finalidade do programa de pulverização mantido pelo Estado por quatro décadas, indicando que $25 \%$ acreditam que era para matar as moscas domésticas e $82 \%$ não faziam nada para prevenir a malária. Por outro lado KORAM et al. (1995), em pesquisa realizada em Gâmbia, encontrou que mesmo que o 
conhecimento sobre mosquitos e malária seja aceitável, nem sempre se vê refletido nas medidas adotadas. KROEGER et al. (1995b) citam que a efetividade dos mosquiteiros impregnados com piretróides é elevada quando a população participa, ainda que a incidência de casos severos seja elevada. No presente estudo é pouco fatível se consideramos que as condições econômicas não permitem acessar esses produtos.

Por tanto estes resultados mostram que, estatisticamente quem não faz nada para se proteger da picada do mosquito, tem 6 vezes $(\mathrm{OR}=6,2 \mathrm{p}=0,01)$, mais possibilidades, de adquirir malária que aqueles que se protegem.

Nesta direção, NAWAZ et al. (2001) dizem que apesar de $98 \%$ da população de alguns lugares da Amazônia peruana utilizam mosquiteiros, a terceira parte não acredita que os mosquitos ocasionam malária. No entanto MENDEZ et al., (2000) num estudo feito na Colômbia encontrou que houve associação entre uso de mosqueteiros e incidência de malária quando comparada com os que não usam. Porem LANSANG et al. (1997), em um estudo em Filipinas, não encontraram risco significativo entre uso de mosquiteiros e a incidência de malária.

Esses impactos estão condicionados aos custos desses materiais. Segundo GOODMAN (2001) os mosquiteiros tratados com inseticidas são significativamente mais eficazes que as pulverizações intradomiciliares com inseticidas residuais para evitar a malária, porém são caros. Mas GUTHMANN et al. (2001) encontraram que a fumigação intradomiciliar, seis meses antes do provável aumento de casos de malária, têm associação com a redução da incidência desta doença.

Falar com a população das medidas de prevenção para evitar a malária pode ser muito importante, uma vez que no presente estudo quando foram realizadas as entrevistas, constatou-se que quem usava mosquiteiros eram somente alguns membros da família ou aqueles que estão ou que adoeceram com malaria ou dengue. Os entrevistados se referiram ao mosquiteiro como "é muito incômodo o seu uso, porque 
sentem mais calor e não podem dormir". Além disso, deve-se levar em conta que algumas destas famílias têm condições de vida precária, sendo que muitas vezes uma cama é compartilhada por três ou quatro pessoas.,

Situação similar foi encontrada por ARATA et al, (1999), no estudo realizado também na Amazônia peruana. Outros estudos como de AIKINS, (1994), mostraram que a população usava o mosquiteiro para se proteger contra o incômodo causado pelos mosquitos e manter a privacidade, mas não para prevenir a malária. DANIS-LOZANO et al. (1999), em estudos no sul do México, determinaram que o risco de infectar-se com malária é 4 vezes maior quando se usa os mosquiteiros em pobres condições, especialmente quando se trata de mulheres e crianças.

Vale ressaltar que, os mosquiteiros vendidos nesta zona são de má qualidade (oferecendo assim uma barreira inferior contra os mosquitos transmissores de malária), sendo que poucos são tratados com inseticida, condição que poderia duplicar a efetividade de um mosquiteiro para prevenir a malária (RUBIO-PALIS \& GUERRA, 2003).

Esta efetividade é desconhecida pela população. Nas entrevistas realizadas, percebeu-se que, são poucos os que têm informação da existência de mosquiteiros tratados e a finalidade destes. Ao final o que determina o acesso a estes e seu uso é o poder aquisitivo das pessoas. A esse respeito, ZIMMERMAN \& VOORHAM (1997) concluem que o uso destes implementos está condicionado pela conduta dos usuários, pelo comportamento dos mosquitos e dos fatores ambientais e GUPTA \& RUTLEDGE (1994) afirmam que o objetivo básico do uso do mosquiteiro é prevenir o contato entre homem-mosquito e diminuir o incômodo que este produz.

Alguns países como o México, têm propostas para controlar a malária, porém o custo aproximado é de 40 milhões e aplicados por, no mínimo, seis anos continuados para alcançar os objetivos (OPS, 2004). Essas condições são insustentáveis para os 
países que possuem outros problemas de saúde que são também prioritários. Para esta organização a utilização de técnicas de estratificação baseadas em parâmetros epidemiológicos e entomológicos pode permitir assegurar as prioridades e selecionar a combinação de métodos de controle da transmissão adequados para cada foco de transmissão da malária (OPS, 2003).

Nas normas de controle entomológico, no Peru, estão previstas medidas de controle de múltipla natureza, resumidas em substâncias e elementos químicos, biológicos e de ordenamento do meio, em conformidade com o chamado Controle Integrado de Pragas (MIP) (NATAL, 2000; ROSE, 2001). Na prática, o uso de substâncias químicas se mantém como estratégia prioritária, em especial no combate aos vetores que transmitem malária.

Em outros lugares, essas experiências deram resultados favoráveis por um curto período de tempo, observando-se que a eficiência destes produtos vai depender da variação na densidade de mosquitos (KHAN et al., 1975; ALONSO et al, 1991; BARNARD et al. 1998; YAP et al, 2000; FRANCES et al, 2001). Como desvantagem aparece o custo que representa para a população em adquirir estes materiais e produtos (SANTOS, 1997).

Alguns investigadores como ZAIM et al, (2000), ressaltam as vantagens dos piretróides pelo nível de segurança e facilidade com que são metabolizados, quando são usados em baixas concentrações. Afirmações que tem desencadeado polemicas, já que, outros especialistas indicam que estes podem produzir disfunções endócrinas e conseqüências gênicas pela exposição crônica a estas substâncias, razões que ainda não têm sido determinadas (MATTESON, 1999). Sobretudo, considerando que os estudos sobre estas substâncias revelam que o principal lugar aonde se guarda os produtos pesticidas é a cozinha. Situação encontrada por BASS et al, (2001) em Douglas (Arizona) ,em 1999, circulavam 198 produtos pesticidas, em média 1,4 por lar, sendo que $70 \%$ desses são guardados na cozinha ao alcance das crianças. 
Por outro lado, nesta zona, os agricultores e alguns órgãos públicos continuam usando o DDT, cuja conveniência de uso ainda é amplamente discutido e que foi usada intensamente com fins de saúde pública, assim, tendo-se usado em grandes quantidades na campanha do controle do vetor na década do $60^{\prime}$, sendo suspensa em muitos países. Fato que segundo alguns críticos pode ter sido determinado por pressões políticas para facilitar a venda de outros produtos químicos (CUETO, 1997).

De fato, um dos aspectos críticos do setor é o controle vetorial, faltando estabelecer um sistema de vigilância que inclua a suscetibilidade dos vetores aos inseticidas. A Região San Martin (Peru) tem experiências de estudos relacionados com a ação de peixes larvívoros autóctones como a Poecilia reticulata («guppy»), a qual pode ser considerada como proposta, dentro do controle vetorial integrado e seletivo de acordo com a geografia e padrões de transmissão de determinadas áreas como a região Amazônica. Assim também o uso de Bacillus thuringiensis israelensis (Bti), é colocado como estratégia eficaz para o controle de larvas de anofelinos (KROEGER et al., 1995 a). Esses microrganismos podem ser cultivados em cocos inteiros, chamados de Bti-côco (REYES, s.d).

As respostas obtidas em relação à hora que os mosquitos picam mais mostram que nem sempre basta dar recomendações, já que a população também tem sua própria versão do problema, especialmente quando as medidas a aplicar vão produzir mais incômodo, como ter que fechar as janelas para evitar que os mosquitos ingressem dentro da moradia em dias em que as temperaturas são muito elevadas.

Além disso, deve ser considerado que o comportamento dos mosquitos não é padronizado, já que em alguns lugares como o município de Anajás, Estado do Pará, SANTOS (2005) encontrou uma atividade maior dos anofelinos entre 21 e 24 horas e não nas horas do crepúsculo, como foi registrado em outras áreas pelas informações entomológicas. 
Tabela 28. Casos e controles segundo se o mosquito é problema para a saúde. Jaén, Cajamarca. Peru. 2004

\begin{tabular}{|c|c|c|c|c|}
\hline \multirow{2}{*}{ Porque é problema } & \multicolumn{2}{|c|}{ Casos } & \multicolumn{2}{|c|}{ Controles } \\
\hline & $\bar{n} .^{\circ}$ & $\%$ & n. $^{0}$ & $\%$ \\
\hline Porque transmite doenças & 60 & 67,0 & 106 & 58,9 \\
\hline Não é problema & 30 & 33,0 & 74 & 41,1 \\
\hline Total & 90 & 100,0 & 180 & 100,0 \\
\hline
\end{tabular}

A percepção do mosquito como elemento problema para a saúde pública em $67 \%$ dos casos e $58,9 \%$ dos controles está traduzida em que "transmitem doenças como a dengue" ou "produzem dano" ou como outros dizem "estragam o sangue". Os restantes de ambos os grupos dizem que não é problema, porém para outros "é uma moléstia, porque não deixam dormir". Quando foi percorrida a zona de estudo, constatou-se que as crianças e a população de algumas localidades como Namballe, Chontalí e outras, sabiam diferenciar a picada da "manta branca" com o "zancudo", porém ignoravam o seu papel como vetores de doenças.

Para os habitantes "o zancudo da chácara não dá paludismo, o zancudo da casa é mais sanguinário". Estas expressões se escutam especialmente nos que trabalham na agricultura ou freqüentam outros espaços, e que têm um significado a partir da vivência dos moradores, identificando ou descrevendo o vetor como elemento vivo agressivo que tira a tranqüilidade do seu dia a dia.

Em cada lugar existe uma versão diferente. Assim, por exemplo, NIETO et al., (1999) encontrou em uma área urbana da costa do Pacífico na Colômbia, que a população entendia o papel do mosquito como transmissor da malária, porém afirmavam que este se infectava quando bebia água contaminada. Neste lugar a automedicação é também um problema muito comum. 
Segundo ARAMBURU (1999), o problema em relação a estes vetores basicamente se dá pela hematofagia da fêmea e como a principal fonte é o homem, este geralmente entra em contato com o mosquito pelas características de sua dinâmica de vida, situação que se agrava quando esses vetores apresentam mudanças em seus hábitos alimentares, como no caso do An. darlingi, principal vetor da malária por $P$. falciparum na Amazônia, o qual desenvolveu exofilia e endofagia.

Tabela 29. Casos e controles segundo o que faz em caso de febre. Jaén, Cajamarca. Peru. 2004

\begin{tabular}{|c|c|c|c|c|}
\hline \multirow{2}{*}{ O QUE FAZ } & \multicolumn{2}{|c|}{ Casos } & \multicolumn{2}{|c|}{ Controles } \\
\hline & n. ${ }^{\circ}$ & $\%$ & n. $^{\circ}$ & $\%$ \\
\hline Da tratamento medicamentoso & 47 & 52,2 & 91 & 50,6 \\
\hline Vai ao posto ou hospital e da comprimidos & 9 & 10,0 & 43 & 23,9 \\
\hline $\begin{array}{l}\text { Da comprimidos e tratamento com medicina } \\
\text { tradicional }\end{array}$ & 32 & 35,6 & 39 & 21,7 \\
\hline Nada & 2 & 2,2 & 7 & 3,9 \\
\hline Total & 90 & 100,0 & 180 & 100,0 \\
\hline
\end{tabular}

Esta pergunta é de suma importância, já que a partir dessa informação se pode deduzir e comparar o atuar e a decisão da população de acessar aos serviços de saúde para uma atenção oportuna, automedicar-se ou praticar a medicina tradicional. Para o estudo $52,2 \%$ dos casos e 50,6\% dos controles, quando alguém em casa está com febre, se automedica; $35,6 \%$ dos casos e $21,7 \%$ dos controles fazem uso de práticas caseiras para acalmar a febre, como eles o referem "fazem banho com erva santa e aguardente" ou "aplicam compressas de álcool ou compressas de água". Apenas $10 \%$ dos casos e $23,9 \%$ dos controles vão direto aos serviços de saúde.

Ao longo da história da humanidade, no tratamento dos sinais e sintomas da enfermidade que atingem as pessoas, o autocuidado é a forma mais utilizada no âmbito familiar, já que tem sido a fonte de conhecimento das técnicas e/ou remédios existentes 
em cada entorno cultural, transmitidas colectivamente às sucessivas gerações. Aparecendo os "expertos" que acumularam habilidades e técnicas de cura, a quem se procura quando o próprio autocuidado não é suficiente para estabelecer a saúde.

Neste contexto aparece a automedicação, definida como a forma clássica de consumo de medicamentos, ervas, remédios caseiros por iniciativa própria ou pelo conselho de outra pessoa, sem consultar um médico. Medidas aprendidas em um âmbito mais ou menos próximo: a família, os amigos, vizinhos, a reutilização de receitas ou a sugestão de um anúncio.

Autores como PENDER (1985) afirmam que a automedicação está influenciada pelas condições socioculturais do usuário e a publicidade farmacêutica, no entanto que outros, como PINILLOS (1980) diz que os principais fatores que influem na automedicação está no fato de que: os serviços públicos não disponibilizam o acesso a distribuição da medicação, existe concentração de médicos nas grandes cidades, a falta de elementos técnico-científicos atualizados que permitam aos usuários não ceder às pressões sociais e a indústria farmacêutica, problemas estes que atingem grande parte da população peruana.

Tabela 30. Casos segundo tratamento utilizado antes de acessar o serviço de saúde. Jaén, Cajamarca. Peru. 2004

\begin{tabular}{l|l|l}
\hline \hline Medidas adotadas & $\mathrm{N}^{\mathrm{o}}$ & $\%$ \\
\hline \hline Utiliza medicamentos & 66 & 73,3 \\
medicamentos e medidas caseiras & 10 & 11,1 \\
Nada & 14 & 15,6 \\
\hline \hline Total & 90 & 100,0 \\
\hline \hline
\end{tabular}

Fonte: questionário utilizado para o estudo 
Essa pergunta foi dirigida apenas para os casos em estudo, questão que permitiu constatar que os pacientes febris suportam por vários dias a sintomatologia da malária, percebendo que: a pouca informação ou informação distorcida entre a dengue e paludismo, a necessidade de trabalhar e a incompatibilidade de horário de atenção do serviço com o tempo disponível pelo usuário(indicado acima), seriam algumas das razoes aludidas pelos pacientes para não acessar o estabelecimento.

Como já referido, Em muitos casos, quando a mãe trabalha, em caso de febre é administrado um antipirético (paracetamol), protelando a consulta com o estabelecimento de saúde, por muitos dias, sendo um febril que pode atuar como foco de infecção para os restantes. Essa situação se confirma pelo fato de que depois de quatro ou cinco dias que o caso inicia seu tratamento, aparecem os familiares com a sintomatologia que logo se confirma ser malária por meio da gota espessa.

Nos testemunhos emitidos nos grupos focais para os casos e controles, um dos integrantes indicava "temos que madrugar as quatro da manhã para pegar a fila nos ambulatórios do hospital e pegar a história clínica e depois, temos que esperar até às 10 ou 11 horas da manha, ou até que o médico atenda. Ainda que nos vejam morrendo, a eles interessa mais nossa história clínica, porque sem isso não nos atendem. Eles não consideram que temos ainda que atender nossos filhos, fazer as coisas de casa ou ir ao trabalho para ganhar o pão de cada dia" ${ }^{14}$.

Contrariamente a esta situação, o MINSA (2001) refere que na Região de Loreto, o tratamento com medicamentos sintomáticos e remédios caseiros, no caso da malária, se dá, porque a população não reconhece uma infecção palúdica, manejando-a como qualquer processo febril, porque têm, grande influência os padrões culturais locais.

No tempo da coleta dos dados, nos serviços ambulatórios pode-se perceber que alguns dos acompanhantes dos pacientes que esperavam eram também pessoas com, mas

\footnotetext{
${ }^{14}$ Mãe de família de 36 anos. Ao mesmo tempo, seu filho teve malária e seu esposo dengue.
} 
que não tinham interesse de solicitar, sendo que esses poderiam ser potenciais transmissores de doenças desconhecidas pelo serviço de saúde. Uma prova a mais de que muitos casos não são captados mesmo estando dentro do serviço ou porque não acessam o estabelecimento com a certeza de que "necessitam de muito dinheiro para ser atendido", ou seja, a gratuidade do serviço para os febris, não é conhecida pela população, mas também porque na estratégia de procura de casos, apenas se considera os que solicitam a atenção e não os acompanhantes

Essa situação ocorre particularmente em alguns serviços públicos como no caso do Hospital de Apoyo de Jaén (HAPJ), onde os usuários dizem ser maltratados, especialmente nos serviços de emergência. Se o usuário não tiver dinheiro no momento do atendimento, este não é atendido, já que deve submeter-se a três ou quatro exames diagnósticos para descartar malária, dengue, bartonelose ou febre tifóide. Para este último caso, devem cancelar previamente em média U\$3,00, sendo que se não pagar não são feitos os exames laboratoriais, já que a febre tifóide não é sujeita do programa de controle

Neste sentido se constatou que, quando as pessoas têm sintoma de doença febril, o tratamento geralmente se baseia em Paracetamol, o Dolocordralan e o Cloromicetyn. Para os que acessam a farmácia como primeira opção para paliar seus sintomas lhes vendem pastilhas "três pastilhas alaranjadas" e "pastilhas para alergia" (entrevistado de Valillo), medicação comprada sem ter a mínima idéia do nome destes medicamentos, se suspeita que sejam antipiréticos e analgésicos ou antiinflamatória porque a queixa mais freqüente como explicado é a "febre e dor nos ossos".

A endemia de enfermidades febris tem determinado que grande parte da população desta área é convencida que a febre "deve passar tomando paracetamol", condição que estaria mantendo a infecção na zona. Assim que algumas pessoas têm uma lógica de desenlace da enfermidade febril como a malária em uma seqüência de “anemia-hepatite e morte", ou também quem foi afetado pela dengue: "já tive dengue 
que não mata, na próxima vez pegarei a outra dengue mais grave. Com essa morro porque dá muita hemorragia". Estas expressões demonstram que a população vem construindo sua própria concepção em torno do dano que prevalece no momento, se difundindo pelas características particulares de cada um.

Deve ser considerado que as culturas acreditam na simbologia das doenças, no imaginário do censo comum, assim como nas categorias diagnosticas, isto se evidencia nas entrevistas, quando eles mesmos vêm a qualificar as enfermidades da zona como "grave ou não". Ao que parece isto depende das experiências que tenham tido, especialmente com a vivência do quadro de malária por $P$. falciparum, situação que se mostrou com maior claridade no grupo focal. Quando dizem que "a dengue e a bartonelose são mais horríveis e fortes porque debilitam em extremo e a febre é tão alta que parece que vai matar", este temor é maior, já que os falecimentos pela bartonelose são de conhecimento de toda a população.

Por outro lado, os próprios trabalhadores de saúde, parecem que também têm sua própria interpretação das atitudes ou concepções da população e dos pacientes a respeito da malária e outras enfermidades febris. Assim vemos o que um profissional de enfermaria disse: "os moradores já se acostumaram com a doença, porque nos anos anteriores haviam mais casos ficavam preocupados e, como agora são menos e tem mudado o esquema de tratamento e as reações são diferentes, parece que por isso mudou... Para a população o mais importante é a dengue, não falam de malária...para eles a malária não existe. Mostram muita indiferença, porque se melhora rápido, também passa rápido e passa e não passa nada. Mas eles não aceitam, porque dizem que estão sãos. A gente tem medo da dengue, por causa da dengue hemorrágica. Parece que na zona urbana os sintomas da dengue o conhecem de memória. Eles vão para o hospital quando vem a febre e o mal estar não passa com o paracetamol, que se dá durante quatro dias e já está?..e porque sabe que a malária tem cura"15

\footnotetext{
${ }^{15}$ Enfermeira com mais de 20 anos de experiência.
} 
Tabela 31. Casos e controles segundo razões para não receber informação em saúde do pessoal dos serviços. Jaén, Cajamarca. Peru. 2004.

\begin{tabular}{llllll}
\hline \hline \multirow{2}{*}{ Porque não recebeu informação } & \multicolumn{2}{c}{ Casos } & \multicolumn{3}{c}{ Controles } \\
\cline { 2 - 6 } & $\mathbf{n .}^{{ }^{\mathbf{0}}}$ & $\mathbf{\%}$ & $\mathbf{n .}^{\mathbf{0}}$ & $\mathbf{\%}$ \\
\hline \hline Andam ocupados e se molestam por tudo & 37 & 41,1 & 42 & 23,3 \\
Estado de saúde não permitia & 9 & 10,0 & 16 & 8,9 \\
Por que não foi ao serviço ou não tem tempo & 12 & 13,3 & 63 & 35,0 \\
Se preocupam somente em dar tratamento & 11 & 12,2 & 12 & 6,7 \\
Não referem & 6 & 6,7 & 14 & 7,8 \\
Sistema* & 15 & 16,7 & 33 & 18,3 \\
\hline \hline Total & $\mathbf{9 0}$ & $\mathbf{1 0 0 , 0}$ & $\mathbf{1 8 0}$ & $\mathbf{1 0 0 , 0}$ \\
\hline \hline
\end{tabular}

Fonte: questionário utilizado para o estudo

* entrevistados que receberam informação de malária

Os dados da tabela indicam que $41 \%$ dos casos e $23,3 \%$ dos controles dizem que não receberam informação de malária, pelos trabalhadores de saúde, porque eles não tem tempo o se molestam por tudo", no entanto $35 \%$ dos controles dizem que eles não vão com muita freqüência para os serviços.

As oportunidades para oferecer uma informação apropriada aos usuários dos estabelecimentos são perdidas principalmente por carecer de pessoal idôneo especificamente para o relacionado com a educação para a saúde. Nos serviços de saúde do primeiro nível de atenção do MINSA, a atenção aos casos com enfermidade infectocontagiosas de notificação obrigatória, estão agrupadas na Área de Riscos e Danos nos quais o responsável geralmente é um enfermeiro (a) e deve atender ao programa da malária, bartonelose, leishmaniose, peste, raiva, dengue e tuberculose e cumprir com atividades administrativas sobrecarregadas pelas exigências do sistema de informação neste país. Por tanto, o acompanhamento, a visita domiciliária e a informação para a saúde são praticamente nulas. 
KOTLER \& ROBERTO, (1992), indicam que o outro pilar deste processo de medicalização é a "educação sanitária, próprio do modelo preventivo promocional" sob o critério de que a educação vai transformar tudo. Nesse sentido tem-se elevados orçamentos às campanhas e programas para oferecer "educação sanitária. Como é o caso do Programa de Informação, Educação e Comunicação em Saúde (IEC), que em Peru passou a se chamar Área de Promoção em Saúde. No entanto, tem sido demonstrado que muitas dessas campanhas criaram fracassos e desigualdades às que já existiam, uma vez que partem da teoria de apontar a culpa à vítima, o enfermo e a pessoa e, erroneamente se conclui que a pessoa não melhora porque "não tem uma adequada educação sanitária", conclusões que dão ares de superioridade à medicina.

A respeito disso, WON-UN (1998) diz que o que poderia estar faltando é a revisão da relação com os outros que até agora os consideramos pouco autorizados, pouco cultos e repletos de prejuízos ou "sentido comum" e "saberes errados" que nos ajude a compreender e propor com os "leigos", que são os que têm práticas sociais em saúde distintos de modernidade, porém são solidários e inclusivos.

Assim também, HEGGENHOUGEN et al (2003) afirmam que existem quatro razões que determinaram o fracasso da educação em saúde no controle da malária: a) o tipo de população que padece de malária endêmica; b) a doença não está entendida pela população como uma prioridade para ajudar a eliminação da pobreza; c) a complexidade da epidemiologia desta enfermidade e d) métodos de controle não apropriados para a população local.

No entanto, segundo FOUCAULT (1984), “(....) a medida que a saúde é objeto de consumo, enquanto pode ser produzida por um (laboratório, Estado) e consumida por outros (enfermos) se tornou um objeto importante, entrou no mercado". A saúde está a caminho de converter-se em um bom negócio. Um negócio circular, já que melhora a saúde de seus clientes. Nesse caso, o setor sanitário é um espaço para investir, privatizar e enriquecer-se. 
Alem disso, nos programas de Educação para a Saúde aplicada pelos serviços de saúde, se observa certa ambigüidade quanto à possibilidade do cidadão de poder eleger (liberdade), ter capacidade de aceitar, reclamar, modificar, definir normas e crenças conforme os interesses pessoais e planos do momento, já que as mensagens são impositivas e proibitivas. Porém se afirma que um dos objetivos da educação em saúde é alcançar o "empoderamento" da população tal de estilos saudáveis para prevenir o dano.

Nessa direção, LÉFEBRE (2004) cita que “(....) o profissional de saúde também precisaria ser empoderado, na medida em que talvez não esteja devidamente consciente de que hoje (...) o simples fato de que ser profissional de saúde, não dá a este sujeito nenhuma garantia definitiva de que sua mensagem seja entendida ou adotada".

Nas manifestações dos entrevistados deixam entrever essa percepção quando dizem "o doutor me disse o que eu tenho que fazer...” ou também “...eu não digo nada à senhorita porque fica brava...,dirá que sou burra e como não sei ler, não entendo nada do que disse" ${ }^{" 16}$. As mensagens geralmente são dirigidas para evitar o dano, não para experimentar práticas que ajudem a desenvolver capacidades, então quando se oferece informação sobre práticas sanitárias somente escutam frases como "você deve fazer..." ou "você tem que fazer...".

Tabela 32. Casos e controles segundo opinião do atendimento no estabelecimento de saúde. Jaén, Cajamarca. Peru. 2004.

\begin{tabular}{l|l|l}
\hline \multicolumn{1}{c|}{ Atenção } & \multicolumn{2}{c}{ Casos } \\
\cline { 2 - 3 } & $\mathbf{n .}^{\circ}$ & $\%$ \\
\hline \hline $\begin{array}{l}\text { Sim, porque melhorou, ainda que teve reações. } \\
\text { Não, porque não melhorou e teve que comprar outros } \\
\text { medicamentos em outro lugar }\end{array}$ & 63 & 30,0 \\
\hline \hline Total & & 30,0 \\
\hline \hline
\end{tabular}

Fonte: questionário utilizado para o estudo

\footnotetext{
${ }^{16}$ Mãe de família com 40 anos, com uma filha de 10 anos que teve malária.
} 
Segundo a opinião dos entrevistados, $30 \%$ indicaram que não dão boa atenção no serviço, porque "não melhoraram elou tiveram que comprar outros medicamentos". Respostas dadas, maiormente por aquelas que experimentaram os efeitos adversos do tratamento antimalárico e os da própria doença, para tanto os casos recorrem a outras consultas particulares, seja em consultórios médicos ou clínicas ou aos "entendidos", neste caso, o curandeiro da zona onde residem. Este personagem cumpre um papel chave no tratamento das doenças febris, como já comentado anteriormente. Quando foi perguntado se receberam informação sobre malária por parte do pessoal dos serviços de saúde, apenas $18,9 \%$ dos casos e 20,6\% dos controles afirmaram que sim, porém o restante disse que não e algumas das razões estão indicadas nas tabela seguinte:

Tabela 33. Casos e controles segundo parte do corpo que afeta a malária. Jaén, Cajamarca. Peru. 2004.

\begin{tabular}{lcccc}
\hline \multirow{2}{*}{ Parte afetada } & \multicolumn{2}{c}{ Casos } & \multicolumn{2}{c}{ Controles } \\
\cline { 2 - 5 } & $\mathbf{n .}^{\mathbf{0}}$ & $\mathbf{\%}$ & $\mathbf{n .}^{\mathbf{0}}$ & $\mathbf{\%}$ \\
\hline \hline Cabeça ou cérebro & 17 & 18,9 & 57 & 31,7 \\
\hline \hline Todo o corpo & 42 & 46,7 & 51 & 28,3 \\
\hline \hline Fígado e o sangre & 12 & 13,4 & 31 & 17,2 \\
\hline \hline Ossos & 4 & 4,4 & 21 & 11,7 \\
\hline \hline Não sabe & 15 & 16,7 & 20 & 11,1 \\
\hline \hline Total & $\mathbf{9 0}$ & $\mathbf{1 0 0 , 0}$ & $\mathbf{1 8 0}$ & $\mathbf{1 0 0 , 0}$ \\
\hline \hline Fonte: questionário utilizado para o estudo & p-Value $=0,006$ \\
\hline
\end{tabular}

Mais da metade dos casos e dos controles $(65,6 \%$ e $60 \%)$, indicam que a parte afetada de quem tem malária é "a cabeça, o cérebro, os ossos e todo o corpo", explicação própria, já que é onde mais se manifesta a sintomatologia, sendo que o restante assegura que a parte afetada "é o sangue, fígado e os ossos". Para aqueles que manifestam que a parte afetada é o sangue ou o fígado, provavelmente o relacionam com a anemia como conseqüência da doença ou receberam informação sobre estes aspectos. 
Esta doença nesta região, não apresenta padrões característicos ou de tercã. Nos casos do estudo. Esses referem que as crises febris se produzem todos os dias. Estas características clínicas foram confirmadas por MENDOCILLA \& VILLAR (2001) que indicam que a febre por $P$. falciparum não tem padrões característicos, e esta pode ter ou não também calafrios, cefaléia, anorexia, lombalgias, náuseas e vômitos. De acordo com as fichas epidemiológicas revisadas, $14,4 \%$ dos casos estudados apresentaram icterícia além da sintomatologia típica.

Tabela 34. Casos e controles segundo a quem atacam mais a malária. Jaén, Cajamarca. Peru. 2004.

\begin{tabular}{lcccc}
\hline \multirow{2}{*}{ Ataca mais } & \multicolumn{2}{c}{ Casos } & \multicolumn{2}{c}{ Controles } \\
\cline { 2 - 6 } & $\mathbf{n .}^{\mathbf{0}}$ & $\mathbf{\%}$ & $\mathbf{n .}^{\mathbf{0}}$ & $\mathbf{\%}$ \\
\hline \hline Crianças, jovens e adultos & 12 & 13,3 & 65 & 36,1 \\
\hline \hline Todos & 71 & 78,9 & 93 & 51,7 \\
\hline \hline Aos que não se cuidam & 2 & 2,2 & 2 & 1,1 \\
\hline \hline Adultos & --- & --- & 13 & 7,2 \\
\hline \hline Não sabem & 5 & 5,6 & 7 & 3,9 \\
\hline \hline Total & $\mathbf{9 0}$ & $\mathbf{1 0 0 , 0}$ & $\mathbf{1 8 0}$ & $\mathbf{1 0 0 , 0}$ \\
\hline \hline Fonte: questionário utilizado para o estudo & & p-Value $=0,000$ \\
\hline
\end{tabular}

A tabela mostra que segundo $78,9 \%$ dos casos e $51,7 \%$ dos controles, todos poderiam ser afetados pela malária. No entanto, $13,3 \%$ dos primeiros e $36,1 \%$ dos segundos consideram que são as crianças, os adultos e os jovens os mais atingidos pela malária”.

O drama vivido pelas pessoas que afetadas pela malária passa despercebido por quem não vivenciou antes esta experiência. Foi observado que famílias completas adoeceram com a malária, quase na mesma época ou também teve quadro febril de 
malária e febre tifóide ou malária e dengue, simultaneamente, como constatado nos registros de hospitalização do HGJ.

Nos grupos focais, as mulheres contaram que "em minha casa caiu primeiro meu filho maior, depois meu esposo, depois meus outros dois filhos. Eu não sabia o que fazer, me desesperava...quando meu filho maior volteava os olhos e ardia com febre, parecia que ia morrer. Isso é desesperante. Fiquei de um lado para outro no hospital. Foi horrivel, senhorita".A maioria dos entrevistados, tanto os casos quanto os controles, já manifestaram um quadro de febre tifóide, doença febril que encobre os quadros clínicos de malária, dengue ou bartonelose.

As entrevistas realizadas aos casos permitiram perceber a forma como a malária desestabilizou a situação emocional de todos os membros da família dos casos. O significado desta doença é de caráter fundamentalmente psicoeconômico. Assim vemos que $60 \%$ dos casos indicaram que o custo do tratamento da malaria foi de aproximadamente de dois até 300 "nuevos soles", aproximadamente 100 dólares, gasto realizado em grande parte nos passagens para se deslocar aos serviços de saúde e na compra de medicamentos complementares ao tratamento antimalárico, os mesmos que são procurados pelos pacientes em razão principalmente dos efeitos adversos dos medicamentos.

Como indicado anteriormente, muitos casos tiveram um processo prolongado, situação que determinou maior gasto e, que não se justificaria para o tratamento com malária.

Estas circunstâncias determinaram que o paciente volte para sua casa e tenha que procurar a outros meios para "melhorar" seu estado, mantendo-se como fonte de infecção permanente no lugar onde residem. Essas considerações geralmente não são tomadas em consideração nas avaliações dos serviços e não se faz pesquisa. Situações que explicam porque a malária continua incidente em determinados lugares, apesar dos 
esforços dos serviços de saúde. BONILLA et al. (1991) dizem que a malária acarreta efeitos negativos em todos os lugares onde algum ou alguns de seus membros padecem da doença $[\ldots .$.$] tanto o tempo de trabalho como os recursos monetários do indivíduo e o$ lugar são afetados quando a doença se apresenta.

Tabela 35. Casos e controles segundo remédios caseiros usados para tratar malária. Jaén, Cajamarca. Peru. 2004.

\begin{tabular}{llllll}
\hline Remédios usados & \multicolumn{2}{l}{ Casos } & \multicolumn{2}{l}{ Controles $^{\text {p-value }}$} \\
\hline \hline Remédios em casa & $\mathbf{n .}^{\mathbf{0}}$ & $\mathbf{\%}$ & $\mathbf{n .}^{\circ}$ & $\%$ & 0,000 \\
\hline \hline Poções & 2 & 2,2 & 9 & 5,0 \\
Emolientes & 5 & 5,6 & 43 & 23,9 \\
Outras ervas & 1 & 1,1 & 9 & 5,0 \\
Não tiveram experiência & $\mathbf{8 2}$ & 91,1 & 119 & 66,1 \\
\hline \hline Total & $\mathbf{9 0}$ & $\mathbf{1 0 0 , 0}$ & $\mathbf{1 8 0}$ & $\mathbf{1 0 0 , 0}$ \\
\hline \hline Preparados do curandeiro & & & & \\
\hline \hline Amargos servidos com cachaça & 3 & 3,3 & 7 & 3,9 \\
Preparados com ervas & 2 & 2,2 & 15 & 8,4 \\
Não sabem & 85 & 94,4 & 158 & 87,8 \\
\hline \hline Total & $\mathbf{9 0}$ & $\mathbf{1 0 0 , 0}$ & $\mathbf{1 8 0}$ & $\mathbf{1 0 0 , 0}$ \\
\hline \hline
\end{tabular}

Fonte: questionário utilizado para o estudo

No presente estudo, para 16,7\% dos casos e 33,9\% dos controles, "é possível curar a malária utilizando remédios caseiros, com base em emolientes preparados com ervas amargas" que são administradas nos enfermos. Além disso, para 7,8\% dos casos e $17,2 \%$ dos controles "o curandeiro pode ajudar a curar a malária".

Muitos dos casos com diagnóstico confirmado de malária são atendidos pelos chamados "curandeiros" que preparam poções para tratar a doença. A entrevista em profundidade permite esclarecer a situação, já que muitos deles negam procurar estes personagens, atitudes adotadas especialmente quando quem pergunta é um trabalhador dos serviços de saúde, determinando que os indivíduos negam esta condição. 
O conteúdo dos preparados à base de ervas amargas, especialmente a "cascarilla" que contém quinina, é macerado com aguardente, no qual se agrega comprimidos probabelmente antibióticos. Nas histórias de muitos casos de malária os atores que participam no processo de tratamento e recuperação do paciente, além da família e o pessoal de saúde, são os curandeiros que "vão tratar a recuperação" desse. Esse paciente vão na procura para acalmar os efeitos adversos dos medicamentos antimaláricos, para"melhorar o fígado que é afetado pela medicina". Esses preparados têm um custo superior ao próprio tratamento convencional.

As plantas usadas para "tratamento da malária" segundo a referência dos entrevistados e a pesquisa de exemplares no mercado da sub-região de Jaén são: Chuqizaga weberbaneri tovar - Asteraceae (Amaro); Gentianellachamuchui (reimers) fabris - Gentianaceae (amargón); Verbena sp. -vebenaceae (berbena); Picrosia longifolea D. Don - Asteraceae (achicoria). Cinchona sp ? -Rubiceae (cinchona); Schkuria pinnata (lamasek) kunze - Asteraceae (cancha al água); Laderbergia sp ?Rubiaceae (azarcito); Artemisia - absintium L. - Asteraceae (ajenjo); Hirtella subglandulifesa pilgues? - Rosaceae (chuchuguasa -) ${ }^{17}$.

Outras ervas cujos nomes folclóricos são: erva santa, rosas brancas, anispuero, palo huaco, palo amarillo, flores de azar, berros, corteza de guayaba, palta(abacate), chicoria, la hoja de tumbo, flor de overo, sangurache, lancetilla que são mixturados com pastilhas de aralén ou fansidar. Muitos preparados são usados como enemas. Assim também os moradores têm para controlar os vetores, assim, por exemplo: o preparado a base de "monte hediondo, saumario, marco, ruda y chancua".

Nestes últimos tempos, os cientistas têm aumentado o interese de resgatar plantas nativas, usadas pela população como repelentes ou para o no tratamento da malária,

\footnotetext{
${ }^{17}$ Estudo das plantas realizado pelo Doutor Isidoro Sánchez Vega. Docente Investigador da Universidade Nacional de Cajamarca. Perú
} 
para seu estudo, como no caso das experiências em Nairobi e a Universidade de Ovagadougou Center of Recherche in Sciencies Biologiquer Alimentaires et Nutritionnelles (SEYOUM et. al., 2002; KAROU et al., 2003).

Tabela 36. Casos e controles segundo costuma descansar perto da vegetação ou de água parada. Jaén, Cajamarca. Peru. 2004.

\begin{tabular}{lcccc}
\hline \hline \multirow{2}{*}{ Descansa ao redor da vegetação } & \multicolumn{3}{c}{ Casos } & \multicolumn{2}{c}{ Controles } \\
\cline { 2 - 6 } & $\mathbf{n .}^{\mathbf{0}}$ & $\mathbf{\%}$ & $\mathbf{n .}^{\mathbf{0}}$ & $\mathbf{\%}$ \\
\hline \hline Sim & 35 & 38,9 & 57 & 31,7 \\
Não & 32 & 35,6 & 111 & 61,7 \\
Às vezes & 23 & 25,6 & 12 & 6,7 \\
\hline \hline Total & $\mathbf{9 0}$ & $\mathbf{1 0 0 , 0}$ & $\mathbf{1 8 0}$ & $\mathbf{1 0 0 , 0}$ \\
\hline \hline Fonte: questionário utilizado para o estudo & \multicolumn{3}{c}{ p-Value $=0,000$}
\end{tabular}

Para quem freqüenta criadouros potenciais de mosquitos, se expõe às picadas tem probabilidade de ser infectado com enfermidades endêmicas, como as mencionadas anteriormente. Em média $35 \%$ dos casos e controles dizem que se acostumaram a descansar onde tem vegetação, a chamada "maleza", sendo que $35,6 \%$ dos casos e $61,7 \%$ dos controles indicam que às vezes.

Esta experiência é freqüente nas pessoas que trabalham em agricultura e descansam para consumir seus alimentos, contudo o horário de almoço não é o de atividade das fêmeas do vetor. Porem, se observa com muita freqüência reuniões de jovens que praticam esportes em zonas desportivas, geralmente no crepúsculo (entre 17 e 19 horas), bem como a presença de torcedores no local. Essa situação não é considerada como antecedente dentro da lógica de transmissão desta enfermidade visto sua importância dentro da epidemiologia da doença.

Segundo OLANO et. al, (1997), as atividades sociais (jogos de crianças) e conversação entre vizinhos fora da casa, neste lugar, provavelmente é o melhor momento para adquirir a doença, visto que tem sido demonstrado que a espécie vetora 
Anopheles albimanus tem uma grande atividade peridomiciliar entre 18 e 20 horas, considerado o um dos principais vetores da malária nesta área. Alguns pesquisadores como LANSANG et al. (1997) em estudo realizado nas Filipinas, dizem que existem várias atividades socioeconômicas que tiveram uma significativa associação com a malária, especialmente as visitas noturnas à floresta.

Neste sentido, INHORN \& BROWN (1990) têm notado que “...os grupos humanos intencionalmente têm facilitado a cadeia de enfermidades contagiosas através de padrões culturalmente codificados de comportamento ou através das mudanças na relação crucial entre os agentes contagiosos, seus hospedeiros humanos e animais e o ambiente no qual o hospedeiro e a interação do agente tomam lugar”.

Tabela 37. Casos e controles segundo tempo de residência na zona. Jaén, Cajamarca. Peru. 2004.

\begin{tabular}{|c|c|c|c|c|}
\hline \multirow{2}{*}{ Tempo em anos } & \multicolumn{2}{|c|}{ Casos } & \multicolumn{2}{|c|}{ Controles } \\
\hline & n. ${ }^{\circ}$ & $\%$ & n. $^{0}$ & $\%$ \\
\hline $1-5$ & 18 & 20,0 & 31 & 17,2 \\
\hline $6-10$ & 32 & 35,6 & 40 & 22,2 \\
\hline $11-15$ & 10 & 11,1 & 31 & 17,2 \\
\hline $16-20$ & 8 & 8,9 & 32 & 17,8 \\
\hline 21 e mais & 22 & 24,4 & 46 & 25,6 \\
\hline TOTAL & 90 & 100,0 & 180 & 100,0 \\
\hline
\end{tabular}

Fonte: questionário utilizado para o estudo $\mathrm{p}=0,002$

Jaén iniciou sua expansão urbana há mais ou menos trinta e cinco anos, sob a Lei 1220 que autoriza a colonização de terras de montanha, dando origem a uma intensa migração, não somente nesta zona, como também em outras da Amazônia. Atualmente, Jaén se converteu em um lugar aonde se concentra a maioria das transações comerciais da zona norte da Região de Cajamarca. Por esta razão, no presente estudo vemos que $55,6 \%$ dos casos e $29,4 \%$ dos controles têm menos de dez anos de residência nesta área geográfica. 
Muitos destes moradores procedem de províncias vizinhas como Cutervo, Santa Cruz, San Ignacio ou de outras regiões. Deve-se levar em conta de que não se trata de uma migração estática, pois muitas famílias se deslocam por diversos motivos a esta cidade, permanecendo por curto período de tempo (dias ou semanas) até retornar ao destino ou dirigir-se para outro lugar, a fim de efetuar suas transações comerciais, porem não existe referência escrita.

Em conseqüência a incidência de malária pode estar sendo mantida pelo fluxo migratório (BOTHELO, 1988). Em vista disso, os objetivos do controle desta enfermidade requerem muita atenção ao movimento populacional (MARTENS \& HALL, 2000).

Tabela 38. Casos e controles segundo histórico de malária. Jaén, Cajamarca. Peru. 2004

\begin{tabular}{|c|c|c|c|c|}
\hline \multirow{2}{*}{ Histórico malária } & \multicolumn{2}{|c|}{ Casos } & \multicolumn{2}{|c|}{ Controles } \\
\hline & $\overline{n .}{ }^{\circ}$ & $\%$ & $\mathrm{n}^{\circ}$ & $\%$ \\
\hline Sim & 22 & 24,4 & 58 & 32,2 \\
\hline Não & 68 & 75,6 & 122 & 67,8 \\
\hline Total & 90 & 100,0 & 180 & 100,0 \\
\hline
\end{tabular}

Fonte: questionário utilizado para o estudo

Os resultados obtidos mostram que $24,4 \%$ dos casos e $32,2 \%$ dos controles manifestam ter sido atingidos pela malária. $\mathrm{O}$ tempo transcorrido entre essa experiência e o momento da entrevista para $54,4 \%$ dos que foram afetados por malária é de seis anos e, como é lógico, indicam que o tratamento recebido foi o indicado no estabelecimento de saúde, isto é, o fansidar e ou a cloroquina.

Afirmar que existem determinados fatores de risco para adquirir malária é uma falácia, considerando a natureza e o emaranhado dos componentes deste processo. Para tanto, 
somente se poderia falar daqueles que mais predominam no meio aonde se faz uma investigação. Nesse caso, se pode perceber que além das condições de vida da população que reside nesta área geográfica considerada endêmica, tem um grande significado os aspectos sócio-políticos e culturais, já detalhados durante as análises da informação, considerando que não somente é questão de responsabilizar a população ou os serviços por si só. O problema central tem a ver com a formas de como estes atores devem assumir estes deveres, tornando uma realidade o exercício pleno de sua cidadania, a verdadeira participação comunitária.

Nesse caso, o problema mais grave é a distância que existe entre o povo e o serviço de saúde e a carência de informação clara e concisa por parte da população, no que corresponde os danos mais predominantes nesta zona, conhecimento que lhes permitiria ter a capacidade de enfrentar e solucionar suas dificuldades de saúde, não como o setor impõe, e sim como a comunidade e cada uma das pessoas procuram melhorar suas condições de vida e saúde. 


\section{CONCLUSÕES}

\subsection{Características epidemiológicas da malária na sub-região de Jaén.}

- A Sub-Região de Jaén é uma zona hipoendêmica, de malária instável com um IPA menor ás médias nacionais, considerada área de baixo e médio risco.

- Entre o 2000 e 2004 a malária atingiu, maiormente os menores de 19 anos. Especialmente estudantes, donas de casa e agricultores, de ambos os sexos.

- A tendência da incidência da doença é descendente e, a malária por P. falciparum, tende a concentrar-se nos distritos de Jaén e Bellavista.

- As densidades parasitárias más freqüentes foram de uma e duas cruzes. Constatou-se uma importante proporção de gametóforos. Predominando os casos autóctones.

- As temperaturas médias e máximas entre o 2000 e 2004 mostram uma associação significativa com a incidência de malária. As precipitações pluviais são irregulares e não tem relação com a incidência da doença.

- Existe associação significativa entre a idade, sexo e a densidade parasitária com a incidência da malária.

\subsection{Condições de vida dos casos e controles.}

- O estudo de caso controle mostrou que a maioria dos casos são estudantes, donas de casa e agricultores com educação básica e secundária.

- A maioria reside na zona periurbana, em casas próprias, de construção incompleta, basicamente de adobe, telhado de calamina, paredes sem revestir e janelas sem proteção, a maior parte tem serviços básicos.

- A carga familiar supera a capacidade de manutenção e de albergue da vivenda, observando-se condiciones de insalubridade. O principal provedor para mais da metade dos lares é o pai de família e em 1/4 dos lares quem desempenha este papel é a mãe. 
- A maioria declara ter uma renda familiar mensal menor de um MV (U\$ 130,00) e são poucos os beneficiários de programas sociais. Quase a terceira parte teriam uma alimentação "balanceada".

\subsection{Representações sociais e medidas aplicadas.}

- A população conhece a malária somente como paludismo, considerada como não perigosa e não prioritária que preocupe porque tem tratamento medicamentoso. O temor está centrado na possibilidade de adquirir dengue ou bartonelose, significado traduzido em: "dengue clássico, dengue hemorrágico e morte".

- Existe confusão de conceitos quanto à malária e seus mecanismos de transmissão. Para alguns o mosquito não é problema para a saúde, para outros representa uma moléstia na conciliação do sono. O tamanho do mosquito está relacionado como o perigo de transmitir malária

- São poucos os que praticam medidas de proteção: uso de mosquiteiros Há um pobre conhecimento dos mecanismos de transmissão da malária

- A febre é a sinal percebido predominante indicativo de doença, não perigoso, cujo tratamento inicial são as medidas caseiras, medicamentos do estoque familiar ou da farmácia, tendo um esquema padronizado: o paracetamol, um antiinflamatório e um antibiótico.

- A farmácia tem presença preponderante paralela ao curandeiro no "tratamento" das enfermidades febris, principalmente a malária. A maioria desconhece a gratuidade do tratamento antimalárico.

- Estatisticamente, não contar com água potável $(\mathrm{OR}=4,16)$, a má disposição de resíduos sólidos $(\mathrm{OR}=2,12)$, não ter luz elétrica $(\mathrm{OR}=3,16)$, ter entre 7 e 11 integrantes na família $(\mathrm{OR}=3,78)$, não ter uma alimentação balanceada $(\mathrm{OR}=3,21)$, não fazer nada para proteger-se da picada do mosquito $(\mathrm{OR}=6,12)$, acreditar que o mosquito se reproduz no monte $(\mathrm{OR}=2,53)$, o mosquito não é problema para a saúde $(\mathrm{OR}=2,53)$, não saber como se transmite esta doença $(\mathrm{OR}=8,26)$, não acreditar que a malária seja perigosa $(\mathrm{OR}=4,66)$, não saber quais 
são os sintomas da doença $(\mathrm{OR}=2,17)$ e não saber qual é o tratamento da doença $(\mathrm{OR}=3,93)$, estariam atuando como fatores de risco para adquirir malária.

\subsection{Descrição crítica do sistema organizacional institucionalizado.}

- Os serviços públicos de saúde mantêm seu rol tradicional, fundamentalmente normativo, distante da forma como a população percebe suas próprias necessidades e/ou problemas.

- Para os trabalhadores de saúde a malária não é prioridade, justificada pela existência de tratamento e rápida recuperação, ofertando uma atenção basicamente assistencial-recuperativo, baseado na atenção da demanda.

- O papel como responsáveis do controle da malária é limitado pelas precárias condições laborais legais, operativas e salariais, na qual se desempenha, primando a exigência do rendimento e a lógica da cobertura alcançado 


\section{REFERÊNCIAS}

Acosta M, Llancari MJ. Trabajos Entomológicos en focos activos residuales de Malaria IIEstudios en el río Yavarí. 1965-1966. Inf. SNEM-MINSA. 1968. P.10;

Ahorlu CK, Dunyo SK, Afari EA, Koram KA e Nkrumah FK. Malaria-related beliefs and behavior in southern Grana: implications for treatment, prevention and control. Trop Med Int Health. 1997. Vol 2 (5): 488-499.

Aikins MK, Pickering $\mathrm{H}$ e Greenwood BM. Attitudes to malaria, traditional practices and bednets (mosquito nets) as vector control measures: a comparative study in five West African countries. Am J Trop Med Hyg, 1994; 97, p: 81-86

Alarcón, VJ. Perú: perfil epidemiológico en un contexto de demanda reprimida de servicios de salud. Bethesda, MD. PHRplus .Abt Associates Inc. 2003.

Alonso P, Lindsay SW, Armstrong JRM, Conteh M, Hill AG, David PH, et al. The effect of insecticide-treated bed nets on mortality of Gambian children. Lancet. 1991; 337, p: 14991502.

Aramburu GJ, Ramal AC, Witzig R. Malaria Reemergence in the Peruvian Amazon Region. Atlanta, Georgia, USA. Center for disease Control and Prevention.1999 Vol 5 (2) .

Arata AA, Ruebush TK, Porter CHH, Stein JD, Lounibos LP e Fernández DM de. Malaria in the Peruvian Amazon: A review of the Epidemiology, Entomology and insecticide resistance of vectors. Washington (DC) .Environmental Health Project. Activity Report. 1999; (60).

Arruda M Souza RC, Veiga ME. Ferreira AF e Zimmerman RH. Prevalence of Plasmodium vivax variants VK247 and $P$. vivax-like human malaria: a retrospective study in indigenous Indian populations of the Amazon region of Brazil. Short report. Trans R Soc Trop Med Hyg. 1998; 92

Asociación de Municipalidades Distritales de la Provincia de Jaén. Construyendo bases para el desarrollo local con participación y gestión democrática. Jaén 2004. 
Ayres CMJR. O enfoque de risco na programação em saúde: fundamentos e perspectivas. Saúde e Sociedade, 1995, 4 (1/2): 71-74.

Barata BR. Malária e seu controle. São Paulo HUCITEC. 1998; p. 101-117

Barnard DR. Posey KH, Smith D, Schreck CE. Mosquito density, biting rate and cage size effects on repellent test. Med Vet Entomol.1998; 12: 39-45

Barrera R, Grillet ME, Rangel Y, Berti J, Aché A. Temporal and spatial patterns of malaria reinfection in northeastern Venezuela. Am J Trop Med Hyg . 1999; 61(5)

Bass JK, Ortega L. Rosales C, Petersen NJ. E Philen RM. What's being used home: a household pesticide survey. Rev. Panam Salud Pública; 2001; 9 (3).

Baume C, Helitzer D e Kachur SP, Patterns of care for childhood malaria in Zambia. Social Science \& Medicine 2000, 51: 1491-1503.

Belisario VY, Saul A, Bustos MDG, Lansang MA, Pasay CJ, Gatton M et. al., Fiel epidemiological studies on malaria in alow endemic area in the Philippines. Acta Trop., $1997,63: 241-156$

Bértoli M e Moitinho MLR. Malária no estado do Paraná, Brasil. Rev Soc Brás Med Trop $2001 ; 34(1)$.

Blair S, Lacharme LL, Fonseca JC e Tobón A . Resistencia de Plamodium falciparum a tres fármacos antimaláricos en Turbo ( Antioquia, Colombia), 1998. Rev. Panam Salud Pública. 2001; 19(1)

Bonilla CE, Kuratomi LS, Rodríguez P, Rodríguez A. Salud y desarrollo, aspectos socioeconómicos de la malaria en Colombia. $1^{\circ}$ ed. Bogotá Colombia. Edi. Colombia. 1991. $262 \mathrm{p}$.

Bothelo C, Barbosa LSG, Silva MD e Meirelles SMP. Fluxo migratório de casos de malária em Cuiabá/MT, 1986 (1). Rev Inst Med Trop São Paulo 1988; 30 (3) 
Branquinho ME. Estudo da transmissão de malária em população ribeirinha do Estado de Amapá, Brasil. Sorología humana y uso de ELISA en anofelinos.Sao Paulo 2001 [Tese Doutorado Faculdade de Saúde Pública Universidade de São Paulo].

Calderón FG, Fernandez R e Valle TJ. Especies de la fauna anofelina, su distribución y algunas consideraciones sobre su abundancia e infectividad en el Perú. Rev. Peruana Epidemiol. 1995; Vol 8 (1):5-23

Camargo ALM, Ferreira UM, Krieger H, Camargo PE de e Silva PL da. Unstable hypoendemic malaria in Rondonia (western Amazon Region. Brazil): epidemic outbreaks and work-associated incidence in agro-industrial rural settlement. Am J. Trop.Med. Hyg 1994 51(1): 16-25.

Camargo ALM, Colletto DDGM, Ferrerira UM, Gurgel MS, Escobar AL, Marques A. et al., Hipoendemicc malaria in Rondonia ( Brazil, western amazon region): seasonal variation and risk grups in an urban locality. Am. J.Trop.Med. Hyg. 1996, 55 (1): 32-38

Celis SJ, Montenegro R, Castillo TO, Che H, Baquerizo NC e Mendoza YM. Evolución de la malaria en la región Loreto. In: Universidad Nacional Mayor de San Marcos. Facultad de Medicina An. Fac. med. Lima 2003.Vol.64 (4).

Centro Internacional para la Investigación del Fenómeno (CIIFEN) modelización de riesgo ecoepidemiológico, para transmisión de malaria, asociada al fenómeno El Niño (ENOS) en provincia de Manabi. Ecuador. 2005:

Contreras-Ochoa C e Ramsey JM. Gametocitos de Plasmodium vivax y Plasmodium falciparum: etapas relegadas en el desarrollo de vacunas. Salud Pública Mex. 2004 Vol.46, (1)

Costa TLCB. Caracterização epidemiológica da malária no Projeto de Colonização Agrícola Pedro Peixoto Gomide. Estado de Acre. Brasil;1994. [Dissertação de Mestrado_ Faculdade de Saúde Pública da USP] 
Cueto M. El regreso de las epidemias: salud y sociedad en el Perú del siglo XX IEP Lima- Perú. 1997.

Cueto, M. The meanings of control and eradication of malaria in the Andes. Instituto de Estudios Peruanos. Lima Perú. Parassitologia. 1998;40:177-182.

Danis-Lozano R, Rodriguez MH, Gonzalez-Ceron L e Hernadez-Avila M. Risk factors for Plasmodium vivax infection in the Lacandon forest, southern Mexico. Epidemiol. Infect. 1999; 122.

Dirección Regional de Salud- Análisis Situacional de Salud. Cajamarca.Peru 2003.

Dirección Sub-Regional de Salud de Jaén. Análisis Situacional de Salud de la Sub-Región de Jaén. Cajamarca. Peru. 2003.

Direção Sub-Regional de Chota. Análise Situacional da Sub-Região de Saúde- ChotaCajamarca- Perú- 2005.

Direção Sub-Regional de Jaén. Fichas de controle da assistência e administração do tratamento da malária dos serviços de saúde. DISA. Jaen- Cajamarca. Peru. 2004.

Ebrahim Gj. Malaria During Pregnancy. J Trop Pediatr. 1996 Vol. 42, (4), pág. 623

Elzubier AG, Ansari EHH, Nour MHEI, Bella H Knowledge and misconceptions about malaria among secondary school students and teachers in Kassala, eastern Sudan. J Roy Soc Health 1997, Vol. 117 (6) 381-5.

Erhart A, Tang ND, Bien TH, Tung NM, Hung NQ, Hung LX et. al., Malaria epidemiology in a rural area of the Mekong Delta: a prospective community-based study. Trop Med Int Health, 2004: vol 9 (10). 1081-1090

Espino F, Manderson L, Scuin C, Domingo F. e Ventura E. Perceptions of malaria in a low area in the Philippines: transmission and prevention of disease. Acta Trop. 1997; (63):221239 
Felger I, Irion A, Steiger SeBeck H.-P. Epidemiology of multiple Plasmodium falciparum infections. Trans R Soc Trop Med Hyg. 1999; 92. Supl 1.

Ferreira AW \& Ávila LMS, Diagnóstico laboratorial das principais doenças infecciosas e autoimunes: Malaria ABDR. São Paulo. 1996

Filho MMR, Estudo epidemiológico da malária urbana de Porto Velho- Rondônia, no periodo de Julho 1992- Junho 1997. Rondônia 1999 [Tesis Mestrado. Faculdade de Saúde Pública da USP]

Forattini OP. Mosquitos Culicidae como vetores emergentes de infecçoes. Rev Saúde Pública, 1998 32(6): 497-502.

Forattini O. Cudiciología médica. Vol 2. IedUSP. São Paulo, 2002.

Foucault M. Genealogía del racismo. La piqueta. Madrid. 1984. p: 15-32

Frances SP, Cooper RD, Popat S, Beebe NW. Field evaluation of repellents containing deet and AI3-37220 against Anopheles koliensis in Papua New Guinea. J Am Mosq Control Assoc. $2001 ; 17(1): 42-44$.

Franke ED, Lucas CM, San Román A e Wirtz RA. Prevalence of antibody to the variantrepeat of the ciscunsporozoite protein of plasmodium vivax in Peru. Am.J.Trop.Med Hyg, 1992, 46(6) 708-710.

Gallup JL e Sachs JD. The economic burden of malaria. Working Papers . Center International Development at Harvard University. 2000; $\mathrm{N}^{\circ} 52$

Genton BB, Al-yaman F, Beck HP, Mellor SS, Narrara A, Gibson N. The epidemiology of malaria in the Wosera, area East Sepik Province, Papua New Guinea, in preparation for vaccine trials. I. Malariometric indices and immunity. Ann Trop Med Parasitol. 1995. Vol 89, (4): 359- 376. 
Gil LH, Alves FP, Zieler H, Salcedo JM, Durlacher RR, Cunha RP, et. al., Seasonal malaria transmission and variation of anopheline density in two distinct endemic areas in Brazilian Amazonia. J Med Entomol. 2003 40(5):597-606.

González JM, Olano V, Vergara J, Arévalo-Herrera M, Carrasquillas G, Herrera S. e López A . Unstable, low-level transmission of malaria on the Colombian Pacific Coast. Ann Trop Med Parasitol. 1997; Vol $91 \mathrm{~N}^{\circ} 4$.

González TS. El desarrollo humano como espacio de encuentro nacional. Programa de Naciones Unidas para el Desarrollo(PNUD.). Universidad Simón Bolívar. Venezuela 2005.

Goodman CA, Mnzava AE, Dlamini SS, Sharp BL, Mthembu DJ, Gumede JK. Comparison of the cost and cost-effectiveness of insecticide-treated bednets and residual house-spraying in KwaZulu-Natal, South Africa Trop Med.Inte.Health, 2001(4)6:280-295

Greenwood, BM. Impact of culture and environmental changes on epimdemiology and control of malaria and babebiosis: the microepidemiology of malaria and its importance to malaria control. Trans R Soc Trop Med Hyg 1989: vol 83 Supplement, $25-29$

Gunawardena DM, Wickremasinghe AR, Muthuwatta L, Weerasngh S, Rajakaruna J, Senanayaka T, et al. Malaria risk factors in endemic region of Sri Lanka, and the impact and cost implications of risk factor-based interventions. Am. J. Med. Hyg 1998; 58(5):533-542

Gupta. RK e Rutledge LC. Role of repellents in vector control and disease preventing. Am. J.Trop.Med. Hyg 1994. 50 ( suppl) 82-86

Guthmann JP, Hall AJ, Jaffar S, Palacios A, Lines J Llanos-Cuentas A. Environmental risk factors for clinical malaria: a case-control study in the Grau Region of Peru. Trans R Soc Trop Med Hyg 2001; Vol 95.

Guthmann JP, Llanos- Cuentas A, Palacios A e Hall AJ. Environmental factors as determinants of malaria risk. A descriptive study on the northern coast of Peru. Trop Med Int Health. 2002. Vol 7 (6): $518-525$. 
Hamid AS, Ahmed AMR, Mubarak ME e Mahgoub IA: Gender aspects and women's participation $n$ the control and management of malaria in Central Sudan. Soc. Sci.Med.1996 42.(10): 1433-1466.

Hayes J, Calderón G, Falcón R, e Zambrano V. Newly incriminated anopheline vectors of human malaria parasites in Junín Deparment, Perú. J Am Mosq Control Assoc. 1987; 3 (3)

Heggenhougen H K, Hackethal V e Vivek P. The behavioral and social aspects of malaria and its control. Special Programme for Research \& Trainning in Tropical Diseases (TDR) UNDP/World Bank/ WHO. 2003.

Hoffman SL, Wistar R, Ripley W et. Al Immunity to malaria and naturally adquired antibodies to the circunsporozoite protein of plasmodium falciparum. The New England. J Med Hyg, 1986. 315 (10): 601-606

Inhorn MC e Brown PJ. The anthropology of infectius diseases. Annual Review of anthropology. New York 1990.19:89-117

Indacochea A, Avolio B, Bedoya L, Carrillo J, Negrón G, Sánchez L, Santillana M, Cajamarca. un poco de historia: Cajamarca Competitiva. Lima,Perú. Ed Saywa; 1998.

Instituto Nacional de Estadística e Informática. Encuesta Demográfica y de Salud Familiar 2000. Fimart S.A.C.

Instituto Nacional de Estadística e Informática.Encuesta ENDES. Cajamarca. Perú. 2003.

Kagani IG., Evaluation of the indirect hemagglutination test as an epidemiologic technique for malaria.. Am J Trop Med Hyg 1992 Sep;21(5):683-9

Karou D, Dicko MH, Sanon S, Simpore J, Traore AS.Antimalarial activity of Sida acuta Burm. f. (Malvaceae) and Pterocarpus erinaceus Poir. (Fabaceae).Malar J. 2003 Oct $8 ; 2(1): 33$.

Khan AA, Maibach HI, Skidmore DL. Insect repellents: effect of mosquito and repellentsrelated factors of protection time. J Econ Entomol 1975; 68: 43-45 
Kirchatter K, Cimerman S, \& Di Santi SM, Diagnóstico Laboratorial de Malária. News Lab. 21 ed. 1997. Pag.176-178

Knudsen $\mathrm{AB}$ e Sloff $\mathrm{R}$. Vector -borne disease problems in rapid urbanization: news approaches to vector control. Bull World Health Organ. 1992; 70 (1)

Koram KA, Bennett S, Adiamah JH e Greenwood BM. Socio-economic risk factors for malaria in peri-urban area of the Gambia. Trans R Soc Trop Med Hyg 1995; 89

Kroeger A, Horstick O Riedl C, Kaiser A, Becker N. The potential for malaria control with biological larvicide Bacillus thuringiensis israelensis ( Bti) in Peru and Ecuador. Acta Trop. 1995a; 60

Kroeger A, Mancheno M, Alarcón J, Pesse K. Insectcide-impregned bed nets form malaria control: varying experiences from Ecuador, Colombia and Peru concerning acceptability and effectiveness. Am J Trop Med Hyg. 1995b; 53(4)

Kotler Philip, Roberto EL. Naturaleza del papel de las campañas sociales para cambiar la conducta pública: Mercadotecnia social. Editorial Diana . México 1992

Lansang DMA, Belizario VY, Bustos MDG, Saul A y Aguirre A. Risk factors for infection with malaria in a low endemic community Bataan, the Philippines. Acta trópica 1997 . (63) 257-265.

Lefébre F e Lefévre CAM, Saude, empoderamento e triangulaçao. In: Saúde e Sociedade 2004. Vol 13,(2). 32-38.

Lindblade KA, Walker ED, Onapa AW, Katungu J, Wilson ML. Highland malaria in Uganda: prospective analysis of an epidemic associated with El Niño. Trans R Soc Trop Med Hyg 1999; 93: 480-487) 
Magill AJ, García C, Solari L, Ylquimiche L, Vásquez M, Carey C, et al. Therapeutic efficacy of pyrimethamine-sulfadoxine in Peruvian Amazon. Am Soc Trop Med Hyg Meeting, Abstract; Washington D.C. 1999. №329

Mc Gregor J. Malarial immunity: currents trends and prospects. An Trop Med Parasit. 1987. 81 (5) 647-656.

Marquino W, Huilca M, Calampa C, Falconi E, Cabezas C, Naupay R, Ruebush TK II. Efficacy of mefloquine and mefloquine-artesunate combination therapy for the treatment of uncomplicated Plasmodium falciparum malaria in the Amazon Basin of Peru. Am J Trop Med Hyg 2003; 68: (5): 608-12.

Martens P, e Hall L. Malaria on the move: human population movement and malaria transmission. Emerg Infect Dis. Perspectives 2000; Vol 6, (2)

Matteson PC. Food and agriculture organization programme for community integrated pest magnament in Asia, Hanoi, Vietman. Emerg Infect Dis. 1999; Vol. 3 (2).

Mendez F, Carrasquilla G e Muñoz A.Risk factors associated wit malaria infection in an urban setting. Trans R Soc Trop Med Hyg 2000; 94: 367-371

Mendocilla RM \& Villar LA. Epidemiología y farmacoresistencia de malaria por Plamodium falciparum. In: Revista de Salud y Medicamentos Perú. 2002. Año 15 (27).

Ministerio de Salud del Perú. Estado actual del programa de control de malaria en el Perú. Oficina de Planes y Programas. Oficina Sectorial de Planificación Lima: 1983

Ministerio de Salud del Perú. Dirección General de Atención a las Personas, Dirección de Enfermedades Transmisibles. Manual de normas y procedimientos técnicos para ejecutar las actividades antimaláricas en los niveles de atención I y II. Lima: MINSA; 1993

Ministerio de Salud del Perú. Manual de normas del programa de control de malaria. MINSA, Lima - Perú 1996. 
Ministerio de Salud del Perú. Impacto económico de la malaria en el Perú. Serie Vigia № 1. Ed. MINSA. Lima Perú. 1999.

Ministerio de Salud del Perú. Normas del Programas Nacional Malaria. Productores Gráficas Peruanas. Lima. Perú 2000.

Ministerio de Salud del Perú. Factores de riesgo de la malaria grave en el Perú. Lima 2001.

Ministerio de Salud del Perú. Distribución de los principales insectos vectores de enfermedades en el Perú. Doc. Técnico $N^{\circ} 4$. Enfermedades emergentes y re-emergentes. Lima. Perú. 2002.

Ministerio de Salud del Perú. Protocolo de Investigación: Evaluación de la Implementación de Terapias de combinación de Mefloquina-Artesunato y Sulfadoxina/PirimetaminaArtesunato para Infecciones por Plasmodium Falciparum en el Perú, 2003.

Ministerio de Salud de Perú. Enfermedades metaxémicas: estrategia sanitaria nacional de prevención y control de enfermedades Metaxénicas y otras transmitidas por vectores. Dirección General de de Salud de las Personas abril del 2005.

Motta EGFda. Fatores determinantes da situação da malária na Amazônia. Anais do $2^{\circ}$ Simpósio de Malária . Rev. Soc Bras Med Trop 1992; 25 (supl. II).

Njama MD, Kamya MR, e Dorsey. Asymptomatic parasitemia as risk factor for symptomatic malaria in a cohort of Uganda children. Trop Med Inter Health. 2004. vol 9 (8) $862-866$.

Natal D. Manejo Integrado de mosquitos. São Paulo. Faculdade de Saúde Pública da USP. 2000 (apostila)

Nawaz H, Rahman MA, Graham D, Katz DL e Jekel JE. Health risk behaviors and health perceptions in the Peruvian Amazon. Am J Trop Med Hyg. 2001; 65(3) pp.252-256 
Neves PD, Melo L de A, Genaro O e Linardi PM. Parasitología Humana. Atheneu 1998. 151-173

Neyra D, Cabezas C, Trenton K e Ruebush II .El proceso de adecuación y cambio en la política del tratamiento de la malaria por Plasmodium falciparum en el Perú, 1990-2001. Rev.peru.med.exp.salud pública 2003.Vol 20.(3)

Nieto T, Mendez F e Carrasquilla G. Knowledge, beliefs and practices relevant for malaria control in an endemic urban area of the Colombian Pacific. Social Science \& Medicine 1999 .49: 601-609.

Nosten F, van Vugt M, Price R, Luxemburger C, Thway KL, Brockman A, et al. Effects of artesunate-mefloquine combination on incidence of Plasmodium falciparum malaria and mefloquine resistance in western Thailand: a prospective study. Lancet Infect Dis 2000; 356: 297-302.

Olano V, Carrasquilla, G \& Mendez F. Urban malaria transmission in Buenaventura, Colombia: entomological aspects Pan Am Journal of Public Health, 1997 2: 378-385

Organización Mundial de la Salud/Organización Panamericana de la Salud. Comité de expertos de la OMS, en paludismo. Serie de Informes Técnicos. Ginebra 2000. $20^{\circ}$ Informe 892

Organización Mundial de la Salud. Consejo Ejecutivo EB115/10 115 reunión 7 de enero de 2005 Punto 4.11 del orden del día provisional Paludismo.Informe de la Secretaría

Organización Panamericana de la salud. Manual del enfoque de riesgo en la Atención Materno-Infantil. Washington D.C. serie paltex $N^{\circ} 7$ 1986, pag. 1-39

Organización Panamericana de la Salud. Diagnóstico de Malaria. Publicación Científica No 512 Washington, DC. Primera reimpresión 1994.

Organización Panamericana de la Salud/Organización Mundial de la Salud. Informe de la Situación de los Programas Regionales de Malaria en las Américas $43^{\circ}$ Consejo Directivo y $53^{\circ}$. Comité Regional. Washington D.C., EUA 2001. 
Organización Panamericana de la Salud. Situación de los Programas de Malaria en las Américas, 2002a. 2 (1).

Organización Panamericana de la Salud/ Organización Mundial de la Salud. 26 Conferencia Sanitaria Panamericana 54.a Sesión del Comité Regional. Washington, D.C., EU de A. $2002 b$.

Organización Panamericana de la Salud. División de Prevención y Control de Enfermedades. Programa de Enfermedades Transmisibles (HCP/HCT) 2003.

Paredes C, Aspectos sociológicos y económicos del paludismo. El caso de los llanos occidentales venezolanos. In: FERMENTUM. Revista Venezolana de Sociología y Antropología. ULA. Mérida Venezuela. 1993, 1994.Año 3 (8) y Año 4 (9)

Pender, Graig C: Beliefs expect values and volunter work behavior.en Larry $\mathrm{F}$. More $<<$ Motivating Volunteer: How the rewards of unpaid work can meet people's need $>>$ Vancouver Volunteer Centre, Canada 1985.

Pinillos JL, Principios de Psicología. Alianza Universidad Madrid 1980

Preventing Emerging Infectious Disease. A strategy for the 21st Century U.S. Department of Health and human services. Atlanta. Georgia. Emerg Infect Dis 1998.

Quimper M. Malaria en la Región Loreto: Investigación para el Proyecto Integrado de Malaria en la Región Loreto. CARE-Perú, Julio 1998.

Programa Nacional de Apoyo Alimentario (PRONAA). Oficina de Estadística. Jáen. Cajamarca. Peru. 2005.

Rey L, Bases da Parasitologia Médica. $2^{\circ}$ ed. Guanabara/Koogan- Rio de Janeiro. 2002. Malaria: os plamódios humanos. 112-145 
Reyes E, Velez J, Novak P, Guerra H, y Ventosilla Sugerencias para un programa de control biológico de vectores con participación comunitaria. La experiencia del Salitral en control biológico usando Bti-coco. (s.d.)

Roberts DR, Laughlin LL, Hsheih P, Legters LLJ. DDT, global strategies, and a Malaria Control crisis in South America. Center for disease Control and Prevention, Perspectives. 1997; Vol 3 (3).

Rodríguez VT (1997): Del caos al efecto mariposa. En Utopía siglo XXI. Revista de la Facultad de Ciencias Sociales y Humanas de la Universidad de Antioquia. Vol 1, n 11997. Medellín (Colombia) pág 43.

Rodríguez MH, Gonzales-Cerón L, Hernández JE, Nettel JÁ, Villarreal C, Kain KC e Wirtz RA. Different prevalences of Plasmodium vivax phenotypes VK210 and VK247 associated with the distribution of Anopheles albimanus and Anopheles pseudopunctipennis in Mexico. Am.J.Trop.Med.Hyg. 2000; 62 (1) 122-127.

Rogers N, Hall B, Obiero J, Targett G, Sutherland C. A model for sequestration of the transmission stages of Plasmodium falciparum: Adhesion of gametocyte-infected erythrocytes to human bone marrow cells. Infect Immun 2000;68(6):3455-3462

Roper MH, Carrion TRS, Cava GCG, Andersen EM, Aramburú GJS, Calampa C Hightower AW et al., The epidemiology of malaria in an Epidemic area of the Peruvian Amazon. Am. J. Med. Hyg. 2000; 67(2)

Rose RI, Pesticides and public health: integrated Methods of Mosquito management. Emerg Infect Dis. U.S Environmental Protection Agency. Washington, DC,USA. 2001; Vol.7 (1). 17-23.

Rosenberg R, Andre RG, Somcit L, Higly efficient dry season transmission of malaria in Thailand. Trans. R Soc Trop Med Hyg. 1990. 84: 22-28

Rubio-Palis, Y e Zimmerman, RH. Ecoregional classification of malaria vectors in the neotropics. J.Med.Entomol, 1997, 34:499-510 
Rubio-Palis Y \& Guerra LA, Evaluación del poder residual del insecticida deltametrina en telas e mosquiteros. Entomotropica 2003 vol 8(1) 63-68.

Sachs J, Malaney P. The economic and social burden of malaria. Nature 2002; 415.

Sáez, S. Marqués F; Colell R. Educación para la salud. Técnicas de trabajo con grupos reducidos. Pagés Editors, Lleida. 1995

San Sebastián M, Játiva R e Goicolea I. Epidemiology of malaria in the Amazon Basin of Ecuador. Rev Panam Salud Pública. 2000; 7(1).

Santos BJ, Estudo sobre o uso de mosqueteiros impregnados com Deltametrina, numa área endêmica de malaria na Amazônia brasileira. Mina Gerais. 1997 [Tese Doutorado. Medicina Tropical da Faculdade de Medicina Universidade Federal de Mina Gerais1997]

Santos LCR, Sucupira CIM, Lacerda LRN da, Fayal SA da e Póvoa MM. Inquérito entomológico e infectividade durante epidemia de malaria no Municipio de Anajás Estado do Pará. Rev Soc Bras Med Trop. 2005 Vol 38(2) 131-212

Sawaia B.B. Análise psicossocial do processo saúde-doença. Resumo. (copia s. d)

Sen Amartya. Desarrollo y libertad 3ra edición. Ed. Planeta 1998.

Seyoum A, Kabiru EW, Lwande W, Killeen GF, Hassanali A, Knols BG. Repellency of live potted plants against Anopheles gambiae from human baits in semi-field experimental huts. Am J Trop Med Hyg 2002. 67(2):141-4

Smalley ME, Abdalla S, Brown J. The distribution of Plasmodium falciparum in the peripheral blood and bone marrow of Gambian children. Trans R Soc Trop Med Hyg 1981;75(1):103-105.

Small J, Goetz SJ, Hay SI. Climatic suitability for malaria transmission in Africa, 19111995. J Immunol. 2003;171(12):6961-7. 
Sulzer AJ, Adams JL, Cantella RA, Colichon A, Soto J, Bustamante J et al. Malaria antibody and parasitaemia patterns in one non-inmune and one non inmune population in a rnalarious area of northen Peru. An Trop Med Parasit. 1981 Vol. 75. N 4, 375-381.

Souza MCM de O analfabetismo no Brasil: sob enfoque Demográfico. texto para discussao No 639. Instituto de Pesquisa Económica Aplicada (IPEA) 1999

Suárez FG . Diagnóstico de la malaria en áreas rurales de la Amazonia peruana Rev peru med exp salud publica. 2004 21(1),

TELLO Ch M. A los lados del fuego. Comunicación y política.1 ra ed. Lima Peru. 1995

Vundule C e Mharakurwa S. Knowledge, practices and perceptions about malaria in rural communities of Zimbabwe: relevance to malaria control. Bull World Health Organ 1996; $74(1) 55-60$

Waldman EA, Silva LJ e Monteiro CA. Trajetória de Doenças Infecciosas: da Eliminação da poliomielitis à reintrodução da cólera. Informe Epidemiológico do SUS. São Paulo Brasil 1999; 8(3) 5-47.

Weissenbacher M, Salvatella R e Horta M. El desafío de la enfermedades emergentes y reemergentes. Sindicato Médico del Uruguay. Publicaciones. Montevideo,Uruguay.1997.

White NJ. Antimalarial drug resistance and combination chemotherapy Trans R Soc Lond B Biol Sci. 1999 29;:739-49.

Wong-Un JÁ. Control comunitario de las infecciones endémicas: pensando en los haceres sanitarios colectivos de los campesinos de los Andes Peruanos. Cad Saúde Pública, Rio de Janeiro. 1998;14 ( supll .2)

World Health Organization. Malaria. Fact Sheet No 94. 1998 
World Health Organization. Highlights of activities in 1999 and major challenges for the future. Communicable Disease Geneva. 2000a

World Health Organization. Severe falciparum malaria. Trans R Soc Trop Med Hyg. 2000b; 94 (suppl 1)

Wongsrichanalai Ch, Pickard AL, Wornsdorfer WH, Meshnick SR. Epidemiology of drugresistant malaria. Lancet Infect Dis [serial online] 2002; 2: 209-18.

Yap HH, Jahangir K e Zairi J. Field efficacy of four insect repellent products against vector mosquitoes in a tropical environment. J Am Mosq Control Assoc. 2000; 16(3)

Zaim M, Aitio A, e Nakashima N. Safety of pyrethroid-treated mosquito nets. Med Vet Entomol. 2000; 14: 1-5

Zimmerman RH, e Voorham J, Use of insecticide-impregnated mosquito nets and other impregnated materials for malaria control in the Americas. Rev Panam Salud Pública. 1997; 2(1). 


\begin{abstract}
ANEXO 1
QUESTIONÁRIO

“MALARIA E FATORES DE RISCO. SUB-REGIÃo JAÉN. CAJAMARCA. PERU. 2005".
\end{abstract}

\title{
DADOS GERAIS
}

Questionário No......... Ficha de aplicação.

Nome

Direção

Distrito.

Localidade

Ponto de referência.

Família.

Idade.

sexo

Ocupação

instrução.

grau de

Zona de residência

\section{PERCEPÇÃO-CONHECIMENTO DA DOENÇA}

1. Sabe o que é malária ou paludismo?.

2. Por que acredita que se produz esta doença?

3. É uma enfermidade contagiosa? SIM $\square$ NÃO

4. Como se transmite a malária?.

5. Quem a transmite?.

(Se a resposta foi o zancudo)

6. Como se reproduz este zancudo?

7. Aonde o mosquito se cria?

8. Como se chama?.

9. Quais são os sintomas da doença?.

10. Sabe quantas formas de paludismo existem?

11. Quem deve controlar o paludismo?

12. Que se pode fazer para prevenir a malária?

13. Quais medidas pratica para se proteger da picada dos zancudos? 
14. A que hora do dia os zancudos picam mais?

15. Que faz quando um mosquito pica?.

16. Você acredita que os mosquitos são um problema para a saúde?

SIM $\square \quad$ NÃO
que?

17. Que faz quando alguém em casa tem febre?

18. Sabe como tratar do paludismo?

19. Sabe quais medicamentos devem ser dados para curar o paludismo?

20. Quanto tempo deve ser o tratamento?.

21. Que "tratamento" utilizou antes de procurar o estabelecimento de saúde? (somente para os casos).

22. Acredita que foi suficiente a atenção dispensada no estabelecimento de saúde? Somente para os casos) $\square$ SIM $\square \tilde{A} O$

Por que?

23. Que parte do corpo é afetado pelo paludismo

24. Acredita que o paludismo é perigoso?

SIM $\square$ NÃO

Por que?

25. A quem o paludismo afeta mais?

26. Você utiliza remédios caseiros para tratar o paludismo?

SIM NÃO

Quais. Especifique

27. Tem alguma experiência que deu ltado?

29. O curandeiro pode ajudar a curar a malária? SIM NÃO Como.

30. Costuma descansar aonde tem água parada? 
31. O pessoal da saúde forneceu informações sobre paludismo?

Se não recebeu, sabe qual o motivo?

32. Quem lhe deu informação?.

foi entregue folhetos ou outro material educativo? 


\section{GUIA DE OBSERVAÇÃO}

\section{CONDIÇÕES DE VIDA}

Direção.

\section{A moradia é:}

Própria

Alugada

Hipotecada

Outros. Especifique.

2. Se é alugada ou hipotecada, quanto paga?

\section{Moradia (intradomiciliário)}

\subsection{Material:}

Adobe

Tijolo acabado

Tijolo semiconstruido

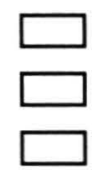

Quincha

Outros

Especificar.

\subsection{Janelas}

Com vidro $\square$

Com malha

Com tela

Outros

Especificar.

\subsection{Paredes Teto}

Revestidas

Não revestidas

Frestas

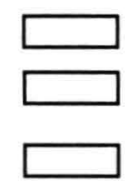

\subsection{Portas}

Com porta

Sem porta

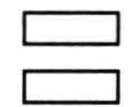

íntegra

Com frestas
Concreto
Folhas
Outras

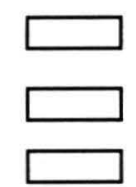

4. Saneamento básico:

\subsection{Abastecimento de água}

Rede

Poço

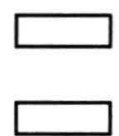

\subsection{Resíduos sólidos}

depósito com tampa

bolsa descoberta 


$\begin{array}{llll}\text { Fonte } & \square & \text { Depósito sem tampa } \\ \text { Rio } & \square & \text { No solo } & \square \\ \text { Outros } & \square & \text { Chácara } & \square\end{array}$

\subsection{Eliminação Excretas}
Inodoro

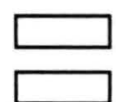
Latrina
Poço cego
Campo aberto

\section{Serviço de luz:}

Elétrica

Lâmpada a querosene

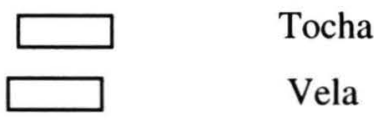

Tocha

Vela

Outros (especificar).

\section{Peridomicílio}

Charcos ao redor da casa

Acequia ao redor da casa

Rio ao redor da casa

Maleza ao redor da casa

Criadouros de mosquitos ao redor da casa

Presença e localização de curral na casa

Outros (especifique).

8. $\mathrm{N}^{\circ}$ de moradores

$\begin{array}{llll}1 & \square-5 & \square \\ 2-3 & 6 \text { e mais } & \square\end{array}$

9. $\mathrm{N}^{\circ}$ de pessoas que habitam a casa

$1-2$

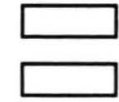

$5-6$

$3-4$

7 e mais

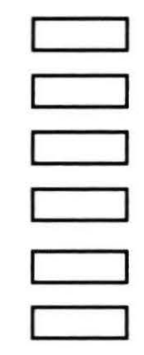

10. $\mathrm{N}^{\circ}$ de dormitórios

11. Composição familiar atual

\begin{tabular}{|l|l|l|l|}
\hline Pessoas com que vive & Idade atual & Sexo & Ocupação \\
\hline & & & \\
\hline & & & \\
\hline & & & \\
\hline & & & \\
\hline & & & \\
\hline & & & \\
\hline
\end{tabular}


12. Quando alguém fica doente em casa procura:

\begin{tabular}{llll} 
MINSA & \multicolumn{1}{r}{} & clínicas \\
ESSALUD & consultório privado \\
OTROS &
\end{tabular}

13. Uso de meios de informação.

14. Quem sustenta a

familia?

15. Renda média familiar

mensal.

16. Outras rendas econômicas (especifique a

origem)

17.

Elétrodomésticos

18. Condições sanitárias da moradia:

\begin{tabular}{|l|l|l|l|}
\hline \multicolumn{1}{|c|}{ Condições } & Bom & Regular & Ruim \\
\hline Higiene & & & \\
\hline Ventilação & & & \\
\hline Iluminação & & & \\
\hline Aglomeração de pessoas & & & \\
\hline
\end{tabular}

19. Beneficiário de programa

local..............qual.

20. Horas que dedica ao trabalho extrafamiliar

21. Dedica algumas horas para descansar durante o dia.? SIM $\square \quad$ NÃO

22. Alimentos que consome

regularmente.

23. Quantas vezes ao dia consome

alimentos?

24. Hábitos:

Consumo de álcool 
Tipo e

freqüencia:

Consumo de tabaco

Tipo e freqüencia:. 


\section{FICHA EPIDEMIOLÓGICA}

Estabelecimento

Nome

\section{HISTÓRICO}

1.1 Viajou nos últimos 30 dias? SIM NÃO

1.2 Ficha 1.3

Lugar.

1.4. Vale .1.5.

Distrito

1.6.

Província.

1.7. Motivo da viagem para a zona aonde se manifestou a enfermedade

1.8. Transfusão de sangue SIM

NÃO

1.9. Ficha. 1.10. Estabelecimento.

1.11. Doador

1.12. Histórico de malária SIM

NÃO

1.13. Faz quanto tempo?

1.14. Tratamento SIM

NÃO

1.15. Quem indicou este tratamento?

1.16. Medicamento

1.17. Automedicação.

1.18. Freqüenta lugares aonde tem zancudos? SIM

NÃO

\section{RESULTADOS DE LABORATÓRIO}
2.1. Tipo de parasito:
P. vivax
P. falciparum

2.2.

Densidade.

2.3. Dias que passaram até receber o tratamento desde que iniciaram os sintomas

2.4. Modalidade do tratamento:

Ambulatório

hospitalizado

\section{CUADRO CLÍNICO}

\subsection{Síntomas:}

Cefaléia

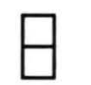

palidez

coriza

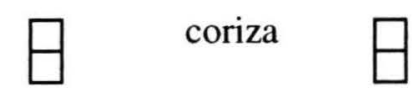


Dores musculares Calafrios Icterícia

3.3. Hospitalização

3.4 Tratamento hepatomegalia esplenomegalia outro

SIM 3.5. Início febre sudorese

3.6 Medicamentos

Doses

3.7. Durante quantos dias recebeu tratamento antimalárico?

3.8. Reações adversas ao tratamento

3.9. Resultado tratamento: curado

3.10. Recaída:

SIM $\square \quad$ NÃO

3.11. Frequiência da febre:

Cada 24 hrs. $\square \quad$ cada 48 hrs. $\square \quad$ Cada 72 hrs.

3.12..Resultado gota espessa

Primeira $\square$ segunda $\square$ terceira $\square$ quarta

3.13. Tipo: Autóctone $\square \quad$ Importado

3.14. Dias da enfermidade.

3.15. Aonde acredita que se contagiou com a doença?

3.16. Quem acredita que lhe contagiou?

3.17. Tempo transcorrido entre o início dos sintomas e a atenção do serviço de saúde:

Para diagnóstico

Para tratamento

3.18. Quem atendeu pela primeira vez quando se iniciaram os sintomas?

3.19. Qual a distancia entre o estabelecimento de saúde e sua casa?.

3.20. Quanto tempo perdeu ou tem perdido para submeter-se ao tratamento da malária?

3.21. Que significou para a família esta doença?

3.22. Quanto gastou em seu tratamento?

3.23. qual sua opinião sobre esta doença? 
3.24. Realizou exame de sangue. quantas vezes.

3.25. Quanto tempo vive nesta zona? 


\section{PERGUNTAS GRUPO FOCAL}

\section{TRABALHADORES DE SAÚDE}

Quais doenças consideram que são mais graves e prioritárias para uma intervenção? Por que?

Na condição de trabalhador de saúde que opinião tem a respeito da malária como problema de saúde pública?

Qual a sensação, os sentimentos que são produzidos quando chega um paciente com malária no setor?

Conhece a vivência e o sentimento que os pacientes com malária apresentam? E qual delas lhe causa maior impacto?

Como os pacientes percebem este problema de saúde?

Quais foram as experiências gratificantes e negativas pessoais e profissionais que teve até agora?

Segundo a sua percepção quais seriam os verdadeiros riscos desta doença na população?

Tem alguma limitação para trabalhar com este problema?

\section{CASOS E CONTROLES DE MALÁRIA}

Quais as doenças mais freqüentes nesta zona?

Qual delas é a mais perigosa?

Porque acredita que lhe dará febre?

Quais destas doenças você tem mais medo?

Como acredita que se contagiou com o paludismo?

Se foi pelo zancudo, qual em especial?

O que se passa dentro do corpo quando o zancudo pica e transmite malária?

O mesmo acontece com a dengue e o paludismo?

Qual a sua opinião sobre o pessoal da saúde?quais os prejuízos que teve na economia com a ocorrência da malária? 
TARJETA DE CONTROL DE ASISTENCIA Y ADMINISTRACION DE TRATAMIENTO

AÑO 200

NN DE ORDEN:

REGION YIO SUBREGION DE SALUD:

DPTO.:

PROV:

EST. DE SALUD:

NOMBRES Y APELLIDOS H. CL:

EDAD: SEXO:

PROCEDENCIA: OCUPACION:

DIAGNOSTICO: vivax $\square$ falciparum $\square$ malaria $\square \underset{\text { probable }}{\text { caso }} \square \quad$ FECHA DIRECCION ACTUAL:

(...... PESO:

ANTECEDENTES:

GOTA GRUESA

AUTOCTONO $\square \quad$ IMPORTADO $\square \quad$ NUEVO $\square$ REINGRESO $\square$

ANTECEDENTES: ..........

FECHA DE INICIO DE TRATAMIENTO

\begin{tabular}{|c|c|c|c|c|c|c|c|c|c|c|c|c|c|c|c|c|c|c|c|c|c|c|}
\hline \multicolumn{2}{|c|}{ DAADE TRATAMIENTO } & $\sqrt{1}$ & $\overline{2}$ & 3 & 475 & $\sqrt{6}$ & $\sqrt{7}$ & \begin{tabular}{l|l}
8 & \\
8
\end{tabular} & \begin{tabular}{l|l|}
9 & 10 \\
\end{tabular} & \begin{tabular}{|l|l|}
11 & 12 \\
\end{tabular} & 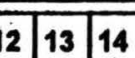 & \begin{tabular}{l|l|}
4 & 15 \\
\end{tabular} & \begin{tabular}{|l|l|}
16 & 17 \\
\end{tabular} & \begin{tabular}{|l|l|}
18 & 19 \\
\end{tabular} & 20121 & \begin{tabular}{|l|l|}
21 & 22 \\
\end{tabular} & \begin{tabular}{|l|l|}
23 & 24 \\
\end{tabular} & \begin{tabular}{|l|l|l|}
4 & 25 & 2
\end{tabular} & \begin{tabular}{|l|l|}
28 & 27 \\
\end{tabular} & 28 & \begin{tabular}{|l|l|}
29 & 3 \\
\end{tabular} & \begin{tabular}{|l|l|l}
0 & rotul Dosis
\end{tabular} \\
\hline FECHA & & & & & & & & & & & & & & & & & & & & & & \\
\hline MED. & DOSIS & & & & & & & & & & & & & & & & & & & & & \\
\hline & & & & & & & & & & & & & & & & & & & & & & \\
\hline & & & & & & & & & & & & & & & & & & & & & & \\
\hline & & & & & & & & & & & & & & & & & & & & & & \\
\hline \begin{tabular}{|l|} 
CONTRR \\
\end{tabular} & G.G. & & & & 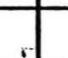 & & & & & & & & & & $\Gamma$ & & & & & & & \\
\hline \begin{tabular}{|l} 
No Regk: \\
do mues
\end{tabular} & & & & & & & & & & & & & & & & & & & & & & \\
\hline
\end{tabular}

CONDICION DEEGRESO: Curado $\square \quad$ Abandono $\square$

Resistente $\square \quad$ Fallecido

Fecha:

RAM:

OBSERVACIONES: 


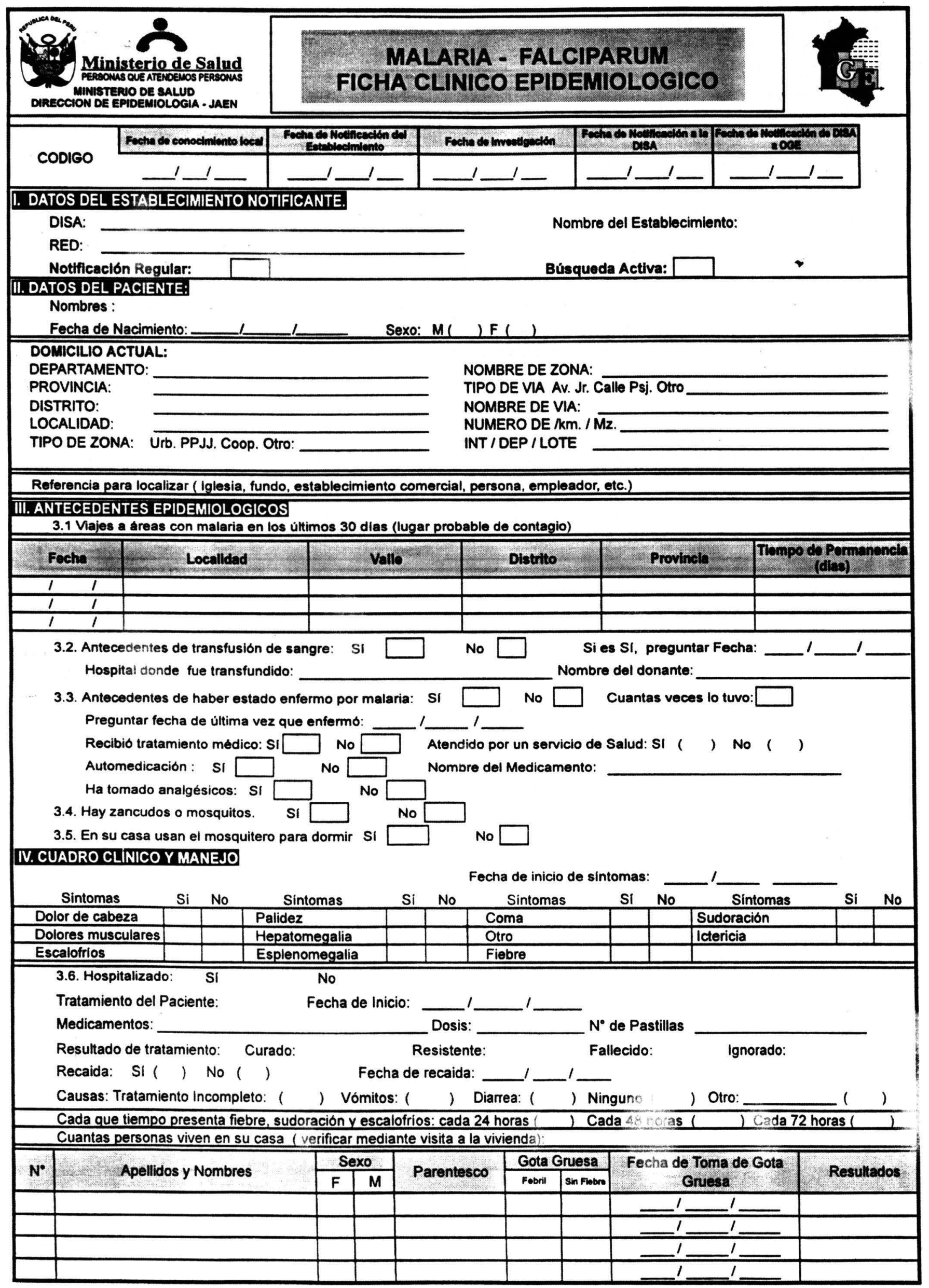


V. LABORATORIO (Para ser llenado por el responeable de diagnostico de laboratorio)

PROCESAMIENTO DE LA MUESTRA

Fecha de Recepción en el Laboratorio Nombre del Laboratorio:

1

\begin{tabular}{|c|c|c|c|c|c|c|}
\hline $\mathbf{N}^{*}$ & Establecimiento de Salud & Muestra & Fecha de Toma & Examen Realizado & Fecha de Examen & Resultado \\
\hline 1 & & Sangre & 1 & \multirow{2}{*}{ Cote Cruese () Frotte () } & & \\
\hline 2 & $\theta$ & & 1 & & 111 & \\
\hline
\end{tabular}

Control Parasitologico posterior al tratamiento:

$$
\text { A los } 7 \text { dias } \square \text { A los } 14 \text { dias }
$$

A los 20 dias

VI. CLASIFICACION FINAL DEL CASO

\begin{tabular}{|c|c|c|c|}
\hline CASO CONFIRMADO & Fecha de Confirmación & Caso Descartado & Fecha de Descarte \\
\hline Caso Conflirmedo: & & & $T$ \\
\hline - Autoctonel I importado ( I & & & 1 \\
\hline Caso confirmado de Malaria complicada & $\bar{I}$ & & $\bar{t}$ \\
\hline Muerte por Maleria & $T$ & & I \\
\hline Frecesso al tretamiento Terapdutico & 7 & & I \\
\hline
\end{tabular}

VII. OBSERVACIONES

Nombre de la persona que investiga el caso:

Cargo:

Firma: 
TEMPERATURA PROMEDIO MENSUAL MAXIMA ${ }^{\circ} \mathrm{C}$, MINIMA ${ }^{\circ} \mathrm{C}$. POR ANOS

ESTACION : CP JAEN

- OFIOINA CE INFORMMCION AGRARIA : JAEN.

\begin{tabular}{|l|l|l|l|}
\hline MESES & EMERO & FEBRERO & MARZO \\
\hline
\end{tabular}
marzo

RESPONZABLE: ING HEFNANDO DUZZ DELGADO MaYo 3010 \begin{tabular}{l|l|l|}
\hline OCTUBRE & MOMELMERE & DICIEMGBRE \\
\hline
\end{tabular}

\begin{tabular}{|c|c|c|c|c|c|c|c|c|c|c|c|c|c|c|c|c|c|c|c|c|c|c|c|c|}
\hline 1996 & 33.0 & 19.8 & 31.5 & 18.3 & 31.3 & 17.7 & 31.7 & 17.0 & 31.7 & 19.3 & 31.5 & 18.5 & 31.5 & 17.9 & 30.8 & 16.0 & 32.7 & 11.8 & 33.1 & 9.1 & 33.7 & 11.5 & 31.7 & \\
\hline 1997 & 33.0 & 16.5 & 30.1 & 16.5 & 32.3 & 16.2 & 32.2 & 17.1 & 30.2 & 25.1 & 31.5 & 159 & 31.7 & 15.3 & 31.9 & 15.0 & 33.8 & 16.5 & 33.9 & 17.4 & 32.2 & 16.9 & 31.4 & 17 \\
\hline 1996 & 31.8 & 19.0 & 32.8 & 22.3 & 32.2 & 22.7 & 32.3 & 22.8 & 31.2 & 21.9 & 31.1 & 21.3 & 32.1 & 20.8 & 33.0 & 20.8 & 33.8 & 20.8 & 33.0 & 21.1 & 33.4 & 20.4 & 34.8 & 20.0 \\
\hline 1999 & 33.4 & 20.9 & 31.9 & 20.1 & 30.4 & 21.0 & 29.5 & 21.0 & 29.3 & 20.5 & 29.7 & 20.6 & 29.1 & 19.6 & 30.7 & 19.4 & 31.6 & 20.9 & 31.5 & 20.4 & 32.5 & 20.7 & 31.3 & 20.4 \\
\hline 2000 & 31.6 & 20.2 & 30.1 & 20.4 & 29.0 & 20.2 & 28.6 & 20.3 & 29.5 & 20.8 & 29.5 & 19.1 & 28.6 & 14.7 & 29.4 & 15.1 & 30.5 & 15.5 & 31.4 & 15.9 & 14.3 & 13.8 & 30.9 & 16.3 \\
\hline 2001 & 29.4 & 15.5 & 28.8 & 15.7 & 30.3 & 15.7 & 31.2 & 16.1 & 30.8 & 16.2 & 30.3 & 15.5 & 30.5 & 15.5 & 31.6 & 14.5 & 32.6 & 14.7 & 33.6 & 16.6 & 33.2 & 21.6 & 33.3 & 22 \\
\hline 2002 & 32.5 & 21.7 & 31.6 & 21.8 & 31.9 & 21.6 & 31.7 & 21.8 & 30.2 & 21.4 & 31 & 20.3 & 30.1 & 20.7 & 32.8 & 21 & 34.2 & 21.2 & 32.8 & 21.6 & 31.3 & 21.5 & 319 & 22 \\
\hline 2003 & 32.3 & 21.3 & 31.3 & 22 & 32.4 & 21.4 & 32.4 & 21.7 & 30.7 & 21.3 & 30.3 & 21.1 & 30.1 & 19.9 & 32.7 & 21 & 339 & 20.9 & 33.6 & 213 & 33.0 & 22.0 & 31.2 & 22 \\
\hline 2004 & 33.3 & 21.2 & 32.3 & 213 & 30.9 & 21.8 & 32.1 & 21.2 & 31.3 & 21.6 & 31.3 & 21.6 & 313 & 21.6 & 31.9 & 20 & 325 & 20.3 & 32.4 & 21.4 & 32.1 & 21.0 & 33.0 & \\
\hline 2005 & 32.9 & 21.0 & 31.8 & 22.0 & 31.7 & 21.8 & & & & & & & & & & & & & & & & & & \\
\hline
\end{tabular}

PRECIPTIACION PLUMIAL.

ESTACION : CP JAEN

SENAMHI

\begin{tabular}{|c|c|c|c|c|c|c|c|c|c|c|c|c|c|}
\hline \multirow{2}{*}{$\begin{array}{l}\text { MESES } \\
\text { ANO }\end{array}$} & \multicolumn{12}{|c|}{ PRECIPITACIONPLUMAL $(\mathrm{m}-\mathrm{m})$ MESES DE ANO } & \multirow{2}{*}{ TOT AL } \\
\hline & ENE & $F E B$ & MAR & $\overline{A B R}$ & MAY. & JUN & JuL. & AGOS & SET. & DCT & OV & DIC & \\
\hline 1996 & 27.4 & 126.4 & 53.1 & 53.5 & $\overline{55.1}$ & 343 & 0.5 & 9.5 & $\overline{27.5}$ & 34.0 & 176 & $\overline{86.7}$ & 525.6 \\
\hline 1997 & 36.0 & 76.6 & $\triangle 4.1$ & 79.7 & 67.6 & 46.6 & 350 & 30.0 & 6.9 & 48 & 72.4 & 20.9 & 562.7 \\
\hline 1998 & 36.6 & 57.6 & 92.6 & 138.7 & 83.5 & 40.8 & 252 & 9.7 & 9.0 & 126 & 73.6 & 2.6 & 696.0 \\
\hline 1999 & 55.8 & 232.4 & 102.9 & 68.4 & 118.8 & 68.5 & 60.3 & 5.9 & 66.0 & 60 & 37.5 & 145.2 & $1,021.3$ \\
\hline 2000 & 66.0 & 120.6 & 150.2 & 89.8 & 58.4 & 84.0 & 96.8 & 21.8 & 59.6 & 23 & 13.8 & 65.4 & 849.0 \\
\hline 2001 & 100.2 & 25.9 & 42.5 & 43.4 & 61.7 & 6.6 & 12.8 & 11.9 & 59.2 & 36 & 84.4 & 73.9 & 558.2 \\
\hline 2002 & 34.0 & 101.9 & 40.6 & 105.5 & 111.7 & 15.8 & 75.1 & 23 & 23.1 & 135 & 77.2 & 40.2 & 762.1 \\
\hline 2003 & 36.7 & 135.6 & 47.7 & 114.3 & 123.3 & 78.0 & 30.1 & 23.1 & 12 & 86 & 44.5 & 64.9 & 796.1 \\
\hline 2004 & 15.3 & 20.7 & 78.8 & 120.6 & 102.7 & 30.1 & 8.4 & 10.9 & 23.5 & 68 & 84.7 & 51.8 & 615.5 \\
\hline 2005 & 25.8 & 119.7 & 152.8 & & & & & & & & & & 298.3 \\
\hline
\end{tabular}

Jaén, 12 de Abril de 2005

OFICINA DE weF ORMacion

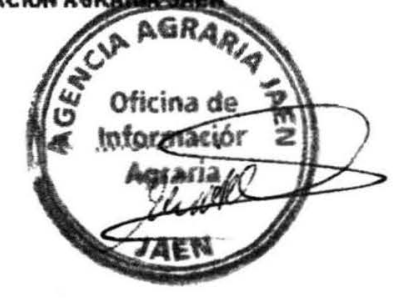




\begin{tabular}{|c|c|c|c|c|c|c|c|c|c|c|c|c|c|c|c|}
\hline \multirow{4}{*}{$\mathrm{N}^{*}$} & \multirow{4}{*}{$\begin{array}{c}\text { PROCEDENCIA } \\
\text { EMPRESA, ASOCIACIONES, COMITES O JUNTAS } \\
\text { DE ADMINISTRACION DE AGUA POTABLE }\end{array}$} & \multirow{4}{*}{ DISTRITO } & \multirow{4}{*}{ PUNTOS DE MUESTREO } & \multirow{4}{*}{$\begin{array}{c}N^{0} \text { de } \\
\text { Viviendas o } \\
\text { total de } \\
\text { Doblación }\end{array}$} & \multirow{2}{*}{\multicolumn{2}{|c|}{$\begin{array}{c}\text { SISTEMA DE } \\
\text { ABNSECIMIENTO } \\
\end{array}$}} & \multirow{2}{*}{\multicolumn{4}{|c|}{$\begin{array}{l}\text { VIGILANCIA Y MONITOREO } \\
\text { MUESTREO DE CLORO RESIDUAL }\end{array}$}} & \multirow{2}{*}{\multicolumn{5}{|c|}{ CALLDAD DEL AGUA DE CONSUMO }} \\
\hline & & & & & & & & & & & & & & & \\
\hline & & & & & \multirow{2}{*}{$\pi / p o$} & \multirow{2}{*}{$\begin{array}{c}\text { Cont- } \\
\text { nuidad } \\
\text { horassidal }\end{array}$} & \multirow{2}{*}{$\begin{array}{l}\text { Fecha } \\
y \\
\text { Hora }\end{array}$} & \multirow{2}{*}{\begin{tabular}{|c|} 
Riesso \\
0.0 .02 \\
\end{tabular}} & \multirow{2}{*}{$\begin{array}{l}\text { Medlo } \\
\text { Rlespo } \\
0.3-0.4\end{array}$} & \multirow{2}{*}{$\frac{\text { Seguro }}{0.5 \mathrm{~A}}$} & \multirow{2}{*}{$\begin{array}{l}\text { Fechay y } \\
\text { Hora do } \\
\text { Analisis }\end{array}$} & \multirow{2}{*}{$\begin{array}{l}\text { Colon. Totales } \\
\text { NMP:100mi }\end{array}$} & \multirow{2}{*}{$\begin{array}{l}\text { Colon. } \\
\text { Temotolerantes i } \\
\text { Fecal ) } \\
\text { NMP1400mi } \\
\end{array}$} & \multirow{2}{*}{ PH } & \multirow{2}{*}{$\begin{array}{l}\text { Turbledad } \\
\text { (UNT) }\end{array}$} \\
\hline & & & & & & & & & & & & & & & \\
\hline \multirow[t]{3}{*}{1} & E.P.S.S & \multirow[t]{2}{*}{ JAEN } & \multirow{2}{*}{$\begin{array}{l}\text { St. BELERVINO LENA ROCHA } \\
\text { CALLLE MARISCAL URETA N* } 1990\end{array}$} & & & & $0103 / 05$ & & & 0.5 & 0103105 & 0 & 0 & \multirow{2}{*}{7.30} & \\
\hline & $\begin{array}{l}\text { MARANON } \\
\text { E.PS.S }\end{array}$ & & & & & & $\frac{11.00 \mathrm{am}}{010305}$ & & & & $\frac{3.10 \mathrm{pm}}{010305}$ & & & & \\
\hline & MARANON & JAEN & CALLE MARISCAL CASTILLA N 355 & & & & $11.10 \mathrm{am}$ & & & 0.5 & $3.20 \mathrm{pm}$ & 0 & 0 & 7.30 & \\
\hline 2 & $\begin{array}{l}\text { ASOC. DE USUARIOS DE AGUA Y ALCANT. } \\
\text { PUEBLO NUEVO }\end{array}$ & JAEN & $\begin{array}{l}\text { LOCAL DE LA ASOCIACIÓN DE AGUA PUEBLO NUEVO } \\
\text { CALLE ORELLANA Ne" } 728\end{array}$ & & & & $\frac{0103 / 05}{1120 \mathrm{am}}$ & 0.1 & & & $\frac{010305}{3.30 \mathrm{pm}}$ & 36 & 8 & 8.50 & \\
\hline 3 & $\begin{array}{l}\text { COMITE DE SALUBRIOADY IENENESTAR } \\
\text { PUEBLO LIBRE }\end{array}$ & JAEN & $\begin{array}{l}\text { LOCAL OEL COMITE } \\
\text { AV. VILANUEVA PINILLOS N } 1257\end{array}$ & & & & $\begin{array}{l}010305 \\
1130 \mathrm{am}\end{array}$ & & & 0.5 & $\frac{3.30 \mathrm{pm}}{010305}$ & 30 & 0 & 8.50 & \\
\hline 4 & $\begin{array}{l}\text { COMITE DE AGUA Y AL CANTARILLADO } \\
\text { PUEBLO JOVEN MIRAFLORES }\end{array}$ & JAEN & $\begin{array}{l}\text { AVV VILLANUEVA PINIILOSS N } 1257 \\
\text { S. BENEDICTO SADANA VARGAS } \\
\text { CALLE NUEVE DE OCTUBRE N* } 53\end{array}$ & $\therefore$ & & & 0110305 & 0.0 & & & $\begin{array}{l}3.40 \mathrm{pm} \\
01.03 / 05 \\
\end{array}$ & 1110 & 112 & 850 & \\
\hline 5 & COMITE DE AGUA & & $\begin{array}{l}\text { CALLE NUEVE DE OCTUBRE N* } 53 \\
\text { Sr. OSWALDO MORE GUTIERREZ }\end{array}$ & & & & $\frac{11.40 \mathrm{am}}{01,03 / 05}$ & 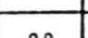 & & & $\frac{3.50 \mathrm{pm}}{01 / 03 / 05}$ & & & & \\
\hline 5 & MIRAFLORES ALTO & JAEN & CALLE GARCILAZO DE LA VEGA N" 912 & & & & $11.50 \mathrm{am}$ & 0.0 & & & $400 \mathrm{pm}$ & 1440 & 160 & 850 & \\
\hline 6 & COMITE DE AGUA & JAEN & $\begin{array}{l}\text { Sr. VIRGILIO DIAZ URIARTE } \\
\text { CALLE UNION N* } 209\end{array}$ & & & & $0103 / 05$ & 00 & & & $-01 / 03 / 05$ & 1560 & 160 & 8.50 & \\
\hline 7 & COMITE DE AGUA & $\triangle A E N$ & Sr. MARCIAL RUIZ CIGUENAS & & & & $\frac{12.00 \mathrm{~m}}{010305}$ & 00 & & & $\frac{4.10 \mathrm{pm}}{01 / 03,05}$ & 1690 & 170 & & \\
\hline 1 & LA PORTADA DEL SOL & JAEN & CALLELOS CASQUIS SIN & & & & $1210 \mathrm{pm}$ & 0.0 & & & $420 \mathrm{pm}$ & 1,680 & 170 & 850 & \\
\hline 8 & $\begin{array}{l}\text { ASOC. PROG. DE AGUA Y ALCANTARILLADO } \\
\text { MORRO SOLAR }\end{array}$ & JAEN & $\begin{array}{l}\text { LOCAL DE LA ASOCIACION DE AGUA MORRO SOLAR } \\
\text { CALLE LOS LAURELES N" } 988\end{array}$ & & & & $\frac{03,03 / 05}{10.10 \mathrm{am}}$ & & & 0.5 & $\frac{03 / 03 / 05}{2.30 \mathrm{pm}}$ & 8 & 0 & 800 & \\
\hline . & $\begin{array}{l}\text { ASOC. PROG. DE AGUA Y ALCANTARILLADO } \\
\text { MORRO SOLAR }\end{array}$ & JAEN & $\begin{array}{l}\text { ALCIBIADES BANCES MAYANGA } \\
\text { CALLE DOS DE MAYO NA } 498\end{array}$ & & & & $\begin{array}{l}03030305 \\
1020 \mathrm{am}\end{array}$ & & & 0.5 & $\begin{array}{l}0310305 \\
2.40 \mathrm{pm} \\
\end{array}$ & 6 & 0 & 800 & \\
\hline 9 & COMITE DE AGUA & $J A E N$ & Sr. ATILIO VASQUEZ VASQUEZ & & & & 03,0305 & 00 & & & 0310305 & 350 & 32 & 800 & \\
\hline & SANTA BEATRIZ & & CALLE JOSE GALVEZ No 145 & & & & $1030 \mathrm{am}$ & & & & $2.50 \mathrm{pm}$ & & & & \\
\hline 10 & COMITE DE AGUA & JAEN & St. GRISERIO GARCIA ALARCON & & & & 030305 & 0.0 & & & $\frac{0310305}{300 \mathrm{pm}}$ & 236 & 22 & 7.00 & \\
\hline & $\begin{array}{l}\text { AROMOS ALTO } \\
\text { COMITE DE AGUA }\end{array}$ & & $\begin{array}{l}\text { CALLE PEDRO CORNEJO N' } 700 \\
\text { Sr. JUSTIMIANO ACUNA FLORES }\end{array}$ & & & & $\frac{10.40 \mathrm{am}}{0.0305}$ & & & & $\frac{3.00 \mathrm{pm}}{03 / 03 / 05}$ & & & & \\
\hline 11 & $\begin{array}{l}\text { AROMOS BANO } \\
\text { AROA }\end{array}$ & JAEN & PROLONGACION MANCO CAPAC N* 1005 & & & & $10.50 \mathrm{am}$ & & & 0.5 & $3.10 \mathrm{pm}$ & 0 & 0 & 700 & \\
\hline 12 & $\begin{array}{l}\text { COMITE DE AGUA } \\
\text { NUEVO HORIZONTE }\end{array}$ & JAEN & $\begin{array}{l}\text { SF JOSE SANCHEZ NUNEZZ } \\
\text { CALLE JUAN FELIX CORREA SIN }\end{array}$ & & & & 030305 & 00 & & & $\frac{03103 / 05}{320 \mathrm{pm}}$ & 1120 & 55 & 750 & \\
\hline 13 & ASERAM & JAEN & Sr. SALOMON RIOJA RONCAL & & & & 030305 & 00 & & & $03 / 03 / 05$ & 1360 & 57 & 8.00 & \\
\hline & $\begin{array}{l}\text { MONTEGRANDE } \\
\text { ASOC. DE AGUA Y ALCANTARILLADO }\end{array}$ & & $\begin{array}{l}\text { CALLE SABOGAL Cora } 1 \\
\text { Sra MARIA PENA YANGUA }\end{array}$ & & & & $\frac{11.10 \mathrm{am}}{060305}$ & & & & $3.30 \mathrm{pm}$ & & & & \\
\hline 14 & FILA ALTA & JAEN & CALLE VICTOR ANDRES BELAUNDE SIN. & & & & $-6.30 \mathrm{am}$ & 0.0 & & & $9.00 \mathrm{am}$ & 1860 & 190 & 7.40 & \\
\hline & $\begin{array}{l}\text { ASOC DE AGUA Y ALCANTARILLADO } \\
\text { FILA ALTA }\end{array}$ & JAEN & $\begin{array}{l}\text { ST. LIDIA DELGADO TINOCO } \\
\text { AV. VICTOR RAUL HAYA DE LA TORRE SNN. }\end{array}$ & & & & $\frac{080305}{6502 m}$ & 0.0 & & & $08 / 03 / 105$ & 1740 & 180 & 7.40 & \\
\hline 15 & COMITE DE AGUA & & AV. VICTOR OSWALAO DIAZ PEREZ & & & & $\frac{0.30 \mathrm{din}}{0.03 / 05}$ & & & & $08 / 03 / 05$ & 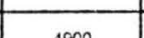 & 750 & 750 & \\
\hline 15 & SAN MARTIN Y SANLUIS & JAEN & PASAJE SAN JUAN N 114 & & & & $930 \mathrm{am}$ & 0.0 & & & $9.20 \mathrm{am}$ & 4900 & 750 & 7.50 & \\
\hline
\end{tabular}

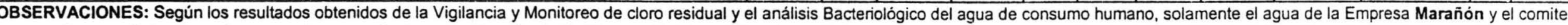

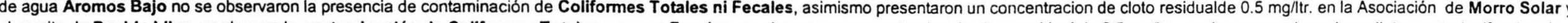

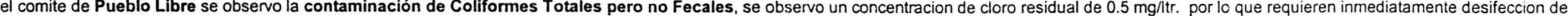
tuberias, en los demas comités presentan un alto indice de contaminación de Coliformes Totales y Fecales sinendo aguas no Aptas para el consumo humano según los parametros dados por OMS y el

MINSA para agua de consumo humano.
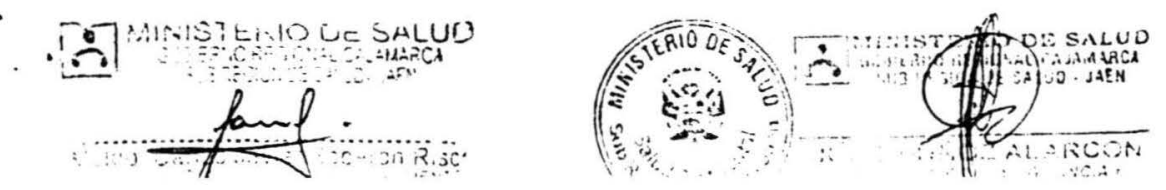